\title{
KLARA SVALIN
}

RISK ASSESSMENT OF INTIMATE PARTNER VIOLENCE IN A POLICE SETTING? Reliability and predictive accuracy
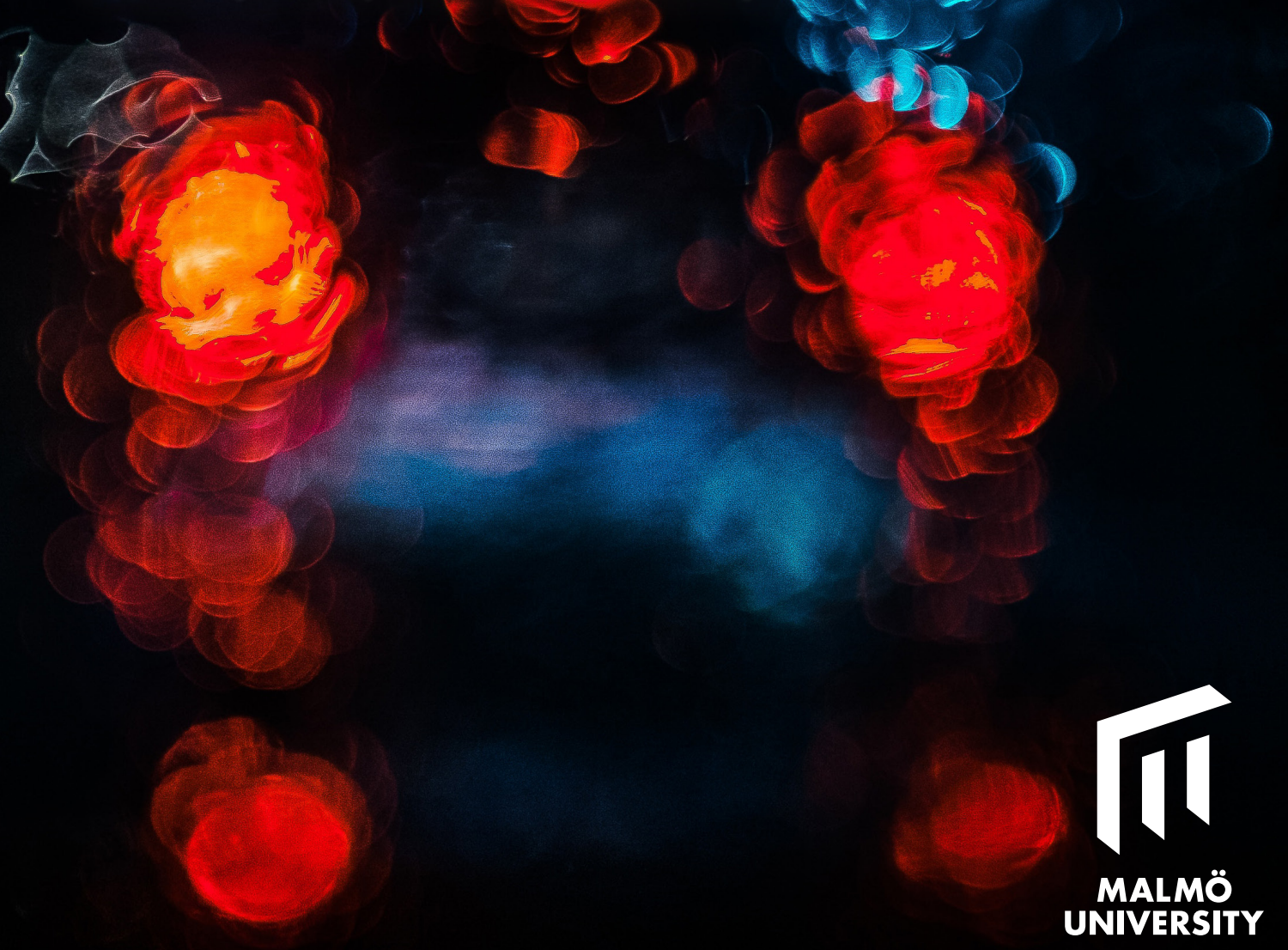

RISK ASSESSMENT OF INTIMATE PARTNER VIOLENCE IN A POLICE SETTING 
Malmö University

Health and Society, Doctoral Dissertation 2018:4

(c) Klara Svalin 2018

Photo by Osman Rana on Unsplash

ISBN 978-9I-7I04-898-I (print)

ISBN 978-9I-7I04-899-8 (pdf)

ISSN (I653-5383)

Holmbergs, Malmö 2018 


\section{KLARA SVALIN \\ RISK ASSESSMENT OF INTIMATE PARTNER VIOLENCE IN A POLICE SETTING}

Reliability and predictive accuracy

Malmö University, 2018 Faculty of Health and Society 
This publication is also available at:

http://dspace.mah.se/handle/2043/24791 
To Gustav and Maja 



\section{CONTENTS}

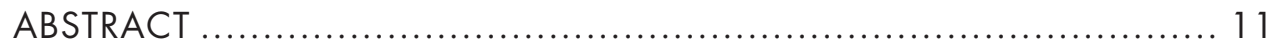

LIST OF PUBLICATIONS ................................................. 13

INTRODUCTION .................................................... 15

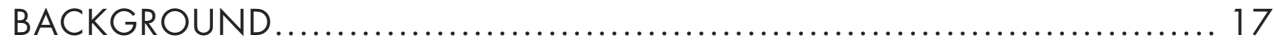

Approaches to violence risk assessment................................................ 17

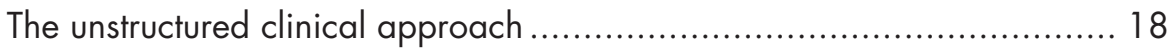

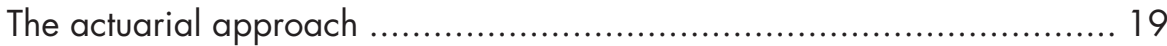

The structured professional judgement (SPJ) approach ........................ 20

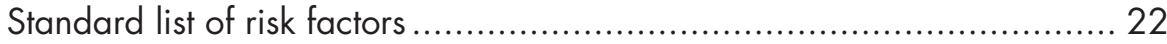

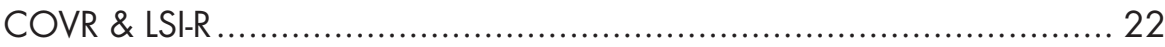

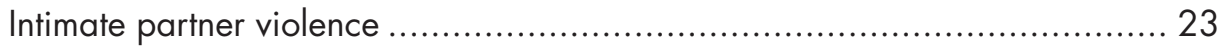

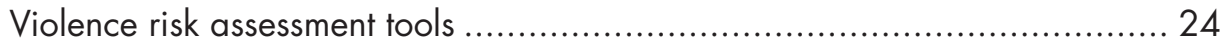

The Police Screening Tool for Violent Crimes (PST-VC) ........................... 25

The Brief Spousal Assault Form for the Evaluation of Risk (B-SAFER) ......... 25

Police employees' violence risk assessments .......................................... 27

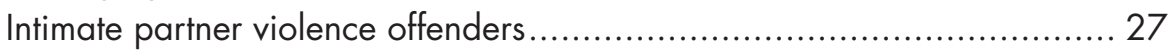

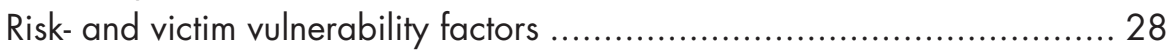

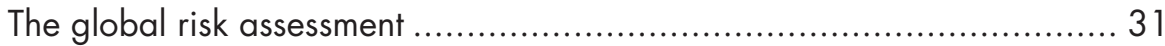

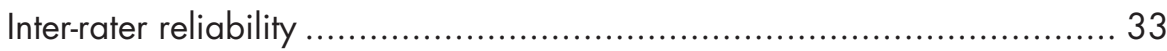

The predictive validity of IPV assessments............................................ 35

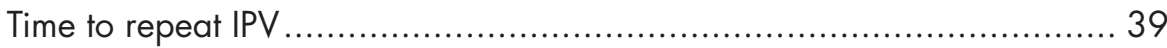

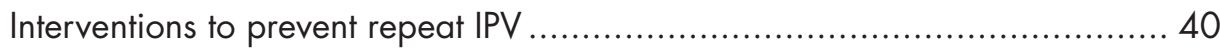

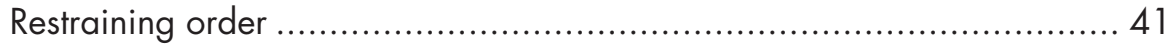

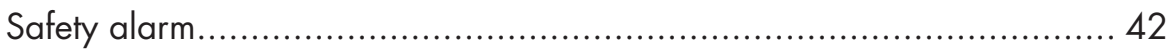

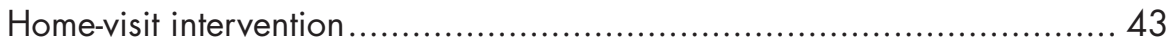

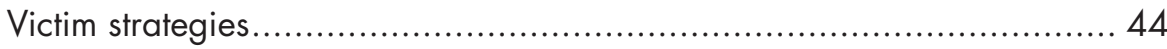


METHODS ............................................................... 49

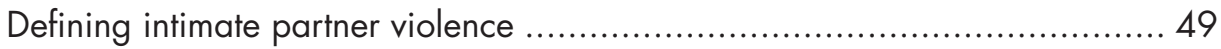

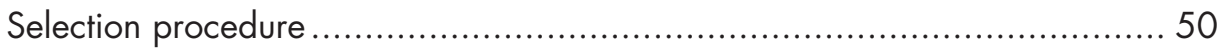

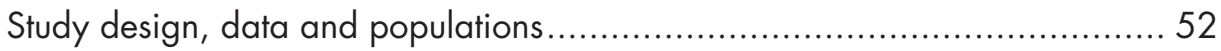

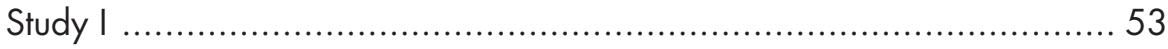

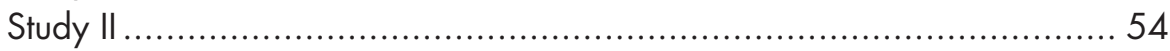

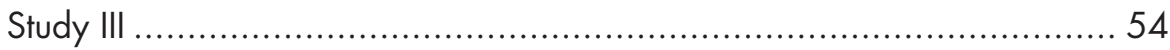

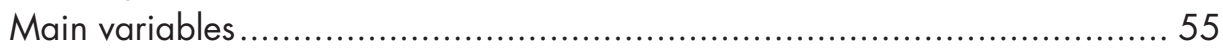

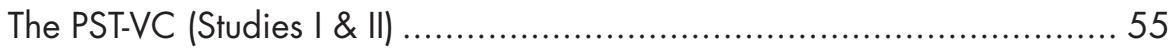

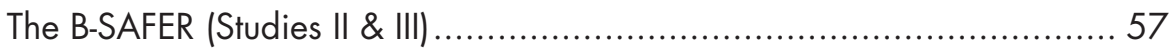

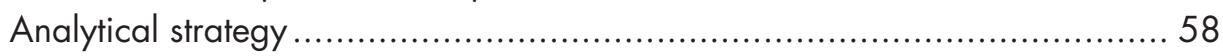

Kendall's tau (Studies I, II \& III)........................................................ 58

Receiver operating characteristic (ROC) (Studies I \& III) ........................ 58

Logistic regression (Studies I \& III) ................................................... 59

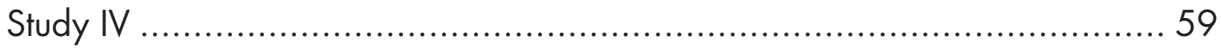

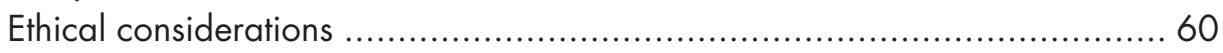

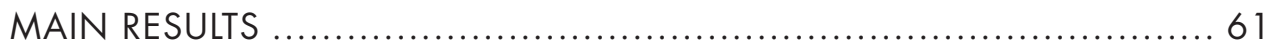

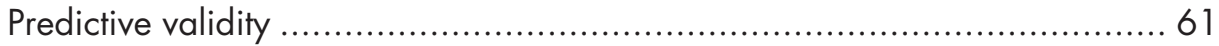

The predictive validity of practitioners' IPV risk assessments

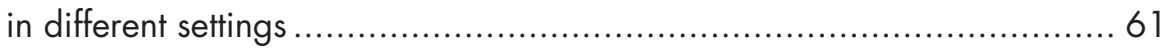

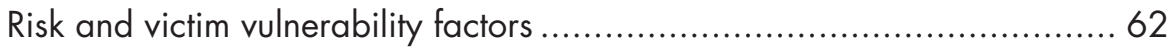

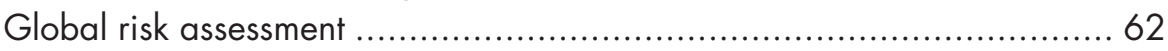

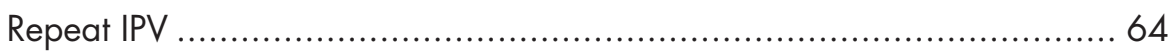

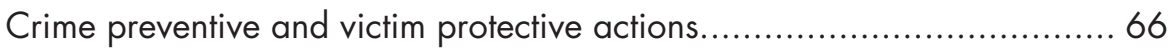

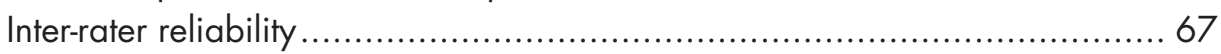

DISCUSSION AND CONCLUSIONS .................................. 69

IMPLICATIONS AND FUTURE DIRECTIONS _............................ 75

The initial screening procedure.......................................................... 75

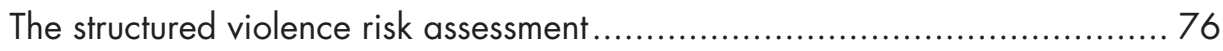

The risk assessor and training in IPV risk assessment .............................. 77

The implementation of interventions to prevent repeat IPV ......................... 78

Recommendations for the Swedish Police Authority ................................. 81

Evaluations of the initial screening procedure and the effect

of the recommended protective actions ........................................ 81

Future work with IPV assessment .................................................... 82 
POPULÄRVETENSKAPLIG SAMMANFATTNING 83

ACKNOWLEDGEMENTS 87

REFERENCES. 89

ORIGINAL PAPERS I-IV 99 



\section{ABSTRACT}

The Swedish Police Authority conducts violence risk assessments in cases of intimate partner violence (IPV) using specific assessment tools. Such assessments are conducted in order to identify high-risk offenders and thereafter implement suitable interventions to prevent repeat IPV. In this thesis, two different risk assessment tools have been evaluated: The Police Screening Tool for Violent Crimes (PST-VC) and the Brief Spousal Assault Form for the Evaluation of Risk (B-SAFER, Kropp, Hart, \& Belfrage, 2005; 2010). The overall aim has been to contribute to improving the knowledge on police employees' violence risk assessment and management, specifically with regard to the predictive validity and inter-rater reliability of such assessments.

In the first study, we evaluated whether the PST-VC can be used by police employees to identify high-risk cases of repeat IPV. In addition, the preventive effects of the recommended crime preventive and victim protective actions were discussed and also whether these create a confounding problem with respect to predictive validity. The results showed that the predictive accuracy of the tool was fairly weak. Further, the assessors recommended a higher level of interventions in high-risk cases, but these did not reduce the rate of repeat IPV.

Study II aimed to examine the inter-rater reliability of the PST-VC and the BSAFER. Police employees conducted pairwise assessments of IPV cases using one of these tools. The tools were evaluated separately and the cases used for the assessments were different for each tool. This means that the consistency of the assessments could not be compared head-to-head across the tools. The results were nonetheless rather similar for both tools; the inter-rater reliability 
for the individual items was low for most of the individual factors, but was relatively high for the global risk assessments. A suggested explanation for this was that the assessors may have used their tacit knowledge, rather than the individual items, in their global risk assessments and that they shared this tacit knowledge, at least to some extent.

The third study focused on the B-SAFER tool, and on the predictive accuracy of the individual items and the global risk assessments in relation to repeat IPV. The study also aimed to examine to what extent the recommended crime preventive and victim protective actions were implemented and whether these interventions had a preventive effect on repeat IPV. The predictive accuracy of the individual B-SAFER items and the global risk assessments was low overall. The majority of the recommended interventions were not implemented, and they did not prevent repeat IPV.

The final study (IV) took the form of a systematic literature study with the aim of evaluating the predictive accuracy of IPV risk assessments conducted by practitioners in different settings, with IPV recidivism as the outcome measure. The number of studies that fulfilled the inclusion criteria was small $(\mathrm{N}=11)$. One of these studies was conducted in a treatment setting, while all the others were conducted in criminal justice settings. The predictive accuracy for the global risk assessments ranged from low to medium, and the role of treatment or other interventions to prevent repeat IPV had been analyzed in one way or the other in eight of the studies. However, there was no consistency with regard to the importance of the interventions for repeat IPV.

In summary, the predictive accuracy of the police employees' IPV risk assessments was rather low, and the same applied to the inter-rater reliability for most of the individual items included in the tools. The level of consistency was higher, however, for the global risk assessments. The IPV preventive interventions were not effective in preventing repeat IPV. The predictive validity of IPV risk assessments conducted in other settings was found to be similar, but results regarding the potential mediating role of interventions were mixed. 


\section{LIST OF PUBLICATIONS}

This thesis is based on the following four studies. These studies will be referred to in the text by their Roman numerals:

I. Svalin, K., Mellgren, C., Torstensson Levander, M., \& Levander, S. (2017). Assessing and managing risk for intimate partner violence: Police employees' use of the Police Screening Tool for Violent Crimes in Scania. Journal of Scandinavian Studies in Criminology and Crime Prevention. Vol. 18, 1: 84-92. doi: 10.1080/14043858.2016.1260333

II. Svalin, K., Mellgren, C., Torstensson Levander, M., \& Levander, S. (2017). The Inter-Rater Reliability of Violence Risk Assessment Tools Used by Police Employees in Swedish Police Settings. Nordisk Politiforskning. Vol. 4, 1: 9-28. doi: 10.18261/ISSN.1894-8693-201701-03

III. Svalin, K., Mellgren, C., Torstensson Levander, M., \& Levander, S. (2018). Police employees' violence risk assessments: The predictive validity of the B-SAFER and the significance of protective actions. International Journal of Law and Psychiatry. Vol. 56: 71-79. doi: 10.1016/j.ijlp.2017.09.001

IV. Svalin, K. The predictive validity of intimate partner violence risk assessments conducted by practitioners in different settings - A review of the literature.

All papers have been reprinted with the kind permission of the publishers. 
Studies I-III were designed together by all authors and Klara Svalin and Caroline Mellgren conducted the data collection. Klara Svalin conducted the statistical analyses and analyzed the results in Studies I and II. The statistical analysis and the analysis of the results in Study III was conducted by Klara Svalin and Sten Levander. The manuscript for Study I was written by Klara Svalin in co-operation with Caroline Mellgren and Sten Levander. Studies II and III were written by Klara Svalin. All authors have contributed with valuable comments, and have read and approved the final manuscripts. Study IV was carried out by Klara Svalin. 


\section{INTRODUCTION}

The overall aim of violence risk assessment in practical settings is to prevent future violence by trying to predict a person's future behavior. This is usually carried out by considering information from different sources regarding the person's history and current life conditions, e.g. criminal behavior, social network, mental health etc. However, a person's future behavior is not merely the sum of different risk factors; it is also dependent on the situation and on interactions with other people. Thus, many different factors, on different levels and under different circumstances, must be considered, which makes violence risk assessment a complicated task. In order to facilitate decision making and to obtain more accurate assessments, a large number of tools have been developed over the years.

Violence risk assessments are conducted in many different settings, by practitioners working in different professions, and with or without the guidance of assessment tools. For instance, prison officers conduct violence risk assessments as a basis for decisions on institutional placements, and probation officers do so in order to make decisions regarding treatment. Social workers in many different settings conduct violence risk assessments with many different aims, e.g. as a basis for decisions on offender treatment and in order to provide victims with appropriate support to prevent future victimization. Police employees conduct violence risk assessments as a basis for decisions on preventive measures relating to offenders and on measures intended to protect victims and it is this that constitutes the focus for this thesis: police employees' violence risk assessment and risk management, conducted in a Swedish police context. 
The overall aim of this thesis is to contribute to improving the knowledge on police employees' violence risk assessment and risk management, more specifically focusing on the predictive validity and inter-rater reliability of such assessments. The number of studies in this field has increased over the last decade, but additional research is still needed. The first three studies presented in the thesis were conducted in Swedish police settings and the majority of the assessments covered by the study concerned intimate partner violence. The occurrence, characteristics and consequences of this type of crime will be described later in the background section. The fourth study, which is a review of the literature, examined the predictive validity of IPV assessments conducted by practitioners in different settings.

Studies I-III are based on data from an evaluation conducted by the Department of Criminology at Malmö University on behalf of the Swedish National Police Authority (formerly Rikspolisstyrelsen ${ }^{1}$ ). The overall aim of the evaluation was to study the use of a number of risk assessment tools in Swedish police settings. The results were presented in five different reports (Mellgren, Svalin, Levander, \& Torstensson Levander, 2014; Mellgren, Svalin, Torstensson Levander, \& Levander, 2012; 2014a; 2014b; Svalin, Mellgren, Torstensson Levander, \& Levander, 2014).

1 At the time of the data collection, the National Police Authority was divided into 21 separate regional police authorities. The data for studies I-III were collected in two of these. 


\section{BACKGROUND}

The definition of violence risk assessment employed in this thesis is borrowed from Hart (1998, p. 122): "[...] the process of evaluating individuals to (1) characterize the likelihood they will commit acts of violence and (2) develop interventions to manage or reduce that likelihood". Descriptions of violence risk assessment have changed over time and they differ between different violence risk assessment approaches or traditions. Hart's definition is related to the so-called structured professional judgement (SPJ) approach. The development of this and other approaches to violence risk assessment will be described in the following pages.

\section{Approaches to violence risk assessment}

The number of approaches associated with the development of violence risk assessments varies somewhat across different sources (e.g. Andrews \& Bonta, 2010; Heilbrun, Yasuhara, \& Shah, 2010). This thesis employs the classification presented by Skeem and Monahan (2011). In addition to the three violence risk assessment approaches that are for the most part always included: the unstructured clinical approach, the actuarial approach and the SPJ approach, two additional approaches are also described, with these being referred to as the "standard list of risk factors" approach and the "COVR and LSI-R" ${ }^{2}$.

\footnotetext{
2 The COVR (Classification of Violence Risk; Monahan, Steadman, Silver, Appelbaum, Robbins, \& Mulvey, 2001) and the LSI-R (Level of Service Inventory; Andrews, Bonta, \& Wormith, 2004) are violence risk assessment tools that are used here to describe this specific approach.
} 
Approaches to assessing violence risk vary in the degree to which they are structured. Skeem and Monahan (2011) propose a continuum of structure, with unstructured clinical assessments placed at one end, the actuarial approach at the other, and with the other approaches being located in between. The positioning of the different approaches along the continuum is based on four components of violence risk assessments, which are in turn related to the 1) identification of risk factors, 2) measuring of risk factors, 3) combining of risk factors and 4) the production of a global risk assessment (Skeem \& Monahan, 2011, p. 39) (see Table 1).

Table 1. Violence risk assessment approaches and their structured components (Skeem \& Monahan, 2011, p. 39)

\begin{tabular}{|c|c|c|c|c|}
\hline \multirow[b]{2}{*}{ Approach } & \multicolumn{4}{|c|}{$\begin{array}{l}\text { Structured components of the violence risk } \\
\text { assessment process }\end{array}$} \\
\hline & $\begin{array}{l}\text { Identify } \\
\text { risk factors }\end{array}$ & $\begin{array}{l}\text { Measure } \\
\text { risk factors }\end{array}$ & $\begin{array}{l}\text { Combine } \\
\text { risk factors }\end{array}$ & $\begin{array}{l}\text { Produce final } \\
\text { risk estimate }\end{array}$ \\
\hline \multicolumn{5}{|l|}{ Unstructured clinical judgment } \\
\hline Standard list of risk factors & $X$ & & & \\
\hline Structured professional judgment & $x$ & $x$ & & \\
\hline COVR \& LSI-R & $X$ & $x$ & $X$ & \\
\hline Actuarial & $x$ & $x$ & $x$ & $x$ \\
\hline
\end{tabular}

Note: Certain approaches are given different labels in different sources. Some of these labels have therefore been changed to correspond to the terms employed in this chapter.

\section{The unstructured clinical approach}

The unstructured clinical approach is the earliest risk assessment approach (Andrade, O'Neil, \& Diener, 2009) and it is suggested to be historically the most commonly used violence risk assessment approach (Hart, 2008). Unstructured clinical judgements are based on the clinical assessor's reasoning, using the information that he/she considers important (Litwack \& Schlesinger, 1999). The assessment can thus be tailored to the specific case, which has been argued to be one of the advantages of using this approach (Hart, 2008). However, there has been extensive negative criticism of this way of determining a person's violence risk (in clinical settings), with the main argument focusing on the low level of accuracy of such assessments (e.g. Cocozza \& Steadman, 1978; Ennis \& Litwack, 1974; Grove \& Meehl, 1996) and the low level of inter-rater reliability (see Hart, 1998). Somewhat more recently, a number of studies have found somewhat higher predictive values 
for assessments of this kind. For example, Fuller and Cowan (1999) studied the accuracy of clinicians' violence risk assessments in a forensic hospital. The predictions of serious risk to staff or other patients, measured as the area under the curve (AUC) of the Receiver Operating Characteristic (ROC), were 0.86 and 0.69 respectively.

\section{The actuarial approach}

In 1984, Monahan published a review of the violence risk assessment research that has since been described as constituting the starting point for a second generation of violence risk assessments (based on the actuarial approach) (Strand, 2006). Monahan (1984) called for studies of violence risk assessments in different populations, with short-term predictions, based on actuarial assessment techniques using clinical factors and also including situational factors as predictors of violence.

These criteria were all met, for example, in the MacArthur violence risk assessment study (see MacArthur Foundation, 2001). This was a comprehensive North American study that aimed to produce both the best violence risk assessment research possible and an actuarial violence risk assessment tool for the use of clinicians in mental health settings. A large number of studies have been published over the years (and are still being published) based on the MacArthur data. These include, for example, studies based on understudied populations in this context (e.g. civil psychiatric patients with controls living in the same neighborhoods, see Steadman et al. (1998)) and studies that included situational factors as predictors of violence (Steadman \& Silver, 2000). Another violence predictor examined in the MacArthur study is psychopathy (as measured by a screening version of the Hare Psychopathy Checklist, Hart, Cox, \& Hare, 1995) (see Skeem \& Mulvey, 2001). Finally, an actuarial classification tree approach was also developed (see Steadman et al., 2000).

Actuarial tools usually include a small number of empirically validated risk factors that are assessed according to specific guidelines (Hart, 1998) and thereafter weighted and combined statistically to a global risk measure (Grove \& Meehl, 1996). The global risk assessment is thus a probability measure of the individual's violence risk (ibid.). One of the most well-known and commonly used actuarial assessment tools is the Violence Risk Appraisal 
Guide (VRAG, Harris, Rice, \& Quincey, 1993). As compared to the unstructured clinical assessment, which lacks structure on all four of the components referred to in Skeem and Monahan's continuum (2011) (see Table 1), the actuarial risk assessment approach includes guidelines regarding all four components.

\section{The structured professional judgement (SPJ) approach}

In 1994 an IPV risk assessment tool called the Spousal Assault Risk Assessment (SARA) was launched (Kropp, Hart, Webster, \& Eaves, 1994) ${ }^{3}$, and it was at this time that the SPJ approach was born (Hart \& Guy, 2016). The previously mentioned actuarial tool VRAG had recently been presented, and the SPJ approach was developed in reaction to this and subsequent actuarial tools (ibid.). The criticism of actuarial risk assessment tools was mainly based on the fact that the assessor had no influence on the global risk assessment. The assessor's role in the SPJ assessments is thus more influential, which is further described below.

The SPJ approach is placed somewhere in the middle of the structure continuum (see Table 1), and includes elements of both the unstructured clinical and the actuarial approach. SPJ tools usually consist of checklists of risk factors, such as the previously mentioned SARA guide and the HCR-20 (Douglas, Hart, Webster, \& Belfrage, 2013; Webster, Douglas, Eaves, \& Hart, 1997; Webster, Eaves, Douglas, \& Wintrup, 1995), with definitions and descriptions of how to assess the occurrence of a specific factor. A number of different information sources are often recommended for use (Douglas \& Kropp, 2002), such as police reports, interrogations, victim interviews etc. (e.g. Kropp et al., 2010). In addition to the mandatory factors, the assessor can add case-specific factors (Douglas \& Kropp, 2002). However, the global risk assessment is not only based on the factors included in the checklist, but also on the rater's professional knowledge, and there are no rules or cut-offs regarding the number of factors that need to be present for the different risk levels (ibid.). Thus, the first two structured components in the continuum (see Table 1) are managed, while the other two are not.

3 Since then, a number of new versions of the tool has been published (Kropp, Hart, Webster, \& Eaves, 1995; 1999; Kropp \& Hart, 2015). 
The different parts of the SPJ approach, together with the connections among them and the process involved are illustrated in Figure 1 (adapted from Belfrage, Strand, Storey, Gibas, Kropp, \& Hart, 2012, p. 61). In addition, the model illustrates how the tools examined in this thesis were evaluated (Studies I and III). ${ }^{4}$ The following description is overall based on the study by Hart and Logan (2011).

The first step of the SPJ assessment ((a) in the figure) is related to the assessment of the risk- and victim vulnerability factors included in the checklist, together with possible case-specific factors (which are added by the rater). When all factors have been assessed, a global risk assessment is conducted based on the checklist (a) and the rater's professional knowledge (b). Thus, in line with the unstructured clinical judgement, but unlike the actuarial approach, the assessor's professional knowledge constitutes part of the global risk assessment (c). As mentioned previously, there are no cut-off scores related to the different risk levels.

With the development of the SPJ approach, the aim of violence risk assessments shifted from violence prediction to violence prevention (see Hart, 1998), and the recommendation/implementation of measures to prevent repeat violence became part of the risk assessment procedure (d). The last part of the model (e) refers to the outcome associated with the risk assessment, i.e. repeat violence. This outcome is expected to be prevented by means of the protective measures. In some evaluations of SPJ tools (Belfrage et al., 2012; Storey et al., 2014) the results have been interpreted in line with the Risk-NeedResponsivity model (Andrews \& Bonta, 2010); a low level of intervention in low-risk cases and a high intervention level in high-risk cases. The SPJ approach has been further developed over the years (see e.g. Hart, Douglas, \& Guy, 2016), which will to some extent be further addressed later in the thesis.

4 The outcome measured in the studies presented in the thesis is included in the model even though it is not a part of the violence risk assessment process. 
Figure 1. The different parts of Structured Professional Judgement (SPJ) tools, adapted from Belfrage et al. (2012, p. 61)

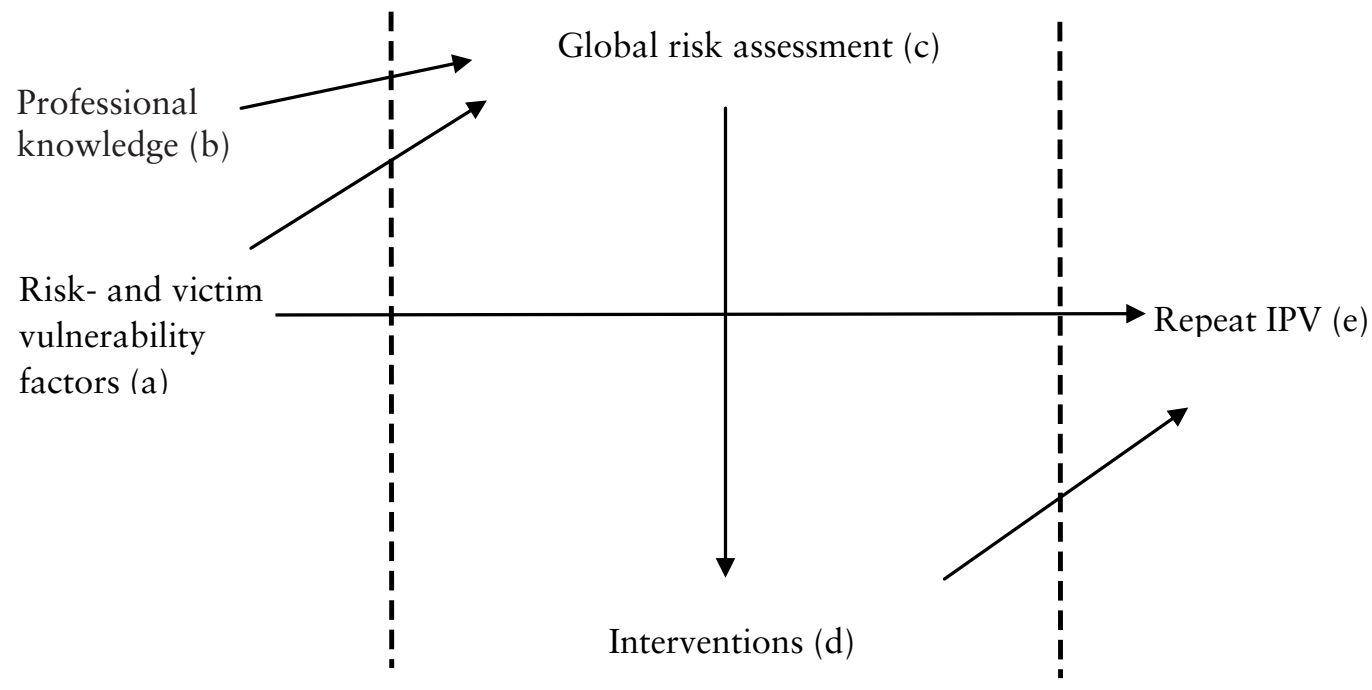

\section{Standard list of risk factors}

As the name of this approach indicates, it involves the use of a standard list of risk factors to conduct the violence risk assessment. According to Skeem and Monahan (2011) the list is comprised of empirically validated factors and is used in order not to forget any important factors in the assessment. The list thus relates to the first of the structured components in the violence risk assessment process. The other three components (measure risk factors, combine risk factors and produce a final risk estimate) are not managed in this approach however.

\section{COVR \& LSI-R}

This partially structured approach (represented by the COVR and the LSI-R tools) is positioned between the actuarial and the SPJ approach on the continuum of structure (see Table 1). Risk is assessed in terms of pre-defined risk factors which are summed by means of scores or combined in a classification-tree (Skeem \& Monahan, 2011). However, in the global risk assessment, case-specific factors should also be considered (ibid.). 


\section{Intimate partner violence}

The violence risk assessments in all of the studies in the thesis related to intimate partner violence (IPV) (except the PST-VC assessments in Study II, which included different kinds of violence). Intimate partner violence is a public health problem with severe consequences (García-Moreno et al., 2013). A common definition of IPV is that of the World Health Organization (WHO), which includes physical, psychological and sexual victimization and controlling behaviors by former or current intimate partners (World Health Organization/London School of Hygiene and Tropical Medicine [WHO/LSHTM], 2010).

Both women and men are exposed to and commit IPV, and the violence occurs in both homosexual and heterosexual relationships (ibid.). In a Swedish study of IPV victimization, the rates of IPV victimization in 2012 were similar for women and men; 7.0 and 6.7\%, respectively (National Council for Crime Prevention [NCCP], 2014 ${ }^{5}$ ). However, female victims generally more often suffer repeat violence and more severe forms of IPV, with more severe consequences, as compared to male victims (ibid.). Thus studies of IPV often focus on men's violence against women.

In a World Health Organization report, women living in countries on six different continents were asked if they had been victimized physically- and/ or sexually by a current or former intimate partner since they turned 15 (GarcíaMoreno et al., 2013). The overall results showed that $30 \%$ of the women who had ever been in an intimate relationship had been victimized. Similar questions were examined in the first large-scale Swedish victim survey examining violence against women (Lundgren, Heimer, Westerstrand, \& Kalliokoski, 2001). Surveys were sent to a probability sample of 10,000 women aged 18-64 and living in Sweden. The response rate was approximately $70 \%$. Among women who had lived with an intimate partner, $35 \%$ had been exposed to IPV (threats, physical and sexual violence) by their former partners. In a more recent prevalence study of violent victimization among women and men in Sweden, the participants were asked whether they had been exposed to physical violence or threats of physical violence from a current or former intimate partner during adulthood (18 years or older)

5 The data was collected by telephone interviews and in some cases by surveys. 
(NCK, 2014). This had happened to approximately $14 \%$ and $5 \%$ of the female and male participants respectively.

The rate of IPV cases that remain unreported to the police is extensive (Garcia, 2004). For instance, only $3.9 \%$ of those who had been exposed to IPV in 2012 had reported the incident/s to the police (NCCP, 2014).

Global figures for incidents of fatal violence show that $38 \%$ of all murdered women are killed by an intimate partner (García-Moreno et al., 2013). Between 2008 and 2013, an average of 13 women per year were murdered by a former or current intimate partner in Sweden (NCCP, 2015a).

IPV can occur in the form of an isolated event, but repeat victimization is common (NCCP, 2014). The process of repeat IPV has been explained theoretically by reference to a gradual escalation of the offender's control over and isolation of the victim (Lundgren, 2004). The victim's perceptions regarding which actions, such as physical and psychological abuse, are legitimate become gradually normalized. The offender's behavior alternates between violence and tenderness throughout the process, which in combination with the isolation, makes the victim emotionally dependent on the offender.

IPV causes devastating consequences for the victim, her/his family and society at large. At the individual level, female victims of IPV suffer from physical, mental, sexual and reproductive health consequences (García-Moreno et al., 2013). Other consequences are related to the individual's economy and social situation (Heise \& García-Moreno, 2002). The monetary consequences for society in terms of, for example, healthcare and sick leave are extensive (Max, Rice, Finkelstein, Bardwell, \& Leadbetter, 2004).

\section{Violence risk assessment tools}

At the time the data for the studies included in this thesis were collected, the Swedish Police used two different tools to assess IPV risk; the Police Screening Tool for Violent Crimes (PST-VC) and the Brief Spousal Assault Form for the Evaluation of Risk (B-SAFER, Kropp, Hart, \& Belfrage, 2005; 2010). The PST-VC was evaluated in Studies I and II, and the B-SAFER in Studies II and III. Both tools are described below. 


\section{The Police Screening Tool for Violent Crimes (PST-VC)}

The PST-VC was developed by the Scania police department in 2009. It is a general tool, i.e. a tool that is used to assess all kinds of threats and violence. The assessment is based on information from police registers, the rater's professional knowledge and, in most of the cases, information from the victim. Due to the relatively loose structure of all of its components (selecting and measuring risk factors, combining risk factors, generating a final risk estimate) the PST-VC would be placed closer to the unstructured clinical assessments than the actuarial assessments on the previously mentioned structure continuum (Skeem \& Monahan, 2011). Starting with the first component, the selection and measuring of risk factors, the PST-VC does not include a checklist of risk factors, unlike many SPJ tools. Instead, a number of headings and related questions are listed in the tool, with the aim of guiding the rater in the identification of risk- and victim vulnerability factors in the specific case. For instance, whether the offender had committed violent crimes prior to the actual crime. The headings and questions are inspired by the risk- and victim vulnerability factors employed in other tools used by the Swedish police, for instance the B-SAFER, the Stalking Assessment and Management checklist (SAM, Kropp, Hart, \& Lyon, 2008) and the PATRIARCH (Belfrage, 2005). However, the assessment does not include any mandatory factors, nor any definitions or guidelines on how to assess or combine certain factors (the second component in the continuum). The last component, i.e. the generation of a final risk estimate, is also unstructured, like the other components. The rater produces a global risk assessment regarding the offender's risk of recidivism based on the assessment and his/her professional knowledge. The scale ranges from no risk (1) to high risk (5). Based on the risk assessment, the rater recommends crime preventive interventions directed towards the offender and protective actions directed towards the victim.

\section{The Brief Spousal Assault Form for the Evaluation of Risk (B-SAFER)}

The B-SAFER is an SPJ tool developed to assess IPV risk in criminal justice settings (Belfrage, 2008; Kropp, 2008). The need for a tool adapted to the legal context was identified by the authors when the SARA guide (Kropp et al., 1994; 1995; 1999) was implemented and evaluated in Swedish police settings (see Belfrage, 2008). Thus, a number of changes were made in the 
SARA, to make it better suited to police settings ${ }^{6}$. Since the police had some difficulties with the language used, the language and a number of definitions were revised. It was also shortened, from 20 to 10 risk factors, to ease the assessment procedure. This was mainly achieved by merging a number of risk factors together. For instance, B-SAFER item 10 (mental disorder) consists of three SARA items 8, 9, 10 (recent suicidal or homicidal ideation/dependence, recent psychotic and/or manic symptoms, personality disorder with anger, impulsivity, or behavioral instability). In addition, the global risk assessment was changed, and instead of an overall risk assessment, it was divided into three dimensions: imminent risk, long-term risk and severity of potential future violence.

Compared to the older versions of the SARA $(1994 ; 1995 ; 1999)$, the BSAFER (version 2) includes victim vulnerability factors, i.e. factors based on the situation of the victim (e.g. unsafe living situation and inadequate access to resources). In the latest version of the SARA guide (version 3, Kropp \& Hart, 2015) victim vulnerability factors are included. According to Belfrage and Strand (2008), victim vulnerability factors were included in the B-SAFER (version 2), since police officers reacted to the absence of such factors in the former version of the tool, having used such factors in the SAM. The aim of assessing victim vulnerability is to protect victims from repeat violence (Storey \& Strand, 2017). Further, Storey and Strand (2017) exemplify a victim of IPV with an unsafe living situation (item 14) as someone living in an apartment on the ground floor. Based on this information, it becomes clear to those who are responsible for the risk management process that something has to be done to secure the individual's living situation.

Both risk- and victim vulnerability factors are assessed as being either present (coded as 2 ), partly present (coded as 1 ) or absent (coded as 0 ) in the current(the latest 4 weeks) and the past situation (more than 4 weeks back in time). If a factor cannot be assessed because there is a lack of information, it is marked with ". -". The B-SAFER assessment should be based on many different information sources, ideally interviews with the suspected offender, the victim, his/her relatives and/or possible witnesses. Police reports should also be included. Once all the information have been processed and the factors (in the

6 Results from Kropp and Hart (2000) were also the basis of the changes. 
tool and case specific factors) have been assessed, a global risk assessment is conducted, followed by the production of a risk manage plan. In order to use the B-SAFER, the rater should have specialist knowledge in IPV and risk assessment, but no formal training is required.

\section{Police employees' violence risk assessments}

In recent years, a relatively large number of studies have been published on violence risk assessment in police settings. This part of the thesis will begin with a short description of different types of IPV offenders in relation to violence risk assessments, e.g. are there risk factors that are more important for specific types of IPV offenders and are there variations in the risk of violence? Thereafter follows an overview of different aspects of IPV risk assessment in police settings, e.g. can the factors included in the tools be assessed in police settings? This section of the thesis will conclude with a summary of what we know regarding interventions used to prevent repeat IPV.

\section{Intimate partner violence offenders}

Several studies have established that male IPV offenders are a heterogeneous group (e.g. Boyle, O'Leary, Rosenbaum, \& Hassett-Walker, 2008; Holtzworth-Munroe \& Stuart, 1994; Thijssen \& de Ruiter, 2011). ${ }^{7}$ Various numbers of offender subtypes have been proposed, e.g. Thijssen \& de Ruiter (2011) suggested four types, Holtzworth-Munroe \& Stuart (1994) three and Boyle et al. (2008) two. The latter types were called antisocial- and familyonly offenders. In a recent study, these two offender categories were compared based on offender characteristics, global risk assessments and presence of individual violence risk factors (Petersson, Strand, \& Selenius, 2016). The participants had all been subjected to a B-SAFER assessment conducted by Swedish police officers, and the classification into different offender types was based on the B-SAFER factor "general criminality". The offender categories differed in several ways; for example, the antisocial offenders were younger, were more often reported for psychological IPV (index crime ${ }^{8}$ ), had a significantly higher prevalence of all risk factors but one (factor 1, violent

\footnotetext{
7 Both Boyle et al. (2008) and Holtzworth-Munroe \& Stuart (1994) refer to male batterers in their typologies. In Thijssen \& de Ruiter (2011) 94\% of the participants were men.

8 Index crime $=$ the offence that led to the risk assessment.
} 
acts) ${ }^{9}$ and were assessed to have a significantly higher risk of repeat IPV (acute and severe/lethal global risk), than the family-only offenders.

The predictive validity of the individual B-SAFER risk factors in relation to the global risk assessments were examined for each offender category (Peterson et al., 2016). Escalation and violent threats and thoughts significantly predicted the global risk for acute IPV in the antisocial offender group, and violent attitudes significantly predicted the global risk for acute IPV in the family-only group. As regards the global risk of severe/lethal violence, escalation was the only factor that significantly predicted this outcome in the antisocial category whereas it was significantly predicted by violent threats and thoughts and intimate relationship problems in the family-only group. Thus, different risk factors were important for different categories of offenders, which according to the authors should be viewed as "red flags" for the risk rater, and as indicating a need to intervene.

\section{Risk- and victim vulnerability factors}

An important question to answer in evaluating the violence risk assessment tools used in police settings is whether risk- and victim vulnerability factors can be assessed in this specific setting? One way to evaluate this is to study the number of missing factors, which has varied across different studies. For instance, Belfrage (2008) reported a rate of missing values in police officers' SARA assessments ranging between 2 and 39\%. A similar variation (1-36\%) was found in another evaluation of the same tool (Belfrage et al., 2012) ${ }^{10}$. The rate of missing values was somewhat lower in four studies that evaluated the B-SAFER (Belfrage \& Strand, 2008 ${ }^{11}$; Kropp \& Hart, 2004; Storey et al., 2014; Storey \& Strand, $2013^{12}$ ). In these studies it ranged between 0 and $21 \%$ for the risk factors (current and past situation) and between 0 and $9 \%$ for the victim vulnerability factors (current situation). Among these studies, the overall lowest rate of missing values (risk factors) was found by Storey et al. (2014); for some of the factors it was less than one percent and for others there were no missing values at all. A recent study has examined the importance of victim vulnerability factors in both male-to-female and female-

\footnotetext{
9 Risk factor 6, General criminality was excluded, since the offender typology was based on this factor.

10 There might be an overlap between the samples in Belfrage (2008) and Belfrage et al. (2012).

11 The data in Table 3 were used to calculate the missing cases.

12 Since the B-SAFER samples in Storey and Strand (2012) and (2013) seem to be the same, with the exception of a single case, these are not referred to at the same time.
} 
to-male cases (Storey \& Strand, 2017). The rate of missing values ranged between 26 and $45 \%$ for male victims and between 17 and $37 \%$ for female victims. The victim vulnerability factors are usually only assessed in relation to the current situation. In one study, however, the rate of missing values for victim vulnerability factors in the past was presented and ranged between 40 and $42 \%$ (Storey \& Strand, 2013). The population consisted of female-tomale IPV cases. It is unclear whether the assessors had difficulty in finding information regarding the victims, or whether they did not assess these factors for some other reason.

The factors with the highest rates of missing values were related to the psychosocial adjustment domain. For instance, in the SARA studies (Belfrage, 2008; Belfrage et al., 2012) these were: factor 6 (Victim of and/or witness to family violence as a child), 8 (recent suicidal or homicidal ideation/intent), and 9 (recent psychotic and/or manic symptoms). Assessments of factor 17 (attitudes that support or condone spousal assault) were also omitted to a large extent in both studies. In the B-SAFER studies ${ }^{13}$, factor 8 (employment problems) had a large number of missing values (Belfrage \& Strand, $2008^{14}$; Storey \& Strand, 2013). The number of missing values was also high for factor 10 (mental health problems) in Belfrage and Strand (2008) and for factor 9 (substance use problems) in Storey and Strand (2013). Suggested reasons for the large number of missing values among the psychosocial factors in Belfrage (2008) were a lack of information and knowledge regarding how to assess these factors.

Looking to the proportions of missing values for the victim vulnerability factors, the results varied between the different studies. Personal problems had the highest number of missing values in Belfrage and Strand (2008). In Storey and Strand (2013) there were hardly any missing values for the victim vulnerability factors (0-2\%) and in Storey and Strand (2017) item 13, inadequate access to resources, had the highest number of missing values among male victims, and item 5; health problems had the highest number of missing values among female victims.

13 Kropp and Hart (2004) did not present the rate of missing values for each individual item.

14 Since the B-SAFER assessments conducted in the police county of Södertörn in Belfrage and Strand (2008) and Belfrage and Strand (2012) seem to be the same, these studies are not referred to at the same time. 
Another measure of the assessment of risk- and victim vulnerability factors is the presence of such factors, which indicates whether a factor can be assessed and/or is relevant for the cases examined. E.g. if a factor is assessed with a "No" (i.e. not present) in most of the cases in a sample, it may indicate that it is difficult to assess and/ or that it is not of relevance for the assessed cases. The presence (assessed as present or partly present) of each risk factor in a number of the previously mentioned studies varied between 0.9 and $85 \%$ (including both current and past situations) (Belfrage, 2008; Belfrage et al., 2012; Kropp \& Hart, 2004; Storey, Kropp, Hart, Belfrage, \& Strand, 2014; Storey \& Strand, $2012^{15}$ ). The risk factors that were present most often were factors related to substance use problems, the occurrence of violence and intimate relationship problems, in male offender samples (e.g. Belfrage et al., 2012, Kropp \& Hart, 2004) and threatened/ actual/ attempted violence and intimate relationship problems, in female offender samples (Storey \& Strand, 2012). Risk factors that were least often present in the studies conducted in Swedish police settings were factors regarding violations of court orders (Belfrage et al., 2012; Storey et al., 2014; Storey \& Strand, 2012). The same factors, together with the factor regarding mental health problems, were those found to be least often present in the Canadian sample (Kropp \& Hart, 2004). In the studies examining the SARA (Belfrage, 2008; Belfrage et al., 2012) item 6 , victim of and/or witness to family violence as a child or adolescent, was also rarely present.

The presence of victim vulnerability factors was presented in two studies (Storey \& Strand, 2012; 2017) and ranged between 15 and 54\%. The results were characterized by both similarities and differences; the factor found to be least often present was extreme fear of perpetrator in the first study (Storey \& Strand, 2012) and inadequate support or resources in the second study (Storey \& Strand, 2017). The first result related to male victims and the latter to both male and female victims. One of the factors that was most often found to be present among male victims in both studies was inconsistent behavior and/or attitude towards perpetrator as well as personal problems in Storey and Strand (2012).

15 Since the sample consisted of two subsamples that had been measured using two different tools (the B-SAFER and the SARA), similar risk factors from these tools had been merged together. 
Violence risk assessments in cases of female-to-male IPV

No specific tools have been developed for the assessment of female IPV offenders (Storey \& Strand, 2017). However, as mentioned previously, Storey and Strand (2013) examined the use of B-SAFER risk factors in female-tomale IPV, and a few years later the use of victim vulnerability factors was examined in a similar sample (Storey \& Strand, 2017). In addition, the results were compared with results from cases of male-to-female IPV. The overall conclusion of the first study was that the B-SAFER seems to be useful in cases of female-to-male IPV, but that some gender-specific risk factors could potentially improve the assessments of cases with female offenders (Storey \& Strand, 2013). The global risk assessments and the number of management strategies was not significantly related, which according to the authors, may be due to the lack of suitable protective actions for male offenders.

The more recent study (Storey \& Strand, 2017) showed that the victim vulnerability factors were useful in assessing male victims of IPV; the police officers were able to assess the factors and the number of factors were related to the global risk assessment of imminent violence. However, the global risk assessment of life-threatening IPV was not associated to the number of victim vulnerability factors. Further, the number of recommended risk management strategies did not differ between male and female victims, but the relationship between the total score of the victim vulnerability factors and the number of recommended risk management strategies differed for male and female victims. For female victims these variables were significantly related, but not for male victims. Several possible reasons for the results were discussed, for instance, that the management strategies were not suited for male victims of IPV, in line with the previous study.

\section{The global risk assessment}

Global risk assessments generally have a lower number of missing values by comparison with the individual factors (e.g. Belfrage, 2008; Belfrage \& Strand, 2012). As has previously been mentioned, the SPJ approach lacks rules regarding how factors should be combined to form a global risk assessment (see Table 1). However, even if the presence of a single risk factor in the SPJ tool can motivate a high global risk assessment (Kropp \& Hart, 2015) the overall expected pattern is that a higher number of risk factors indicates a high global risk, and vice versa (see Figure 1). Such a relationship between the total 
number or the presence of risk/victim vulnerability factors and global risk assessments has been found in a number of studies (Belfrage et al., 2012; Kropp \& Hart, 2004; Storey et al., 2014).

\section{The influence of individual risk factors on the global risk assessment}

There are a few studies that have evaluated the influence of individual risk factors on global risk assessments (Nesset, Bjørngaard, Nøttestad, Whittington, Lynum, \& Palmstierna, 2017; Petersson et al., 2016; Robinson, Pinchevsky, \& Guthrie, 2016; Trujillo \& Ross, 2008). The overall results show that the number of items that are significantly related to the global risk measures is usually small. Trujillo \& Ross (2008), for instance, evaluated a tool called the Family Violence Risk Assessment and Management Report $\left(\mathrm{L} 17 \mathrm{~A}^{16}\right)$. In an analysis of the most important factors, the shared variance in the assessments was less than .50, meaning that other factors contributed to the global risk assessment to a greater extent that these factors. In the study of the offender typology described earlier, Petersson et al. (2016) examined the predictive validity of all B-SAFER risk factors ${ }^{17}$ in relation to the global risk assessments. In the overall models ${ }^{18}$, one or two individual risk factors in each model significantly predicted the global risk assessments. These results are in line with results from a study in which police officers in the UK and the US rated the importance of different risk factors for the evaluation of IPV (Robinson et al., 2016). Police officers from both countries perceived four risk factors to be very important for the risk assessment; physical assault resulting in injury, strangulation, using or threatening to use a weapon and escalation of abuse (ibid., p. 11).

In a recent study conducted in a Norwegian police setting, researchers examined the relationship between B-SAFER risk factors and police response in terms of the immediate arrest of offenders and the relocation of victims (Nesset et al., 2017). Of the 15 B-SAFER factors, the police officers' decisions regarding immediate arrest or victim relocation were found to be based on six factors. Offenders characterized by substance misuse or offenders who had used physical violence were most likely to be arrested. The importance of

16 Information from the Standard Incident Report (L1) and the Family Incident Report (L17) was also used in the evaluation.

17 Risk factor 6, General criminality was excluded, since the offender typology was based on this factor.

18 Four models were tested, one for each group, using global risk as the outcome measure. 
physical violence was thus in line with the previously described results presented by Robinson et al. (2016). Offenders characterized by escalating violence were less likely to be arrested and their victims were less likely to be relocated (Nesset et al., 2017). According to the authors, this finding is worrying, since escalating violence is a risk factor for fatal violence. Factors associated with an increased likelihood of victim relocation were the presence of children or offender mental health problems.

\section{Inter-rater reliability}

Little is known about the level of inter-rater reliability in police employees' violence risk assessments. I have not been able to find any studies that have evaluated the consistency of police officers' IPV risk assessments. However, there are a number of studies that have compared various practitioners' violence risk assessments with the assessments of academics. For example, Dayan, Fox and Morag (2013) compared the consistency of investigators' and psychology students' assessments using the Spousal Violence Risk Assessment Inventory (SVRA-I) tool. Nineteen cases were included, and each case was assessed by one investigator and two students. The investigators collected data for the assessment by summarizing for instance interview answers from the offender and also the investigator's own perceptions of the offender. Both the investigators and the students based their assessments on this information. The global risk assessments, which consisted of a summed score of the items in the assessment, were compared by computing correlations. Overall, the relationships were strong: $r=.68, .73$ and $.75(p<.01)$. The first two correlation coefficients relate to the comparisons between the investigators' and the students' assessments while the final coefficient relates to a comparison among the students' assessments.

In another study, 86 SARA assessments conducted by staff from correctional settings were compared with the assessment of a clinical psychologist (Kropp \& Hart, 2000). The correctional staff based their ratings on historical information relating to the specific case and an interview, whereas the psychologist only used the historical information. Intraclass correlation (ICC) analyses were conducted in order to compare the individual items, total scores, factors present and critical factors and global risk assessments. The median ICC for the individual items was moderate (.65) and for the global risk assessment it was similar $(\mathrm{ICC}=.63)$. The consistency of the total scores was 
higher (total score, ICC $=.84$, Part 1 , ICC $=.68$ and Part 2, ICC $=.87$ ). The lower consistency for the first part of the SARA compared to the second was suggested to be due to the clinical psychologist possibly assessing the mental health factors more systematically than the correctional staff.

In some studies, cases that have been assessed more than once have been followed up with regard to the stability of the assessment (e.g. Belfrage et al., 2012; Sebire \& Barling, 2016; Storey et al., 2014). The last of these studies examined the DASH assessments of 38 specialist police investigators (Sebrie \& Barling, 2016). The focus was directed at the stability of the global risk assessments (low, medium, high) at the time of a repeat assessment. Between the two assessment occasions, the participants were reminded of the definitions of the national risk grading. The participants came from five different locations in London, and the police officers conducted the assessments individually, assessing four cases each. Those participants working at locations with a high number of domestic violence cases used the lower risk levels to a larger extent than participants working in locations with lower numbers of domestic violence cases. The level of consistency among the officers' first-time assessments was low (ICC $=.18, p<.05$ ), with a small increase at the second assessment (ICC $=.28, p<.001)$, although this change was not statistically significant. $34 \%$ of the participants changed their assessment on the second occasion, with the majority thus not assessing the cases differently.

Belfrage et al. (2012) and Storey et al. (2014) examined the stability in police officers' IPV risk assessments (using the SARA and the B-SAFER respectively) in cases that were repeatedly assessed during the study period $(\mathrm{N}=93$ in Belfrage et al., 2012, N= 59 in Storey et al., 2014). The comparisons focused on the total score, the global risk assessment and in Belfrage et al. (2012) on three mental health risk factors: 8) recent suicidal or homicidal ideation/intent, 9) recent psychotic and/or manic symptoms, 10) personality disorder with anger, impulsivity, or behavioral instability. Both the assessments of the total score and the global risk assessment had significantly increased at the second assessment in both studies. Consistency in relation to the total score was high (ICC $=.76$, the same in both studies) whereas it was lower in relation to the global risk assessment $(\mathrm{ICC}=.45$ in Belfrage et al., 2012 and $\mathrm{ICC}=.32$ in Storey et al., 2014). Consistency in relation to the individual factors was 
moderate (item $8, \mathrm{ICC}=.56,9, \mathrm{ICC}=.68,10, \mathrm{ICC}=.59) \quad($ Belfrage et al., 2012).

To summarize, knowledge regarding the inter-rater reliability/stability of police officers' IPV risk assessments is scarce. Overall those studies that do exist show considerable variation in the level of stability, from low (ICC $=.18$ in Sebrie \& Barling, 2016) to high (ICC= .76, in Belfrage et al., 2012; Storey et al., 2014).

\section{The predictive validity of IPV assessments}

Predictive validity is used synonymously with predictive accuracy, and relates to the ability of a tool to identify true positive and true negative cases. The predictive validity of police employees' violence risk assessments using IPV recidivism as the outcome measure has to date only been examined in a few studies (Belfrage \& Strand, 2012; Belfrage et al., 2012; Lauria, McEwan, Luebbers, Simmons, \& Ogloff, 2017; Storey et al., 2014). All but one of these studies were conducted in Swedish police settings. The tools employed were the SARA (used in Belfrage et al., 2012), the B-SAFER (used in Belfrage \& Strand, 2012; Storey et al., 2014) and the Ontario Domestic Assault Risk Assessment (ODARA, Hilton, Harris, Rice, Lang, Cormier, \& Lines, 2004, used in Lauria et al., 2017). I will begin by describing the study by Belfrage and Strand (2012), and will then move on to present the other two studies conducted in Swedish police settings (Belfrage \& Strand, 2012; Storey et al., 2014). Since these two studies are related to each other methodologically, they will be described together. Finally, the most recent study, focused on the predictive validity of ODARA assessments conducted by police officers in an Australian police setting, will also be summarized (Lauria et al., 2017).

The main aim of Belfrage and Strand's (2012) study was to examine the predictive accuracy of the B-SAFER. The 216 B-SAFER assessments included in the sample were collected over a period of 20 months and the suspected offenders were all males. In cases in which additional assessments had been conducted during the data collection period, only the first assessment was included. The follow up included information regarding repeat IPV, sentences (if any) and implemented protective actions, and the follow-up period ranged between 28 and 48 months. In $42 \%$ of the cases, repeat IPV occurred during the follow up, despite the fact that a high level of protective actions had been 
implemented - in $68 \%$ of the cases. The level of protective actions was higher in cases assessed as high-risk in the form of both imminent/acute- and severe/fatal violence. These relationships were statistically significant.

In the next step, the rates of repeat IPV in the low-, medium-, and high-risk groups (for both imminent/acute and severe/fatal violence) were compared. There were no significant differences. Thereafter, the same comparative analyses were conducted, but with repeat IPV cases included only. Significant differences were found for the global risk assessment of severe/fatal violence; the higher the assessed risk, the lower the rate of repeat IPV. The authors suggested that these differences were due to the police having initiated effective protective actions in the most severe cases. However, the rate of repeat IPV was high, which was assumed to be related to the high levels of social problems in the geographical area in which the participants lived. The level of implemented protective actions in the sample was also considered to be low overall, and the B-SAFER was said to underestimate the global risk.

In line with Belfrage and Strand (2012), both Belfrage et al. (2012) and Storey et al. (2014) evaluated risk assessments conducted on male offenders suspected of IPV towards a current or former intimate partner. The SARA sample included 429 offenders (Belfrage et al., 2012) and the B-SAFER sample consisted of 249 offenders (Storey et al., 2014). The suspected offenders were 18 years or older and had been reported for the index offence during a specified period of time. In addition to the risk assessments, information was also collected regarding recommended protective actions, IPV recidivism and subsequent risk assessments with their associated protective actions, based on a follow-up period of 18 months from the initial police response in Belfrage et al. (2012) and 11 months from the initial police contact in Storey et al. (2014). The rate of repeat IPV was $21 \%$ in the SARA study (Belfrage et al., 2012), and $24 \%$ in the B-SAFER study (Storey et al., 2014).

Three hypotheses were tested in Belfrage et al. (2012) and Storey et al. (2014): The police officers' risk assessments will 1) be positively associated with recommended protective actions and 2) predict recidivism. Further, the recommended protective actions will 3) mediate the association between risk management and recidivism. However, different cases (low- vs. high-risk) will be affected in different ways by the recommended protective actions, as 
suggested by Andrews and Bonta's (2010) RNR model of correctional assessment and treatment.

The first and the second hypotheses were confirmed in both studies: the number of recommended protective actions was positively correlated with both the global risk assessments and total scores. However, the strength of the correlation between the risk assessment and repeat IPV varied across the different risk measures (global risk and total score) for both tools. The predictive accuracy of the B-SAFER total score on IPV recidivism was medium $($ AUC $=.70)$ (Storey et al., 2014) and somewhat lower for the SARA total score with outcome IPV recidivism $(\mathrm{AUC}=.63)$ (Belfrage et al., 2012).

In order to examine the third hypothesis, a number of different analysis were conducted. Step-wise logistic regression analyses showed that both the SARA total score and the number of recommended protective actions significantly predicted IPV recidivism, as did the interaction between them (Belfrage et al., 2012). In Storey et al. (2014) both risk assessment measures (global risk and B-SAFER total score) predicted IPV recidivism significantly. The number of recommended protective actions, on the other hand, did not. Examining the predictive accuracy of the risk assessment and protective actions in interaction led to varying results for the different risk measures. The B-SAFER global risk assessment and protective actions predicted IPV recidivism, but the B-SAFER total score and the protective actions did not predict IPV recidivism.

Further, the RNR model was tested and found to be supported in both studies. The test was conducted by comparing rates of recidivism in high- and low-risk cases, with either a low or a high level of recommended protective actions. There was a lower rate of IPV recidivism in high-risk cases with a high level of recommended protective actions, compared to high-risk cases with a low level of recommended protective actions. For the low-risk cases, the rate of recidivism was lower in cases with a low level of recommended protective actions, compared to cases with a high level of recommended protective actions. These findings emerged in both studies, although with somewhat different rates of recidivism in the different risk groups.

A mediating test confirmed that the association between the SARA total score and repeat IPV was mediated by the number of recommended protective 
actions (Belfrage et al., 2012). Another mediating test was conducted in the BSAFER sample, which showed that the number of recommended protective actions did not mediate the relationship between the risk assessment and IPV recidivism (Storey et al., 2014). Finally, the SARA tool was suggested to be an effective tool in preventing IPV recidivism (Belfrage et al., 2012), but the BSAFER tool was suggested to have some advantages over the SARA in this specific context, e.g. there was a lower rate of missing values on the individual risk factors and the correlation between the global risk assessment and repeat IPV was stronger.

The ODARA tool was developed to be used by frontline police officers (Hilton et al., 2004). However, the study by Lauria et al. (2017) is the first study of the ODARA in which police officers have conducted the risk assessments. The ODARA is an actuarial risk tool and includes 13 risk factors for IPV recidivism. The study was conducted in an Australian police setting and included a sample of 200 IPV cases. The total scores of the ODARA were summed to produce a global risk assessment.

The aim of the study was to examine the predictive accuracy in relation to two different outcome measures: 1 ) repeat physical violence that led to a charge and 2) police-reported offences other than physical violence. Both measures were limited to cases involving the same victim as in the index crime. Overall, repeat victimization occurred in $18.5 \%$ of the cases. There were 19 repeat physical violence offences and 23 repeat offences of other kinds. In some cases, there was more than one repeat offence. Looking at the individual ODARA factors, three out of 13 factors were significantly associated to physical assault recidivism: item 2 (prior nondomestic incident), 3 (prior custodial sentence of 30 days or more), 10 (violence against others ${ }^{19}$ ) (Lauria et al., 2017, p. 1550). Three other factors were significantly associated to the nonphysical violence outcome: item 5 (threat to harm or kill at the index assault), 7 (victims concern) and 11 (substance abuse) (ibid., p. 1550). The predictive accuracy for physical violence recidivism and for non-physical violence was medium (AUC $=.68$ and .72 , respectively). Focusing on the physical violence outcome, the positive (PPV) and negative predictive values

19 Prior violence toward another victim and having a police record of non-domestic violence were coded identically in the study. 
(NPV) for all different cut-off scores ranged between .10 and .24, and .92 and 1.0 , respectively. There was thus no balance between the different values.

Since studies of predictive accuracy are few and differ in many respects, e.g. examining different tools, using different analytical strategies and different definitions, comparing their results is problematic. However, the overall conclusion based on the existing findings is that predictive accuracy has been low to medium (Belfrage \& Strand, 2012; Belfrage et al., 2012; Lauria et al., 2017; Storey et al., 2014). In the SPJ studies, this finding was suggested to be due to effective recommended/implemented protective actions that reduced the level of IPV recidivism and thus affected the measures of predictive validity (Belfrage \& Strand, 2012; Belfrage et al., 2012, Storey et al., 2014). However, since the results of these studies varied in some respects, the effectiveness of IPV risk assessment and management is not fully understood.

\section{Time to repeat IPV}

In a recent study (Petersson \& Strand, 2017) based on almost the same population as the study by Petersson et al. (2016), different aspects of IPV recidivism among antisocial- and family-only offenders were evaluated. The antisocial offenders recidivated into more IPV crimes, and a larger proportion of these offenders recidivated compared to the family-only offenders. The extent to which the antisocial- and family-only offenders recidivated did not differ during the first eight months. Between nine to ten months and after the first year, the antisocial offenders were more likely to recidivate compared to the family-only offenders. Finally, time to recidivism in violent crime did not differ between the groups, but time to recidivism in non-violent crime did. Antisocial offenders recidivated more quickly in non-violent crime than the family-only offenders. One of the implications of this and the former study (Petersson et al., 2016; Petersson \& Strand, 2017) regarding the differences among IPV offenders, which was highlighted by the authors, is the need to differentiate recommended protective actions due to the different needs of different offenders. In another study, the average time to IPV recidivism in a sample of 200 IPV cases was approximately 112 and 97 days, for physical and non-physical violence, respectively (Lauria et al., 2017). 


\section{Interventions to prevent repeat IPV}

Crime prevention strategies in general can be categorized based on the level of intervention, e.g. interventions focused on 1) producing an effect at a general level, e.g. through education (primary prevention), 2) risk groups (secondary prevention) or 3 ) individuals already affected by a specific problem (tertiary prevention) (see Brantingham \& Faust, 1976). In the case of intimate partner violence, primary prevention may include strategies to change attitudes to violence. At the secondary level, interventions include, for example, initiatives involving the routine use of IPV screening procedures in healthcare settings (Murray \& Graybeal, 2007). In this thesis, the focus is directed at the prevention of repeat violence, i.e. tertiary level prevention (e.g. restraining orders and safety alarms).

IPV interventions can be further categorized into IPV preventive interventions focusing on the offender and protective interventions focusing on the victim (Maxwell \& Robinson, 2013). Since there are some differences in the way IPV preventive strategies are used in different countries, and since the studies included in this thesis focus on Swedish police settings, this summary is limited to interventions recommended ${ }^{20}$ by the Swedish police and interventions that are similar to these. In addition, interventions initiated by victims themselves will also be described.

A recent report by the Swedish National Council for Crime Prevention (NCCP, 2017) regarding police methods to prevent recidivism in IPV offenders has concluded that the scientific knowledge in the field is limited at both the national and international levels. The two offender-focused interventions that are used in the Swedish setting are offender dialogues conducted by a police employee and restraining orders. The first of these has to my knowledge not yet been evaluated. On the other hand, the effectiveness of restraining orders on IPV recidivism has been studied somewhat more often.

20 The word recommended rather than implemented is used here since some of the interventions that are recommended by the police are implemented by other actors (e.g. prosecutors and the social services). 


\section{Restraining order}

Restraining orders $(\mathrm{RO})^{21}$ are used in many countries in cases of IPV, and even if there are differences in the use of ROs, the main objective is similar, i.e. to protect the victim from repeat victimization (Strand, 2012). A review by Russel (2012) examined different aspects of the effectiveness of ROs, for example the violation of ROs and reduced levels of repeat violence. Thus, the studies included in the review were not limited to IPV cases. In total, 39 empirical research studies and 4 review studies were included. In sum, the rates of violated ROs ranged from 30 to $70 \%$ and the results regarding the levels of repeat violence in RO cases were mixed. In some studies, the level of violence (physical and psychological) increased following the implementation of ROs while other studies found reduced levels of violence. However, the latter results were given more weight since they came from a number of largescale studies. Russel also discusses some of the difficulties associated with examining the effectiveness of ROs, for example, what should be regarded as an "acceptable" level of re-offending following the implementation of ROs, for the RO still to be labeled effective, and whether a reduced level of violence indicates a real reduction in violence or whether it is due to the fact that victims are not reporting repeat offences.

In a summary of IPV interventions, Maxwell \& Robinson (2013) briefly summarize the results of 21 studies in which the connection between ROs and IPV recidivism and/or repeat victimization was evaluated. In line with the previous study by Russell (2012), the results were mixed. However, the most prevalent finding according to the authors was that there were no significant differences in the rates of recidivism/repeat victimization between those with an $\mathrm{RO}$ and those without. The most recent of the studies included in the summary was conducted in a Swedish police setting (Strand, 2012). In order to recommend protective actions, police officers examined the risk of future violence using the B-SAFER tool. In each case, the global risk (short-term/ long-term and very serious violence) was specified as either low, medium or high. All cases were followed up to examine whether there was any recidivism into new offences (28-52 months), and what protective actions had been implemented following the B-SAFER assessment. ROs had been applied for in

21 Also known as: protection order, stay-away order, protection from abuse order, domestic violence restraining order, intervention order, civil harassment restraining order, or an anti-harassment order (Strand, 2012, p. 255). In the following, the term restraining order $(\mathrm{RO})$ will be used, to get consistency in the text. 
101 cases, and of these the application had been granted in 61 cases. Thus an RO had been issued in 61 cases $(28 \%)$; in 40 cases $(19 \%)$ the application had been denied, and in 113 cases $^{22}(53 \%)$ an RO had not been applied for. A comparison between these groups showed that the cases that were granted an $\mathrm{RO}$ were more severe compared to the other cases in terms of some of the BSAFER items (they had higher scores on 8 of the 15 items), the global risk (they were assessed as being at higher risk of recidivism in the short- and long term) and the sentences imposed for the index crimes (which were prosecuted in court, and led to convictions and prison sentences more often).

The follow up showed that IPV recidivism (same offender and victim) occurred in 90 cases: 28 RO-cases, 16 of the cases where an RO had been denied and 45 of the cases in which an RO had not been applied for. The rates of recidivism were relatively similar in the different groups (between 41 and $48 \%$ ). Among the cases in which an RO was applied for (granted or denied), there was a higher rate of recidivism in those cases assessed as high-risk than in cases assessed as low- or medium-risk for long-term recidivism. Looking specifically at the $28 \mathrm{RO}$-cases, the most common repeat IPV crimes were assaults and threats. In four of the repeat cases, the only offence was a violation of the $\mathrm{RO}$. At the same time, the rate of repeat violent crime was lower in $\mathrm{RO}$ cases compared to the other two groups.

In sum, the RO was suggested to be ineffective in preventing IPV in general (Strand, 2012). However, comparing different IPV cases, ROs seemed to be more effective in preventing repeat IPV in low- and medium-risk cases. Further, it was suggested that the RO might have a protective effect during the period covered by the RO, since a majority of the repeat IPV crimes were committed either prior or subsequent to the period of the RO.

\section{Safety alarm}

A study by the Swedish National Council for Crime Prevention (NCCP, 2015b) followed up the use of safety alarms. One of the aims was to evaluate whether safety alarms were effective in preventing threatening situations (not only in IPV cases). A survey was distributed to individuals who had recently had a safety alarm (had returned it during the last six months) and who were

22 In eight of these cases, an RO was granted after the victim had been re-victimized. 
not currently living under an acute threat. 103 persons answered the survey ( $38 \%$ of the sample). $17 \%$ of the population had used the alarm (pressed the alarm button on purpose) at least once. The data regarding the use of the alarms among the total (national) sample are somewhat uncertain; however approximately $90 \%$ of the individuals who received an alarm from the police between 2010 and 2013 did not have to press the emergency button. According to the authors of the study, it was difficult to determine whether the alarms were preventing threats. However, $50 \%$ of those who completed the survey agreed that the alarm prevented such threats and the other $50 \%$ said it partly did so. 99 of the 103 persons in the sample stated that they felt more safe with the alarm. In addition to the survey, interviews were conducted with 16 of the persons included in the survey. Among these, the majority had been threatened by a former partner. All of those interviewed stated that they felt unable to relax completely despite having the alarm. On the basis of this finding, the authors suggested that the alarms did not provide a false sense of security.

\section{Home-visit intervention}

A number of studies have examined home-visit interventions in IPV cases (e.g. Jack et al., 2012). Even though some of the specific interventions included in the home-visit intervention are comparable to interventions used in Swedish legal settings, overall the initiative does not resemble those actions implemented by the Swedish police. The following description presents an example of an evaluation of a domestic violence home-visit intervention (DVHVI), in which the effectiveness of the intervention was evaluated using police-reported repeat IPV incidents as the outcome measure (Stover, Poole, \& Marans, 2009). The intervention took place shortly after reported incidents (usually within 72 hours). In addition to arresting the offender, the intervention included a range of different services; provision of an emergency phone, conducting a safety plan, providing information on sheltered/alternative housing and protection orders, providing help with a temporary RO and court advocacy, providing information/discussions regarding IPV (for educational proposes), mental health screening (for adults and children), mental health crisis intervention, follow-up home visits and meeting with an advocate. Since the interventions differed for different victims, the cases were divided based on the time spent implementing the interventions (high dosage group, low dosage group, no contact, control 
group). There were some differences between the groups. The reported crimes that lead to the implementation of DVHVI (i.e. the index crime) were more often crimes of physical violence in the high dosage group, and bidirectional violence in the low dosage group. The charges were more severe in the control group compared to the other groups.

The overall results showed that the high dosage group did contact the police more frequently than the other groups. However, there were no significant differences regarding the severity of repeat IPV in the different groups, nor regarding the time of the first repeat IPV incidents (calls to the police). The separate interventions associated with the DVHVI (i.e. police-, mental healthand follow-up services) were also analyzed in relation to recidivism. Mental health services predicted reported recidivism significantly, but the other two interventions did not. Examples of other factors that were relevant to the likelihood of calling the police in cases of repeat IPV were the severity of the index crime (higher severity - lower likelihood of calling the police) and the match of the language/culture between the victim and the DVHVI team (Hispanic women were less likely to call the police when the DVHVI team were non-Hispanic).

\section{Victim strategies}

Previous studies have shown that victims use different strategies to deal with IPV (e.g. Anderson, Renner, \& Bloom, 2013). The Intimate Partner Violence Strategies Index (Goodman, Dutton, Weinfurt, \& Cook, 2003), for example, includes six categories of strategies: resistance, placating, legal, formal network, safety planning, and informal network. The following descriptions and examples are all drawn from Goodman et al. (2013). The main aims of the first four categories (resistance, placating, legal, formal network) are to change the offender's behavior. For instance, the resistance category includes strategies to challenge the offender's sense of control (e.g. breaking up from the relationship), whereas the placating category instead includes strategies that rather function to support his/her sense of control (e.g. following the will/wishes of the offender). Some strategies are conducted in the private sphere (e.g. the hiding of money or other valuables), some in the non-legal public sphere (e.g. medical contacts) while yet others use the legal system (e.g. applying for an RO). The last two categories (safety planning and informal network) relate to strategies that involve preparing to escape/protect oneself 
from potential future violence. The strategies included in the safety planning category remain in the private sphere (e.g. planning how to escape), whereas the informal network category strategies involve public support (e.g. staying with friends/family). In a recent study by Irving and Liu (2016), female IPV victims were reported to use many different strategies to protect themselves from future IPV. Placating strategies were used the most and were considered helpful by many of the victims. However, some strategies were considered helpful by some victims, but not by others. Thus there do not seem to be protective strategies that are universally considered to be helpful. The placating category significantly predicted scores on the risk tool employed in the study, DASH. A suggested interpretation was that this kind of protective strategies might increase the risk of IPV. However, the placating strategy only explained a small proportion of the variance $(14 \%)$.

In summary, there are a number of different approaches to violence risk assessment with related assessment tools. Those used within the Swedish Police Authority are mainly SPJ tools, and the police use them in order to prevent repeat violence. The number of studies focused on risk assessment in police settings has increased over recent years. Studies have shown that both risk- and victim vulnerability factors can be assessed in police settings, but that some factors are more difficult to assess than others. Factors related to mental health problems are one example of factors that are generally difficult for police officers to assess, and this seems to be due to the limited availability of relevant information and a lack of training in how to assess them (see Belfrage, 2008).

Knowledge regarding the predictive accuracy and inter-rater reliability of police officers' IPV risk assessments remains limited. I have not been able to find any studies that have compared the consistency of police officers' IPV assessments. There is somewhat more knowledge regarding the predictive validity of such assessments. Three different tools (B-SAFER, SARA, ODARA) have been evaluated in four studies (the B-SAFER twice, the other tools once). In some areas the results are similar, while they differ in other areas. Overall, levels of predictive accuracy are varying $(A U C=.57-.70)$. Interventions that have been recommended/initiated subsequent to assessment are suggested to prevent repeat IPV in high-risk cases, and thereby to influence predictive accuracy. Knowledge on the effectiveness of these measures is scarce however, 
which complicates interpretations of the research results. In short, further research is needed to ensure the quality of IPV risk assessments. 


\section{AIMS}

The overall aim of the thesis is to contribute to improving the knowledge on police employees' violence risk assessment and management, and more specifically on the predictive validity and inter-rater reliability of such assessments.

The specific aims of the four studies included in the thesis were:

To evaluate whether the Police Screening Tool for Violent Crimes (PST-VC) can be used by police employees to identify high-risk cases of repeat intimate partner violence (IPV). The aim was also to discuss the preventive effects of the recommended crime preventive and victim protective interventions and whether these interventions create a confounding problem with respect to predictive validity. (Study I)

To examine the inter-rater reliability of the Police Screening Tool for Violent Crimes (PST-VC) and the Brief Spousal Assault Form for the Evaluation of Risk (B-SAFER), as used by police employees in two different police authorities in Sweden. (Study II)

To examine to what extent the risk and victim vulnerability factors in the BSAFER predicted the global risk assessments, and to evaluate the predictive accuracy of both the individual B-SAFER factors and the global risk assessments with regard to repeat IPV. The aim was also to study to what extent recommended protective actions were implemented, an issue that has only rarely been addressed in previous studies, and to examine the preventive effect of the implemented protective actions on repeat IPV. (Study III) 
To investigate which different practitioner groups conduct intimate partner violence risk assessment, the required prerequisites in terms of violence risk assessment education/training, and whether the tools used were used as recommended. The aim was also to study the predictive accuracy of their assessments with regard to repeat IPV and to examine the role of the protective measures in relation to studying predictive accuracy. 


\section{METHODS}

Studies I, II and III were based on data collected in two different police authorities in Sweden, and focus on risk assessments conducted by police employees. Studies I and II evaluate violence risk assessments (IPV cases in Study I and general violence cases in Study II) conducted using the PST-VC, and Studies II and III evaluate B-SAFER assessments. This section begins by presenting the definition of intimate partner violence employed in the studies, and then describes the risk assessment procedures employed by the two police departments. It then goes on to present the study design, data and population for each study. This is followed by a description of the main variables and the analytical strategies employed in the studies. Study IV is a systematic review of the literature regarding the predictive validity of practitioners' IPV risk assessments. The method used in the review will be presented separately from the other studies. The final part of this section discusses ethical considerations.

\section{Defining intimate partner violence}

IPV refers to crime between current or former spousal partners (Studies I-III). We decided to include all types of crime in the term intimate partner violence (the same applies to IPV recidivism). Thus, the offences did not have to be violent crimes, but could involve other crimes against the victim; threats, damage and violation of a $\mathrm{RO}$ were included, for example. IPV recidivism did not have to involve the same type of offence as the initial crime (the offence that had resulted in the risk assessment).

Both the initial crimes, that resulted in the risk assessments, and the follow-up crimes were incidents that had been reported to the police, which means that they may be assumed to include the most severe offences (see NCCP, 2008). 
On the other hand, it is well know that the number of unreported cases is high for cases of IPV (Garcia, 2004).

In Studies I and III, IPV recidivism/repeat IPV (used synonymously) was studied by following up whether the suspected offenders repeatedly committed IPV against the same partner. In some other studies, IPV recidivism has included new IPV offences against either the initial victim or a new spousal partner (e.g. Williams \& Houghton, 2004). The latter definition was used in the final study included in the thesis (Study IV).

Since the violence risk assessments examined in the thesis were conducted soon after the crimes had been committed, the offenders are suspects and have not been convicted. However, the studies nonetheless refer to them as offenders.

\section{Selection procedure}

In the Swedish Police Authority, risk assessments are generally conducted according to a three-step model; (1) initial (screening) assessment, (2) structured assessment, (3) in-depth assessment. In the following, the risk assessment processes of the two police departments will be presented as a means of describing which cases are selected for the second step, the structured assessment.

Since 2015, all cases of threats and violence (according to specific crime codes) reported to the Swedish police are screened by the person receiving the report, to identify cases involving a heightened risk of recidivism. This process is administered by means of a mandatory question (is there a threat, and are further interventions required?) in the Police Authority's notification system (Rationell Anmälningsrutin, RAR). Thus, the question must be answered in order to complete the notification (options: yes/ no/ do not know). This screening procedure was developed at the Scania police department, and was used in this specific police department when the PST-VC assessments evaluated in Studies I and II were conducted (in 2010). The screening was not conducted using any specific tool or guidelines, but was instead based on the assessor's professional knowledge. The screening were forwarded to police employees who had been employed to conduct violence risk assessments and 
recommend interventions to prevent repeat crimes. Once they had reviewed the screening, PST-VC assessments were conducted in high-risk cases.

There were eight police employees conducting the PST-VC assessments in Study I. Some of these were police officers, while others had a different educational background and/or work experience. The length of their employment at the police department varied, as did their experience and training in the assessment of violence risk. The latter was generally quite limited. The PST-VC assessment procedure includes recommending crime preventive and/or victim protective actions. The rater is responsible for the implementation of some of these measures (e.g. providing victims with alarms and discussing strategies to reduce the risk of re-victimization with victims), while the implementation of other measures is the responsibility of other actors (e.g. issuing ROs and providing sheltered accommodation). In these latter examples, the police can offer support, for instance by helping the victim to file an application for an $\mathrm{RO}$ or by contacting a victim shelter. In some cases, the rater has subsequent contacts with the victim. However, the majority of the cases are not followed up.

The B-SAFER cases evaluated in Studies II and III were also screened prior to the B-SAFER assessment according to almost the same procedure as the PSTVC cases. One difference from the routines employed by the Scania police was that the screening procedure was based on a questionnaire that included questions regarding the offender/s and victim/s. Based on these, the assessor was required to conduct an overall assessment and answer two final questions: How dangerous is the present situation? Is there a need for protective actions? The results of the initial screening were documented in the RAR-system and forwarded to the rater via a victim coordinator. Based on the type of crime, the rater chose an SPJ tool (either the B-SAFER, SAM, PATRIARK or CHECK-10(+)), conducted the assessment, recommended crime preventive and/or victim protective actions and forwarded the assessment to the team leader, who decided in which cases interventions were required. In these cases, specific police employees proposed crime preventive and/or victim protective actions based on the recommendations in the assessment. The aforementioned team leader then made a final decision on the implementation of interventions. Three police employees conducted the B-SAFER assessments examined in Study III. They were all trained in assessing violence risk and had the task of 
conducting violence risk assessments as part of their daily work. As was the case with the PST-VC raters, not all of them were police officers. In contrast to what is recommended in the B-SAFER guidelines, the assessors did not contact the victims prior to conducting the assessment. This decision was made based on the assessors' wishes not to be influenced by the victims' stories and thereby biased in their assessment.

In the final step of the risk assessment procedure (in both of the police departments studied), an in-depth assessment is conducted. This type of assessment is only produced in a small number of cases which, for instance, present a high level of complexity and thus require a more rigorous assessment. The in-depth assessments and related procedures will not be described further in this thesis since they were not evaluated in any of the studies.

Of the cases that were screened at the time of the police report, approximately $4 \%$ (600 cases) were assessed with the PST-VC in the Scania police department in 2011 (Mellgren et al., 2012) and in the same year, approximately $5.5 \%{ }^{23}$ (388 cases) of the cases that were screened in the other police department were assessed with either the B-SAFER, SAM, PATRIARK or CHECK-10(+) (the Swedish National Police Authority, 2012).

\section{Study design, data and populations}

The data in Studies I-III consist of IPV risk assessments, recommended crime preventive and victim protective actions (as well as implemented interventions for the B-SAFER cases in Study III). Studies I and III also include information on repeat IPV. The assessments in both these studies were conducted in a natural setting, i.e. as a part of the raters' day-to-day work. This is a strength of the data, since the assessments are thus unaffected by response bias. The study design also implies that the raters did not know whether or not repeat IPV was going to occur in the cases examined, which is similar to the prospective design used by Belfrage et al. (2012). It was not possible to employ this design in Study II, since pairwise assessments were required to study the inter-rater reliability, and cases are usually not assessed by more than one rater. Thus most of the assessments in Study II were conducted specifically for

23 In some cases the need for a structured professional judgment was identified later, for instance at the time the case was investigated. These cases are included in the $5.5 \%$. 
the purposes of the study. In the following, the data and populations are further described for each study.

\section{Study I}

The sample in Study I consists of all PST-VC assessments regarding intimate partner violence conducted by the Scania police in 2010. Originally, the sample consisted of 71 assessments. However, a number of cases were excluded due to a lack of important information; three assessments lacked information regarding global risk assessments, and two assessments lacked information regarding whether or not repeat IPV had occurred. In addition, in one case two assessments had been conducted in 2010. Here the most recent assessment was excluded. The final sample consisted of 65 PST-VC assessments. The low number of cases, compared for instance to the number of PST-VC assessments conducted in 2011 (presented above) may be due to two reasons: First, the PST-VC tool and the related risk assessment process was new and there was a lack of routines regarding the assessment procedures. Thus it is possible that some cases that should have been assessed using the PST-VC were not identified by the screening procedure and therefore were not assessed or were identified in the initial assessment/in another way, but assessed by other means than the use of the PST-VC. Another possible reason for the low number of cases may be that all assessments were not filed in accordance with the official routine, and thereby not included in the sample. Finally, Study I only includes IPV cases, whereas the above-presented number of cases assessed in 2011 relates to all types of PST-VC assessments.

All suspected offenders were men $(\mathrm{N}=65)$, with a mean age of 34 (range 1874). Almost all of them ( $95 \%$ ) had been registered by the police for offences prior to the index crime. In 64 of the cases, the victim was a woman and in one case, the victim was a man. The mean age of the victims was 33 (range $19-68)$. In a majority of the cases $(80 \%)$ there was a history of police-reported IPV (threats or violence) prior to the index crime.

As has previously been mentioned, the PST-VC assessments included the raters' recommendations of crime preventive and victim protective actions. In some cases, interventions had been implemented prior to the assessment (e.g. the police had already contacted the victim), but in most cases the recommendations were made in connection with the assessments. The data did 
not include information regarding which interventions were actually implemented, since such data were not available. Implemented interventions were not followed up by the police. However, a follow-up focused on repeat IPV was conducted in all cases by the Scania police for the purposes of this study. This information included all reported crimes with the same victim and suspected offender from the date of assessment until April 2012 (range 16-28 months).

\section{Study II}

Study II consists of two samples; one comprising cases assessed with the PST$\mathrm{VC}$ and one comprising cases assessed with the B-SAFER. The PST-VC sample included 17 cases, with each case being assessed three times. The first assessment was the original assessment conducted at the time of the police report. The other two assessments were conducted subsequently specifically for the present study. A total of ten police employees conducted these new assessments and they were randomly paired. Some of the raters were trained police officers and some were not, but they were all assigned to conduct violence risk assessments as part of their job at the police.

The B-SAFER sample consisted of 23 cases which were each assessed twice, by different raters. The first assessment was the original assessment, and the other assessment was conducted subsequently specifically for the present study. The assessments were conducted by three raters, who were either police officers or persons with other training and experience. They all conducted violence risk assessments as part of their day-to-day work at the police authority. All three possible pairwise combinations of raters were included in the study. One pair conducted six pairwise assessment, another pair eight assessments, and the final pair conducted nine assessments.

\section{Study III}

In Study III, all B-SAFER assessments conducted by a specific police department between March 2011 and December 2012 were examined. However, 20 assessments from the original sample were excluded; in 11 cases, assessments of all the risk- and victim vulnerability factors were lacking and in an additional nine cases, the information was insufficient in one way or the other (for instance, cases where the victim was said to be a man, but where the reported repeat IPV was "violation of a woman's integrity"). The final sample 
consisted of 301 assessments; 114 conducted in 2011 and 185 in 2012. Information on the assessment year was missing in two cases.

The population consisted of 287 male offenders, 11 female offenders and in three cases, information regarding the sex of the offender was missing. 288 of the victims were women, 11 were men and in two cases, the sex of the victim was missing. The mean age of the offenders was 41 (range 19-77 years) and mean age of the victims was 37 (range 16-69 years). Information regarding the offenders' age was missing in six cases, and such information regarding the victims was missing in three cases.

In addition to the different parts of the risk assessment (i.e. the risk- and victim vulnerability factors, the global risk assessments and the recommended interventions) we retrieved information regarding repeat IPV and interventions implemented by the police. The follow up ranged from the date of the risk assessment until October 2013 (range 10-32 months). Up to three offences of repeat IPV were included in the follow-up for each case. We also retrieved information regarding protective actions that were implemented during the follow-up period. Thus the information regarding interventions covered: recommended and implemented interventions following the risk assessment and prior to the first possible re-victimization (referred to as Time 1), between the first re-victimization and the second re-victimization (Time 2 ) and between the second and third re-victimization (Time 3).

\section{Main variables}

This section describes the main variables in Studies I-III.

\section{The PST-VC (Studies I \& II)}

In Study I, the explanatory variables consisted of global risk assessments and recommended protective actions. The police employees used a five point risk scale to assess the risk, ranging from $1=$ "no risk" to $5=$ "high risk". Due to the restricted range of the risk levels, the variable was dichotomized. Risk levels 1 and 2 were merged into a low-risk level, and risk levels 3 and 4 were merged into a high-risk level. Risk level 5 was not used in any of the cases.

The recommended protective actions were also dichotomized in Study I. The low-level protective actions were: victim support and security and/or victim 
support talk with the police. The high-level protective actions were: filing an RO application, contacting a victim shelter, protecting the identity of the victim, providing an alarm and contacting a special police security group that worked with high-risk cases.

The outcome variable was repeat victimization, measured as any new policereported crimes committed by the suspected offender against the same victim as in the index crime (i.e. the crime that led to the risk assessment). We also divided repeat victimization into violent crimes and other crimes (e.g. violation of an RO, interference in a judicial matter, unlawful threat).

In Study II, we compared pairwise PST-VC assessments conducted by different raters. In addition to their global risk assessments and recommended protective actions, we compared a number of different risk- and victim vulnerability factors. The offender risk factors were: access to weapons, previous violence, previous offences other than violence, threats and/or violence against the victim and social problems. The victim vulnerability factors were: fear of the offender, violence and offences other than violence. Threats and/or violence against the victim included both the index crime and prior criminality, which meant that threats and/or violence had occurred in all cases. We coded incidents in the risk assessment as either "threats", "violence" or "threats and violence". All other risk- and victim vulnerability factors were coded as either present (2), absent (0) or missing (1).

As compared to the dichotomized risk scale used in Study I, the original global risk scale (1-5) was used in Study II. The recommended interventions were also categorized slightly differently, based on the type of action. Information/support: contact with a victim support agency, the social services, a police employee, victim information and forwarding a case to the personal security group at the police. Victim protective actions: protect identity of victim, provide an alarm, contact a victim shelter, safety inspection of victim's home and security and/or victim support talk with a police employee. Offender prevention actions: offender dialogue with a police employee and applying for an RO. All interventions were not used in both settings. In cases in which different types of interventions were recommended, this was noted in the coding. 


\section{The B-SAFER (Studies II \& III)}

In both Studies II and III, the B-SAFER risk- and victim vulnerability factors and the global risk assessments were coded in the same way. The risk- and victim vulnerability factors were all coded in line with the B-SAFER guide: present (2), partly present (1) or not present (0). If none of these options was used by the raters, the factor was considered as missing. The global risk assessment was assessed with other risk measures than recommended in the BSAFER guidelines: the likelihood of further IPV and the severity of the potential repeat IPV. Both were rated on a five point scale, $1=$ low risk/no threat and 5= high risk/significant threat. In Study III, risk levels 1 and 2, and risk levels 3 and 4 respectively were merged into a low- and a high-risk level.

In Study III, we either replaced missing values on the risk- and victim vulnerability factors by type values, or when such values were not present, we computed linear regression analyses based on risk/victim vulnerability factors with replaced missing values as predictors and the variable whose missing values were going to be replaced as the outcome variable. The original distribution of 0,1 or 2 was retained as far as possible.

The recommended interventions were also analyzed in both studies (II and III), although the variable was coded in somewhat different ways. In Study II, the interventions were grouped based on the type of action (as described above). In Study III, the following recommended/implemented interventions were included: safety inspection of victim's home, security talk with a police employee, victim shelter, alarm, victim identity protection, $\mathrm{RO}$ and offender dialogue with a police employee. Since the number of implemented protective measures was so small, we dichotomized this variable into the options: no implemented interventions ( 0 ) or at least one implemented intervention (1).

In Study III, we also computed test variables, based on the risk- and victim vulnerability factors and the global risk measures, to predict repeat victimization. The test variables were computed by means of linear regression analyses (enter- and stepwise models), with risk- and victim vulnerability factors (current and past situation) as predictors and global risk assessments as the outcome variables. 
The outcome measures were repeat IPV and repeat violence (dichotomized: no $=0$ and yes $=1$ ), i.e. new police-reported crimes committed by the suspected offender against the same victim as in the index crime (Study III). The following types of repeat violent offences were committed at Time 1: lethal violence, physical abuse, rape, molestation, gross violation of a woman's integrity, unlawful coercion, unlawful persecution, unlawful appropriation and interference in a judicial matter. Repeat offences other than violence reported at Time 1 were: unlawful threat, illegal encroachment, fraud, damage, theft, false incrimination, defamation, violation of a restraining order, embezzlement and arbitrary handling of a child.

\section{Analytical strategy}

Several different analyses were conducted in Studies I-III. The main analyses are briefly described below.

\section{Kendall's tau (Studies I, II \& III)}

Kendall's tau was used to compute bivariate correlations in Studies I-III. Kendall's tau is a robust and powerful non-parametric method of statistical analysis (Winer, 1962), suitable for ordinal scale variables.

\section{Receiver operating characteristic (ROC) (Studies I \& III)}

The Receiver Operating Characteristic (ROC) analysis is perhaps the most frequently used statistical analysis in evaluating the predictive validity of assessment tools. The ROC analysis balances sensitivity and specificity and is graphically illustrated by a curve (Zou, O’Malley, \& Mauri, 2007). Sensitivity reflects the proportion of cases that recidivated among all cases assessed as high-risk, while specificity reflects the proportion of cases that did not recidivate among all cases assessed as low risk (Almvik, Woods, \& Rasmussen, 2000). The measure used in the analysis is called the area under the curve (AUC) of the ROC (Zou et al., 2007), and has been described as showing the likelihood that a person picked at random from a group of recidivists has been assessed as a high-risk offender, as compared to a person who does not recidivate and has been randomly chosen from a non-recidivist sample (Rice \& Harris, 2005). An AUC value of 1.0 means perfect accuracy and 0.5 equals the flip of a coin. 
In both Studies I and III, ROC analysis were applied in order to evaluate the predictive accuracy of the global risk assessments. In Study III, we also examined the predictive accuracy of the individual B-SAFER items on the global risk measures. The accuracy of predictive values drawn from linear regression analysis, in which enter- and stepwise models were estimated with the individual items as test variables and the global risk measures as outcome variables, were also analyzed in relation to repeat IPV/ violence.

\section{Logistic regression (Studies I \& III)}

Logistic regression analysis were conducted in Studies I and III. In both studies, the predictive accuracy of the global risk measures and the protective actions were analyzed with repeat IPV/violence as the outcome variable. We also evaluated whether there were any interaction effects between the global risk assessments and the interventions, in relation to repeat IPV/violence, by combining low/high risk assessment and low/high level of interventions into four dummy variables. In Study III, the intervention variable was coded as no intervention/at least one intervention. One of the measures produced in logistic regression analysis is the odds ratio (OR). The OR represents the odds that an outcome will occur when the test variable is present, as compared to the OR when the test variable not is present (Szumilas, 2010).

\section{Study IV}

The fourth study was a review of the literature regarding the predictive accuracy of IPV risk assessments produced by practitioners in different settings. Searches were conducted in five different databases and at three different publisher sites. A range of different topics thus were covered, e.g. criminology, psychology, sociology, social work, medicine and psychiatry. Inspired by the searches in the review by Nicholls, Pritchard, Reeves and Hilterman (2013), the same clusters and related terms were used. However, some terms were excluded and some other terms were added. In total, 909 unique studies were found.

The next step was the sorting procedure, which was mainly carried out by reading all the abstracts. However, when the information in the abstract was not sufficient to determine whether or not a study would be included, parts of the full text were read. A number of inclusion and exclusion criteria were used to determine if a study was eligible for inclusion. Those criteria were: 

a) Type of study: Only original articles and dissertations were included.
b) Information in the abstract: The abstract had to state that the predictive validity of IPV risk assessments was going to be evaluated.
c) Tool/s: Had not to be IPV tools specifically.
d) Assessment: IPV assessments.
e) Rater: The assessments had to be conducted by practitioners in the specif- ic setting with which they were affiliated (e.g. police employees in a police setting). Studies based on assessments conducted by other actors, e.g. re- searchers, or on victims' self-reports/perceptions (only) were excluded.
f) Outcome variable: IPV recidivism.

\section{Ethical considerations}

There are a number of ethical aspects to consider when conducting research, in particular when the data and topic under study are sensitive. The data (Studies I-III) were anonymized at the time of coding, and the files were stored in a safe. One ethical dilemma that we faced was related to the requirement to collect informed consent from the victims involved in the violence risk assessments. In our opinion, it was not justifiable to contact the victims, since this might endanger their safety and also remind them of potentially traumatic experiences, which could have a negative impact on the victims' mental health. On the other hand, we thought that the studies could provide important knowledge. We therefore argued that the benefits of the study outweighed the requirement to collect informed consent from the victims, since all analyses were to be conducted at the group level. The studies (I-III) were approved by both the Ethical Review Board in South Sweden (2012/176, 2013/72) and the police authorities from which the data were collected.

Violence risk assessments and subsequent risk management can potentially lead to decisions that have a major impact on the suspected offender and/or the victim, for instance by limiting victims' freedom of action. For this reason, Salo, Laaksonen and Santtila (2016) have argued for the importance of studying the accuracy of violence risk assessment. They state that it would be unethical not to implement the most accurate risk assessments and management possible, and that studies regarding the validity and reliability of IPV risk assessments are therefore important for ethical reasons. 


\section{MAIN RESULTS}

This part of the thesis presents the main results from the four studies. The results of the review study will be described first (Study IV), followed by the predictive validity of the PST-VC and the B-SAFER (Studies I and III). Thereafter, the inter-rater reliability findings will be presented (Study II).

\section{Predictive validity}

The predictive validity of practitioners' IPV risk assessments in different settings

Eleven studies met the inclusion criteria, and among these, ten had been conducted in criminal justice settings, while one had been conducted in a treatment setting. There was relatively little information regarding the assessors' experience and training in IPV assessment, but this seemed generally to be rather limited. Both actuarial and SPJ tools had been used in the studies. Half of the studies lacked information regarding whether or not the tools were administered as recommended. In the other half of the studies, some of the tools had been used according to the guidelines and some not. In most of the studies, predictive accuracy was examined by means of ROC analysis. The AUC values for the global risk assessments ranged between .49 and .72 . IPV preventive interventions were included in most of the studies (8), however they were not analyzed in relation to the risk assessment in all of these studies (Hendricks, Werner, Shipway, \& Turinetti, 2006; Hilton, Harris, Popham, \& Lang, 2010; Shepard, Falk, \& Elliott, 2002), which complicated the interpretation of the role of the interventions. In those studies that did analyze the interventions in relation to risk assessment and management, the results were mixed. Some of the studies suggested the interventions to have a preventive effect on repeat IPV (Belfrage \& Strand, 2012; Belfrage et al., 2012; 
Storey et al., 2014) and some did not (Svalin, Mellgren, Torstensson Levander, \& Levander, 2017; 2018).

\section{Risk and victim vulnerability factors}

The presence of risk- and victim vulnerability factors in the B-SAFER was low overall (Study III). The rate of missing cases ranged between 14 and 52\% among the historical offender risk factors and between 0.7 and $39 \%$ in the current situation. The offender's mental health problems was the risk factor with the highest rate of missing values both historically and in the current situation. Assessments of the victim vulnerability factors was lacking in 7-33\% of the cases. The victim's personal problems constituted the vulnerability factor with the highest rate of missing values. Since there are no mandatory risk- and victim vulnerability factors in the PST-VC, a similar analysis was not conducted in Study I. The summed total score of the B-SAFER risk factors in the current situation and the victim vulnerability factors ranged between 1 and 25 (median value was 9).

\section{Global risk assessment}

In both the B-SAFER and the PST-VC, a five point scale was used for the global risk assessments $(1=$ no/low risk, $5=$ high risk). The pattern of the distribution of the use of risk levels was also rather similar. The highest risk level (5) had not been used in any of the studies (Studies I and III). Risk level 2 was the most commonly used risk level in both studies, followed by risk level 3 (see Table 2). Nine percent of the B-SAFER assessments lacked a global risk assessment, meanwhile cases that lacked a global PST-VC risk assessment (three cases) were excluded from the Study (I). This is because the global risk assessment constituted the explanatory variable in the majority of the analyses in the study, as compared to Study III, in which the risk- and victim vulnerability factors were also included as explanatory variables in a number of analyses. Due to the restricted range regarding the use of risk levels in both Studies I and III, we chose to create low- and high-risk groups instead. Cases assessed to have risk levels 1 and 2 constituted the low-risk group and cases assessed to have risk levels 3 and 4 constituted the high-risk group. 
Table 2. The distribution of the use of risk levels in the PST-VC and the B-SAFER

\begin{tabular}{|l|r|r|r|}
\hline Risk level & PST-VC & B-SAFER: Likelihood & B-SAFER: Severity \\
\hline 1 & $3 \%(2)$ & $15 \%(44)$ & $8 \%(24)$ \\
\hline 2 & $54 \%(35)$ & $43 \%(130)$ & $56 \%(168)$ \\
\hline 3 & $39 \%(25)$ & $30 \%(89)$ & $27 \%(82)$ \\
\hline 4 & $5 \%(3)$ & $4 \%(12)$ & $0.3 \%(1)$ \\
\hline 5 & 0 & 0 & 0 \\
\hline Missing & 0 & $9 \%(26)$ & $9 \%(26)$ \\
\hline Total N & 65 & 301 & 301 \\
\hline
\end{tabular}

In SPJ assessments, the risk- and victim vulnerability factors are expected to predict the global risk assessment. We examined the relationship between each risk- and victim vulnerability factor in the B-SAFER and the global risk measures (Study III). Most of the factors correlated significantly with the global risk measures, although these correlations were generally rather weak. All but one of the factors (item 11; inconsistent behavior and/or attitude towards perpetrator) correlated significantly with the global risk assessment of the likelihood of repeat IPV, whereas all but five factors correlated significantly with the global risk assessment of the severity of the potential violence (risk factor 5; violent attitudes (past situation) and four of the five victim vulnerability factors; 11, 13, 14 and 15). The offender's general criminality (item 6), was most strongly correlated with the severity of repeat violence, both in the current and past situation. It was also the factor with the strongest correlation with the likelihood of repeat IPV in the current situation. Intimate relationship problems (item 7) was the factor that correlated most strongly with the likelihood of repeat IPV in the past situation.

By means of regression analyses (stepwise- and enter models) we evaluated the predictive accuracy of the B-SAFER factors (risk factors in the current/past situation together with the victim vulnerability factors (with missing values replaced)) on the global risk assessments (likelihood and severity). The shared variance raged between 0.14 and 0.26 , meaning that the majority of the shared variance was due to something other than the B-SAFER items. Of the 15 items in the B-SAFER, 4-6 were included in the stepwise regression models. 


\section{Repeat IPV}

The rate of repeat IPV was $31 \%$ in the B-SAFER sample and $48 \%$ in the PSTVC sample. Among the cases of repeat IPV in the B-SAFER sample, $60 \%$ were violent crimes (at Time 1) and in the PST-VC sample, 50\% were violent crimes.

A small number of factors seemed to play a more important role for IPV recidivism than the rest, since the mean values of these factors were higher in the cases of repeat IPV compared to the cases in the non-repeat IPV group. In the current situation, one such factor was item nine, i.e. substance abuse problems. The mean value of item nine also differed significantly in the repeat IPV violence group by comparison with the non IPV violence group (current and past situation), as did the mean values of factors 11 and 15, i.e. whether the victim had an inconsistent behavior and/or attitude against the offender and personal problems.

The predictive validity of the global risk assessments on repeat IPV varied between the PST-VC and the B-SAFER, but was overall rather weak. The likelihood of repeat IPV and IPV recidivism correlated significantly but repeat IPV severity and IPV recidivism did not. None of the global risk measures correlated significantly with repeat violence. In the PST-VC sample on the other hand, global risk and repeat IPV/violence correlated significantly. The ROC-values for the PST-VC global risk assessments were .66 and .67 and for the B-SAFER global risk assessments they ranged between .50 and .57 (see Table 3). The AUC of the ROC is a balance between the sensitivity and the specificity of a tool (Zou et al., 2007), and the ideal is to obtain both a high sensitivity and specificity for a given risk classification. Unfortunately, it was not what we found in our studies (see Table 3). The predictive accuracy of the test variables based on predictive values ranged between $.51-.57$, for both outcomes (repeat IPV and repeat violence). 
Table 3. Summary of the predictive validity of the PST-VC and the B-SAFER with repeat IPV/violence as the outcome
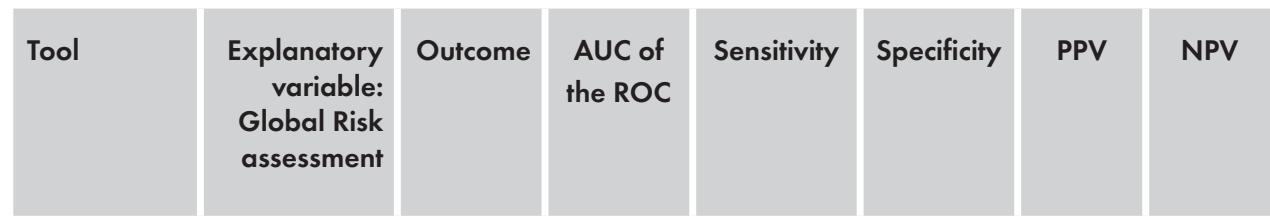

PST-VC

(Study I)

Low/high risk

Repeat
IPV

.66

.59

.73

.68

.65
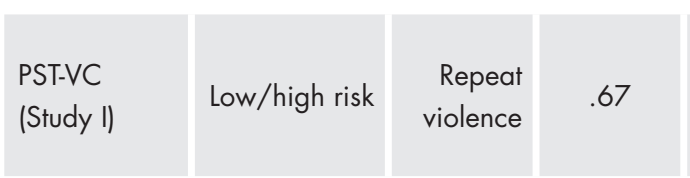

.69

.65

.39

.86

$$
\text { Likelihood }
$$

Repeat
IPV

.57

.46

.68

.39

.74

\section{B-SAFER}

(Study III)

Severity Low/
high risk

Repeat
IPV

IPV $\quad .55$

.55

.37

.27

.37

.72

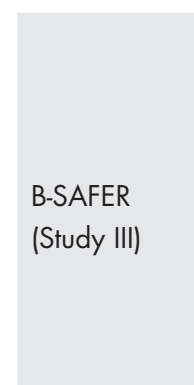

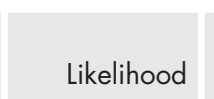

Low/high risk

Severity Low/

high risk

\section{Repeat}

violence

Repeat

violence
.54

.41

.65

.20

.83

.50
.29
.70
.17

Note: Global risk assessment for both tools was categorized as low risk (risk levels 1 and 2) and high risk (risk levels 3 and 4).

24 The only measure presented in the B-SAFER study was the AUC of ROC. The rest of the measures have thus been added for the purposes of this summary of the results. The sensitivity, specificity, PPV and NPV have also been added for the PST-VC assessments, with repeat violence as the outcome. 


\section{Crime preventive and victim protective actions}

The significance of crime preventive and victim protective actions was examined in both Study I and Study III. However, the first study examined recommended interventions, while the third study examined recommended and implemented interventions. The number of recommended interventions differed between the studies. However, since the two studies were conducted in different police authorities, with somewhat different routines and interventions, direct comparisons cannot be made. In $62 \%$ of the PST-VC cases a high level of interventions was recommended and in the B-SAFER sample at least one intervention was implemented in $23 \%$ of the cases. In Studies I and III, the risk level (low/high) and the level of interventions (low/high) correlated significantly. Further, in both studies, logistic regressions were conducted in order to examine the effect of the risk assessments and the interventions, both separately and in interaction, on repeat IPV/violence.

In the B-SAFER sample the likelihood of repeat IPV was the only global risk measure that significantly predicted the outcome (repeat IPV) $(\mathrm{OR}=1.8, p<$ $.05)$. Repeat violence was not predicted by any of the global risk measures. In the PST-VC sample, repeat IPV was significantly predicted by the global risk assessment $(\mathrm{OR}=3.5, p<.05)$. In the second step of the analysis, the recommended/implemented interventions were added. The interventions were not related significantly to the outcomes examined in either of the studies.

In order to examine whether the effect of interventions on repeat IPV/violence was different depending on the risk level of the cases examined, we conducted logistic regressions in which three dummy variables (1) low risk/high level of interventions or any interventions ${ }^{25}, 2$ ) high risk/low level of interventions or no interventions, 3) high risk/ high level of interventions or any interventions) were compared to a fourth dummy variable/reference category (low risk/low level or no interventions). In the PST-VC analyses, only the high-risk group with a high level of interventions predicted IPV recidivism significantly $(\mathrm{OR}=$ $4.6, p<.05)$. In the analyses of the B-SAFER, the high risk assessments of the likelihood of repeat IPV, both with or without implemented interventions, predicted repeat IPV significantly $(\mathrm{OR}=1.9$ and $2.3, p<.05$, respectively).

25 In analyses of the PST-VC, the interventions were categorized as a low or high level of interventions, and in the analyses of the B-SAFER the interventions were categorized as no interventions or at least one intervention. Information regarding the interventions is further described in the methodological part of the thesis. 
None of the other variables, either for the likelihood or severity global risk measure, predicted repeat IPV/violence. In the B-SAFER sample, Cox regression analyses were also conducted to examine whether there were any differences in the time to repeat IPV in the different risk/intervention groups ${ }^{26}$, but no statistical significant differences were found.

Since the B-SAFER data included information on up to three incidents of repeat IPV with related implemented interventions, we followed the distribution of interventions in relation to repeat IPV in a flowchart in order to evaluate whether there were any patterns in the distribution. The key findings produced by this method were that 1) there was a higher rate of repeat IPV among cases in which at least one intervention was implemented and 2) only a small number of cases were subjected to interventions after incidents of repeat IPV. For instance, repeat IPV (time 1) occurred in 93 cases, and in 14 of those, interventions were implemented after the recidivism had occurred.

\section{Inter-rater reliability}

The inter-rater reliability of both the PST-VC and B-SAFER assessments was evaluated in Study II. The evaluation focused on the consistency of the key aspects of the violence risk assessment tools; risk- and victim vulnerability factors, global risk assessments, and interventions.

Overall, the results of the B-SAFER and the PST-VC assessments were similar, despite the fact that the PST-VC, unlike the B-SAFER, included all kinds of violent cases and not only IPV cases. The level of consistency was highest for the global risk assessments; the correlations were $.70, .87$ and $.85(p \leq .001$ in all cases) for the PST-VC, and .72 and .69 ( $\mathrm{p} \leq .001$ in both cases) for the BSAFER. The level of consistency varied in relation to the offender risk factors. In the B-SAFER, four of the ten offender risk factors correlated to a satisfactory degree (item 2; violent threats or thoughts, 3; escalation, 6; general criminality and 9; substance use problems). Item 6 correlated to a similar degree as the B-SAFER global risk assessments. In the PST-VC, two

\footnotetext{
26 Since some cases lacked data regarding repeat IPV, global risk assessment, dates for the risk assessments/ IPV recidivism, or had incorrect dates, the Cox analysis was conducted on smaller samples than the previous logistic regression analysis.
} 
out of five items had a satisfactory level of consistency (previous violence ${ }^{27}$ and threats and/or violence). The remainder of the factors correlated only for one assessment pair or not at all.

The level of inter-rater agreement for the B-SAFER victim vulnerability factors was poor. The agreement percentage ranged between 26 and $43 \%$, and the correlations were not significant for any of the factors. The inter-rater agreement for the victim vulnerability factors in the PST-VC was somewhat better by comparison, but still not satisfactory. For instance, the raters' assessment regarding the victims' fear of the offender correlated for two out of the three assessment pairs. Finally, the level of consistency regarding the recommended protective actions was poor in the PST-VC assessments and fairly high in the B-SAFER.

Summarizing the results, the number of studies that have focused on the predictive accuracy of IPV assessments conducted by practitioners was generally small, and the predictive accuracy reported by the available studies varied from low to medium (Study IV). The most common type of practitioner found to assess IPV risk in the reviewed studies consisted of police employees. In Studies I and III, the police employees produced IPV risk assessments whose predictive accuracy was better than chance. However, the accuracy of the global risk assessments was overall low. The results could not be explained by the effect of protective actions, a conclusion that is based on the lack of a relationship between interventions and repeat IPV/violence in most of the cases. The B-SAFER study also showed that only a small number of interventions were implemented, and there was no pattern in the distribution of interventions in relation to repeat IPV. The inter-rater reliability was varying for the individual risk factors in both tools, but low for most of the factors, and relatively high for the global risk assessments (Study II).

27 Assessor 1-2 assessments regarding previous violence did not correlated significantly, but assessor 1-3 and 2-3 assessments did. 


\section{DISCUSSION AND CONCLUSIONS}

The aim of the thesis has been to contribute to improving the knowledge on police employees' IPV violence risk assessment and management, and more specifically the predictive validity and inter-rater reliability of such assessments. The overall results showed that the predictive validity and the consistency among the risk- and victim vulnerability factors included in the tools were low, with the exception of some individual factors that had a somewhat higher degree of consistency. The inter-rater reliability of the global risk assessments was fairly high. In this section, the results will be discussed further and related to previous research.

There were a large number of missing values for the individual risk factors in our studies (II and III), as in previous studies (e.g. Belfrage et al., 2012; Storey \& Strand, 2017). The proportion of missing values was largest for the past situation as compared to the current situation. The factors with the highest numbers of missing values were psychosocial factors, in line with previous studies (Belfrage, 2008; Storey \& Strand, 2013). Mental health problems was the individual risk factor with the highest rates of missing values, both in the current and past situation. The high number of missing values for psychosocial risk factors noted in a study by Belfrage (2008) was suggested to be due to a lack of information regarding offenders' mental health, and that the police officers were not used to assess such factors. Similar reasons for the many missing values for psychosocial risk factors can probably also be applied to our own studies. The assessors had limited training in how to assess violence risk, and the lack of information in this area applies to Swedish police authorities in general, since they do not have access to health records. This makes the information on victims very important. For instance, in some cases 
in which the offender has not been reported to the police prior to the specific case, the victim's information is the only information on which the assessment can be based. However, it is not unusual that IPV victims do not wish to participate in the legal process (NCCP, 2016), which may be due to the isolation of the victim from her/his family, friends, and other social contacts that constitutes part of the IPV normalization process (Lundgren, 2004). It is thus important that the police support IPV victims throughout the legal process, in order both to enable the victim to get through the process and for the police to gather as much quality information as possible. The police authority in which the B-SAFER assessments were conducted (Studies $\mathrm{II}^{28}$ and III), had decided not to talk to victims before conducting the assessments, in order not to be biased. However, based on the importance of the victim's information, this type of decision is problematic. In addition, previous studies have shown that violence risk assessments conducted by IPV victims themselves can contribute to more accurate assessments (e.g. Heckert \& Gondolf, 2004).

The risk factor that was least often present in the B-SAFER cases (Study III) was item 4; violations of court orders, both in the current and past situation. The proportions of cases where this information was present were $3 \%$ and $4.7 \%$ respectively. In Study II, item 4 was coded as yes/partly present in none of the cases. This risk factor has also been identified as the factor most often assessed as "not present" in a number of previous studies (Belfrage et al., 2012; Storey \& Strand, 2012; Storey et al., 2014). This result is not surprising since only a limited number of cases are granted ROs. There were no similar patterns regarding missing or present values for the victim vulnerability factors in relation to previous studies.

Only a few of the B-SAFER factors were significantly related to the global risk assessment in Study III. Similar results have been found in previous studies (Peterson et al., 2016; Robinson et al., 2016; Trujillo \& Ross, 2008). The majority of the global risk assessments were thus based on something other than the factors included in the tool. These results are in line with the results of Study II, which showed that the police employees' assessments of the tools'

28 The new PST-VC assessments in Study II were not based on information from victims either. However, this decision was related to the design of the evaluation study. Since old cases were used in the pairwise assessments, it was not possible to contact the victims. 
individual items differed for the same cases. At the same time, their global risk assessments were rather consistent. Our conclusion was that the assessors' global risk assessments are based on their tacit knowledge rather than the individual assessment factors. Since the global risk assessments were rather consistent, this tacit knowledge is, at least to some extent, shared by the assessors. Our discussion regarding the assessors' tacit knowledge was related to Tversky and Kahneman's (1974) work on heuristics and biases in assessments. They describe a number of different heuristics. One of these that may be applicable to the police's IPV risk assessments is labeled "insensitivity to prior probability of outcomes". This relates to the use of previous experiences in making assessments, without considering the base-rate of the outcome in the assessment.

The PST-VC global risk assessments were significantly correlated with repeat IPV/violence. The same applied to the relationship between the global risk assessment of the likelihood of repeat IPV and IPV recidivism in the B-SAFER sample. The global risk assessment of IPV severity, on the other hand was not correlated with the outcome measure in this way. The predictive accuracy of the global risk assessments/total scores of the assessments, measured as AUCvalues were generally fairly similar between this study (Studies I and III, AUC= $.50-.67)$ and previous studies conducted in police settings (AUC $=.52-.72$ ) (Belfrage et al., 2012; Lauria et al., 2017; Storey et al., 2014). This also applies to similar studies conducted in other settings, as noted in Study IV (e.g. Hilton et al., 2010; Williams \& Houghton, 2004, Rettenberger \& Eher, 2013). The AUCs in these studies ranged between .50 and .71. However, there are studies of SPJ tools in which the predictive accuracy are higher. E.g. Strand, Belfrage, Fransson and Levander (1999) presented an AUC of .80 in a study of HCR-20 assessments conducted in a sample of 40 mentally disordered patients. Thus, under the right conditions (i.e. trained assessors, access to the required information and a recidivism rate of approximately $50 \%$, which is optimal in ROC analysis) it is possible to produce highly accurate violence risk assessments.

There are however problems associated with comparisons between AUCs from different studies, since key variables (IPV and outcome measures) often are defined in different ways and the follow-up time usually varies (Nicholls et al., 2013). In addition, since most IPV assessments conducted by practitioners are 
intended to prevent future violence, protective measures are implemented subsequent to the risk assessment in order to reduce the risk. Previous studies have argued for the importance of considering these protective measures in the evaluation of the predictive accuracy of violence risk assessments in police settings (Belfrage \& Strand, 2012; Belfrage et al., 2012; Storey et al., 2014).

The role of the protective measures was analyzed both in Study I and Study III. In the first study, the data related to interventions recommended by the assessors, whereas the information in the third study related to interventions implemented by the police authority and interventions that the victims had told the police about (implemented by some other actor or the victims themselves). The PST-VC global risk assessment was significantly related to the level of recommended protective actions. Similar relationships were found between the B-SAFER global risk assessments and the implemented protective actions. The interventions were not significantly related to repeat IPV/violence in either of the studies. However, when the assessed levels of risk and the recommended/implemented protective actions were divided into low/high-risk cases/levels, some significant relationships were found. The high-risk group with a high level of recommended protective actions predicted repeat IPV (Study I), and the high-risk groups (likelihood for repeat IPV), with- and without implemented protective actions predicted repeat IPV (Study III). Our overall conclusion from Studies I and III was that the relatively low predictive validity found in both studies was due to the fact that a large number of cases were misclassified in the assessment. This conclusion is based on the ineffectiveness of the recommended/implemented protective actions in preventing repeat IPV that was identified in our analysis. However, this does not mean the protective measures are ineffective in all cases. In addition, certain combinations can potentially be effective in specific cases. It should also be noted that the number of implemented protective measures in Study III was very small.

The results regarding the effectiveness of preventive interventions were somewhat different in previous studies. Belfrage et al. (2012) found, for example, that the recommended interventions mediated the relationship between the risk assessment and the outcome (repeat IPV). Storey et al. (2014) did not find a similar effect of the recommended interventions, but they did find an interaction effect between the B-SAFER global risk assessment and the 
number of management strategies in relation to IPV recidivism. The role of the implemented protective measures in Belfrage and Strand (2012) is a little difficult to interpret, since there was no relationship between the risk assessment and repeat IPV. The authors suggested that this was primarily due to that fact that effective interventions had prevented repeat IPV in high-risk cases. This suggestion was based on a comparison of the rates of recidivism in the different risk groups (among recidivism cases only), which showed that the rate of repeat IPV was lowest in the high-risk group (for severe violence).

It is difficult to make comparisons with previous studies because of the methodological differences that were noted above. One example of such differences between the studies included in the thesis and previous studies relates to the operationalization of the interventions. In some studies, the interventions were divided into a low- and a high-level group, based on the type of intervention (Study I, Belfrage \& Strand, 2012). Another operationalization was based on the number of recommended interventions (see Belfrage et al., 2012; Storey et al., 2014). In Study III, the number of implemented interventions was very small, and cases with at least one implemented intervention had to be compared with cases without no implemented interventions. None of these studies actually operationalized the interventions in the same way. Overall, the studies that have been conducted on IPV violence risk assessment and management in police settings do not agree with regard to the effectiveness of this work. 


\section{IMPLICATIONS AND FUTURE DIRECTIONS}

This part of the thesis will discuss the findings from the studies that require further attention. It will also provide a number of recommendations with regard to future studies and the work of the Swedish Police Authority.

\section{The initial screening procedure}

All IPV cases reported to the Swedish police are evaluated in an initial screening procedure in order to identify cases that need to be examined further by means of a structured violence risk assessment. This procedure is essential since not all cases reported to the police need to be subjected to a structured assessment. However, the initial screening procedure was not evaluated in the studies in the thesis, and nor has it been evaluated in previous studies. Since this procedure is mainly based on the assessment of the individual who registers the police report, it is unknown which cases are not forwarded for a structured risk assessment (Svalin et al., 2014). What is known, however, is that few cases are forwarded to the next step (structured assessment) and that few of these are assessed to be high-risk cases. Thus, the unstructured process, the low number of selected cases and the low number of high-risk cases that are identified among those that are selected for structured assessment together indicate that high-risk cases are being missed in the initial selection procedure. On the other hand, the high recidivism rates (Studies I and III) could be interpreted as an indication that "the right" cases have been identified.

An evaluation of the initial screening procedure should ideally include a review of all IPV cases reported to the police (e.g. in a representative sample) and related risk factors (e.g. information from police registers). Based on this, the police have to decide which cases should be forwarded to a structured 
violence risk assessment. Both economic conditions (how much money is there to spend on structured violence risk assessments, and how much is the average cost of one case?) and ethical considerations (which cases cannot be left without further action from the police?) are important in this determination. It is recommended that a revised procedure should first be tested in a pilot study prior to being implemented on a larger scale.

\section{The structured violence risk assessment}

Violence risk assessment tools are used in order to guide the process of identifying cases in which repeat IPV is going to occur and cases in which repeat IPV is not going to occur. The ideal would be that we, by using the tool, could accomplish both, i.e. obtaining both high sensitivity and specificity. Unfortunately, it was not what we found in our studies. In such cases, policy makers have to decide what is most important in their specific context and based on their resources: Is it most important not to miss intervening in cases of repeat IPV (focus on sensitivity)? If this is the decision that is made, interventions have to be targeted broadly, which will lead to the implementation of interventions in many false positive cases. The other option is to focus on those who are not going to relapse, i.e. deciding that it is most important not to intervene in cases in which repeat IPV will not occur. Given this strategy, cases in which repeat IPV will occur are likely to be missed. A table similar to Table $2^{29}$ in Study I, which presents the sensitivity and the specificity for all possible cut-off scores, may be helpful when making this kind of determination.

If the balance between the sensitivity and the specificity for all cut-off scores is not satisfying, as was the case with the results for the PST-VC for example (see Study I, Table 2), changes and/or interventions must be implemented in relation to the assessment. Focusing on this specific study, the assessors need more training in how to conduct violence risk assessments. Training could potentially reduce the number of missing factors and thereby lead to more accurate assessments.

29 Observe that the NPVs in Table 2, Study I, are incorrect. The right values are: 1.0, .65 and .50. 


\section{The risk assessor and training in IPV risk assessment}

In our studies, the risk assessors' level of training in how to assess IPV risk was generally low. It is thus not surprising that some factors were difficult to assess or that the global risk assessments were based on tacit knowledge. Assessors needs additional training in how to assess IPV risk, particularly with regard to mental health risk factors. Further, Nesset at al. (2017) showed that escalation of violence in IPV cases, which is a risk factor for fatal violence, was associated with a lower likelihood of the offender being arrested by the police or the victim being relocated as an immediate protective measure. Thus, IPV assessment training should include information on the characteristics of IPV, but also on different types of IPV offenders and on the use of interventions to prevent future IPV (in addition to information regarding the specific tool, risk- and victim vulnerability factors etc.).

Although an evaluation of SPJ violence risk assessment training among employees in criminal justice settings has shown promising results (Storey, Gibas, Reeves, \& Hart, 2011), one could discuss whether the police authority should employ risk assessors with other professional backgrounds than police employees. Aas (2014) discusses a similar question, more specifically whether work related to IPV in the Norwegian police should be a specialty. A recent study describes an ongoing project focused on a new assessment procedure which includes a collaboration between police officers, researchers and forensic mental health professionals (McEwan, Bateson, \& Strand, 2017). The project is being conducted in Victoria, Australia and aims to evaluate whether a changed risk assessment and management procedure would improve the risk assessment and management of cases of family violence. A forensic psychologist supervised and taught the police to conduct violence risk assessments. The project so far seems promising, and it may be something that can inspire the Swedish police. For instance, a collaboration with psychologists would potentially contribute to resolving the problem of the high rates of missing values for psychiatric risk factors.

In addition to the police, there are other actors who deal with IPV cases and conduct IPV risk assessments, e.g. the social services, prosecutors and the health care sector. These different actors cooperate with each other since they have responsibility for different parts of the IPV preventive work. For example, the social services are responsible for protective housing, the 
prosecutors for ROs, and the police for safety alarms. However, an increased level of cooperation would probably be of benefit to all actors. For example, different actors use different tools. If they were instead to choose the same tool, they could coordinate their training and thereby learn from each other's experiences. There are confidentiality regulations that prohibit the sharing of certain information between different actors in specific cases. However, a united approach to risk assessment and management work would probably be beneficial to all the actors involved.

Finally, it has been suggested that a "predictive glass roof" has been reached (Sturup, Forsman, Haggård, Karlberg, \& Johansson, 2013), and that a shift in focus is needed from those who are assessed to those who conduct the assessments in order to obtain more accurate assessments. As has been shown above, many of the questions that require further attention relate to the assessors.

\section{The implementation of interventions to prevent repeat IPV}

The main results regarding the interventions have already been discussed; however, there are some organizational processes (e.g. the implementation of violence risk assessment tools in police settings) that may complicate the implementation of interventions to prevent repeat IPV, which will be discussed below.

1) The use of risk assessment tools by the Swedish police was implemented as a way of identifying and intervening in high-risk cases, and most of the intervention strategies already existed. Thus, two different processes were more or less merged together. While the risk assessment mainly focuses on the offender, the actions are primarily aimed at protecting victims (e.g. victim identity protection, alarm, victim shelter, safety inspection of victim's home and security and/or victim support talk with a police employee). This is probably related to the fact that the interventions are implemented when the offender is no more than a suspect (i.e. has not been prosecuted). Regardless of this, it may nonetheless complicate the recommendation of interventions based on the risk assessment. 
2) Most of the interventions used to prevent repeat IPV in Swedish police settings have not been evaluated in this context. Thus the effectiveness of the interventions is unknown, which complicates the implementation of interventions (see Mellgren et al., 2014b). In addition, different protective measures are suggested to be appropriate for different types of offenders (e.g. Petersson \& Strand, 2017; Strand, 2012). For instance, Strand (2012) found that ROs often are granted in high-risk cases, but are more effective in lowand medium-risk cases. The unawareness of the effectiveness of interventions may not only lead to repeat victimization among victims that we assume we are protecting, but also to money being wasted.

3) To my knowledge, the SPJ approach to violence risk assessment is not developed on the basis of criminological theories of crime. The SPJ tools are rather based on factors that can predict repeat offending. However, predictors need not be related to the causes of crime (Wikström \& Treiber, 2017), nor be of clinical importance (Dahlin, Hellner, Gumpert, Torstensson Levander, Svensson, \& Radovic, 2009). Without knowledge of the causes of crime, it is difficult to prevent crime (Wikström \& Treiber, 2017).

This will be further illustrated on the basis of Situational Action Theory (SAT, see Wikström, 2006), which is a general theory of crime. According to SAT, criminal behavior occurs in the interaction between the individual and the situation (which includes potential triggers, different types of control and moral settings), which means the individual's actions will vary depending on the situation. In situations in which the individual perceives criminal behavior as an option, individual attributes such as morality and self-control will be relevant to whether or not he/she will commit a crime. Thus the interaction between the individual's crime propensity and the situation is the core of the theory. The potential use of SAT, and other action theories (e.g. Routine Activity Theory), as a basis for the formulation of violence risk in SPJ assessments has recently been discussed (see Hart \& Guy, 2016).

To further improve the violence risk assessments regarding the processes that motivate an offender to commit a crime, a greater emphasis might be put on situational aspects. For instance, in the latest version of the SARA guide (version 3, Kropp \& Hart, 2015), the scenario-planning part related to the global risk assessment has been developed. More specifically, the assessor is 
asked to formulate a number of potential risk scenarios regarding the actual case at hand as a basis for the risk assessment. For instance, a scenario similar to prior IPV incidents, a worst-case, and a best-case scenario (ibid.). The assessor is required to evaluate each case scenario with respect to the likelihood, severity, frequency, type and time perspective of repeat IPV.

The use of scenarios in the risk assessment and management procedure is nothing new. According to Hart and Guy (2016), most of the SPJ tools published after 2003 include the use of scenarios in one way or another. For example, the B-SAFER assessor is required to assess the risk of future IPV based on different potential scenarios. However, this part of the assessment is not as well-developed as in the SARA-V3. Looking at the police employees' assessments examined in this thesis, a majority of the assessments lacked any reasoning about situational aspects in relation to global risk. However, this does not mean that the decision regarding the global risk not was based on such reasoning. Ascribing more weight to situational factors in global risk assessments would perhaps facilitate both the global risk assessment and subsequent risk management in police settings.

Shifting the focus to the risk management process, still viewed from a SAT perspective, Wikström and Trieber (2017) suggest that interventions to prevent crime have to change at least one of the following three aspects of the "perception-choice process": 1) The crime propensity of a person, e.g. a person's morality and self-control in relation to crime. 2) Aspects in the setting that influence a person to commit crime, e.g. context-dependent morality or triggers/motivators. 3) A person's contact with criminogenic environments, e.g. by inducing individuals to spend time in other environments (p. 79).

Among the interventions implemented by the Swedish justice system, the majority do not attempt to change the propensity of the offender (but are instead focused on the victim, as previously noted). However, for some offenders, a security talk with a police employee, for instance regarding the potential consequences of repeat IPV, may have a deterrent effect. Most of the interventions are focused on making it difficult for the suspected offender to commit repeat offences by relocating the victim and/or making her/him stay away from the offender as much as possible, e.g. by changing routine activities. ROs, on the other hand, aim to get the offender to stay away from 
the victim by means of a threat of further punishment if the $\mathrm{RO}$ is violated. Thus the interventions are primarily related to those parts of the perceptionchoice process that are related to the setting and are often temporary. One speculation is that for many IPV offenders whom the police aim to identify by means of IPV risk assessments, these interventions are not sufficient to prevent them from relapsing. This hypothesis is based on the results of this thesis.

In sum, IPV interventions need to be evaluated, which has also been suggested in other studies (e.g. NCCP, 2017). Different interventions have been suggested to have varying effects in relation to different types of offenders, which needs to be evaluated further. A recent study examined the time to recidivism for antisocial- and family-only offenders, respectively (Petersson \& Strand, 2017). A majority of the offenders (of both types) recidivated during the first year following the index crime. However, the antisocial offenders continued to recidivate to a larger extent than the family-only offenders, even after the first year. This finding raises the need to examine the length of effectiveness of different kinds of interventions. Another related question is whether certain combinations of interventions are more successful than others. Victims should be asked about their experiences of the effectiveness of various interventions in relation to aspects of recidivism and safety. Another important aspect that should be evaluated further involves victims' own strategies to protect themselves from repeat victimization.

\section{Recommendations for the Swedish Police Authority}

IPV is a major problem with serious consequences, both for the individual and society. Since repeat IPV is common, and often occurs close in time to prior offences, the police can potentially prevent repeat IPV. However, the results of this thesis and the overall knowledge on IPV risk assessments in police settings indicate that some work remains to be done to achieve this goal. Overall, IPV needs to be prioritized by the police, and practical changes have to be implemented:

\section{Evaluations of the initial screening procedure and the effect of the rec-} ommended protective actions

The screening procedure, which is applied throughout the country, is mainly based on the tacit knowledge of the individual who receives the initial police report. Thus there is no systematic procedure to determine which cases are 
forwarded for a structured assessment, and it is therefore unknown which cases are assessed using a structured assessment tool. The initial screening procedure needs to be studied and a systematic way of screening IPV cases needs to be established. Thus the police needs to decide which cases are going to be assessed by means of structured violence risk assessments. Ethical aspects and economic conditions must be considered, and should serve to guide these decisions.

Since the effects of the recommended protective measures that are used by the police and related actors are largely unknown, these need to be evaluated. Questions that need to be evaluated are: For what types of cases do the different interventions (and combinations of different interventions) work? For how long is a certain protective action effective? How do victims of IPV experience the interventions, e.g. how effective do they perceive specific protective actions to be? What kind of strategies do victims use themselves and to what extent? Finally, there is a rather limited number of offender-oriented protective measures. The possibilities of increasing the number of offenderoriented protective actions might be reviewed, for instance by studying measures used in other countries (NCCP, 2017).

\section{Future work with IPV assessment}

The police need to decide on the future of the work with structured IPV risk assessments. Overall, the assessors need training in how to assess violence risk, and particularly in how to assess the mental health factors. However, before starting such training, there are some questions to consider:

Who is going to conduct the assessments? Could persons with another educational background, e.g. psychiatric, contribute in a consultative capacity or be hired by the police? Is it possible to co-operate with other social actors? Which protective actions are going to be implemented, and in which cases?

Finally, strategies regarding the implementation of the procedure that is decided upon can be formulated, including strategies to provide training in how to assess and manage IPV risk, and how to solve the problems regarding the fact that police employees do not have access to all the information needed to make an informed violence risk assessment. 


\section{POPULÄRVETENSKAPLIG SAMMANFATTNING}

Partnervåld är ett globalt samhällsproblem med omfattande konsekvenser. Polisen är en av de samhälleliga aktörer som arbetar för att förhindra återfall $\mathrm{i}$ partnervåld. För att identifiera de ärenden med högst risk för att brottsoffret ska utsättas för upprepat våld och för att välja ut lämpliga åtgärder för att förhindra upprepat våld i dessa ärenden, genomför polisen riskbedömningar. Dessa bedömningar görs med hjälp av verktyg som innehåller riskfaktorer som är kopplade till gärningspersonen och såbarhetsfaktorer som är kopplade till brottsoffret. Exempel på riskfaktorer är om gärningspersonen tidigare har begått våldsbrott och huruvida hens våldsamma eller hotfulla beteende har trappats upp över tid. Exempel på sårbarhetsfaktorer är om brottsoffret har en extrem rädsla för gärningspersonen, som kan göra att hen handlar på ett sätt som leder till ökad risk för att utsättas för upprepat våld.

Polisens riskbedömningar för upprepat partnervåld är utvärderade i ett begränsat antal studier, med delvis varierande resultat. Det är därför inte klarlagt hur väl de fungerar för att identifiera högriskfall och för att förhindra att upprepat våld sker. I föreliggande avhandling utvärderas två olika riskbedömningsverktyg: The Police Screening Tool for Violent Crimes (PSTVC) och The Brief Spousal Assault Form for the Evaluation of Risk (BSAFER). Riskbedömningarna var genomförda av polisanställda i två olika polisområden i Sverige. Det övergripande syftet med avhandlingen var att bidra till mer kunskap gällande riskbedömning och riskhantering i polisverksamhet och särskilt rörande prediktiv validitet och interbedömarreliabilitet i sådana bedömningar. Det vill säga, träffsäkerheten i bedömningarna i relation till upprepad utsatthet och samstämmigheten i olika 
bedömares bedömningar, av samma ärenden. Olika delar av syftet studerades $\mathrm{i}$ olika delstudier. Totalt sett består avhandlingen av fyra delstudier.

Det övergripande resultatet visar att träffsäkerheten i de polisanställdas riskbedömningar var låg. Det var få ärenden som bedömdes som hög risk och återfallen var många bland lågriskärendena. Dessutom saknades det bedömningar av risk- och sårbarhetsfaktorer i många ärenden, detta gällde särskilt faktorer kopplade till psykisk ohälsa. Det kan förmodligen förklaras med att polisen inte har tillgång till information om psykisk ohälsa via andra kanaler än den information de får från gärningspersoner, brottsoffer eller anhöriga. I tillägg till det saknar poliser i stor utsträckning utbildning och träning i hur den typen av faktorer ska bedömas. De åtgärder som följde på polisens bedömningar tycktes inte heller kunna förklara den låga träffsäkerheten. Detta behöver dock undersökas närmare, eftersom det i stor utsträckning saknas studier av effekten av dessa åtgärder för att förhindra upprepat partnervåld för olika typer av gärningspersoner.

I den ena delstudien undersöktes även hur betydelsefulla de enskilda faktorerna i verktyget (B-SAFER) var för den globala riskbedömningen (dvs. den övergripande bedömningen i ärendet), vilket visades var få. Bedömarna byggde alltså sin bedömning $\mathrm{i}$ stor utsträckning på någonting annat än faktorerna $i$ verktyget. Liknande resultat framkom i studien av samstämmigheten i olika bedömares bedömningar av samma ärenden. För båda verktygen var samstämmigheten för de flesta enskilda faktorerna låg. Samstämmigheten var däremot relativt hög för de globala bedömningarna. Bedömarna kom alltså fram till samma slutsats, trots varierande innehåll i deras bedömningar. Förslagsvis baserade bedömarna sina slutsatser i bedömningarna på deras magkänsla, vilken tycks vara relativt lika, med tanke på likheten i de globala bedömningarna.

I den sista delstudien, som är en litteraturöversikt, undersöktes inte bara träffsäkerheten i polisers riskbedömningar för upprepat partnervåld, utan även i andra praktikers partnervåldsbedömningar. Det visades att antalet studier på området är få och att de flesta av de studier som genomförts är studier i rättsväsendet (dvs. med poliser. kriminalvålds- och frivårdsinspektörer som bedömare). Träffsäkerheten i de olika studierna varierade i viss utsträckning, men övergripande var den relativt låg. Eftersom så få studier ingick i 
litteraturöversikten gick det inte att jämföra träffsäkerheten mellan olika praktikerkontexter. I de flesta studier diskuterades/analyserades betydelsen av åtgärder för upprepad utsatthet, men av olika anledningar, exempelvis att resultaten varierade och att antalet studier var få, gick det inte att dra någon övergripande slutsats om effektiviteten av åtgärderna.

Sammanfattningsvis visade avhandlingen att träffsäkerheten $\mathrm{i}$ polisens partnervåldsbedömningar och samstämmigheten för de flesta individuella faktorer var låg. För de globala bedömningarna var samstämmigheten emellertid högre. Det behövs ytterligare studier på området, särskilt gällande effektiviteten av de olika åtgärder som polisen tillämpar för att förhindra upprepat våld. Slutligen, det var tydligt att bedömarna är i behov av mer utbildning och träning i riskbedömning, vilket är en av de rekommendationer som följer, till polisen. Dock bör sådana insatser planeras efter det att hela den process (från anmälningsmottagning till uppföljning av implementerade åtgärder) som riskbedömning för upprepat partnervåld innebär, setts över. 


\section{ACKNOWLEDGEMENTS}

The work on this thesis has been a long process and many people have contributed in different ways. I would like to express my gratitude to the Faculty of Health and Society, where this thesis was written. I also wish to express my special thanks to a number of specific individuals.

First of all, I would like to express my sincerest gratitude to my supervisor Professor Marie Torstensson Levander. Thank-you for giving me the opportunity to study as a doctoral student in criminology, and for your untiring support, your incisive comments and for being a source of inspiration throughout this process. To my co-supervisor Professor Sten Levander thank-you for your invaluable help throughout these years in guiding me in this area of research. For this, I am truly grateful.

To my co-author and friend Caroline Mellgren. Thank you for your support, valuable comments and your friendship. I have learned so much from working with you! Many thanks to Eva-Lotta Nilsson. It is a privilege to have you as a colleague and friend! Thank you for all our discussions, on both work and life, for your comments on my work, for your support and not least, your friendship. To my colleague and friend Anna-Karin Ivert. Thank you for reading and commenting on my work at the final seminar. Your comments were truly helpful. I would also like to thank you for all your help and support throughout these years and for your friendship.

I would like to thank present and former PhD students, Frida Andersson, Mika Andersson, Nina Axnäs, Alberto Chrysoulakis, Alexander Engström, Manne Gerell, Karl Kronkvist, Mia-Maria Magnusson, Simon Wallengren, 
Zoran Vasiljevic and my roommate Susanne Egnell. Thank you all for inspiring discussions, comments on manuscripts and for enriching these years. A special thank-you to Zoran for helping me with my questions on statistical analysis. I would also like to thank all my other colleagues at the Department of Criminology.

Many thanks to all persons at the police department who have contributed to this work in one way or the other, with special thanks to Susanne Gosenius, Bo Wickström and Ulf Haquinius.

David Shannon, thank-you for revising my English and for your comments on my work. Björn Hofvander, of Lund University, and Ola Kronkvist, of Linnaeus University, thank you for your very valuable comments and discussions at the mid-time seminar.

I would also like to thank my friends and family. My dear sisters and best friends, Johanna, Stina and Linn, and their families. I am so lucky to have you in my life! Mum and Dad, thank-you for always being there for me and for your endless support. I would also like to thank you Dad, for introducing me to the field of criminology. Els-Marie, Ulf and Stina - thank-you for your friendship, support and for all your help with baby-sitting. It has been very helpful in completing this work. My dear husband Erik, thank-you for believing in me, for your endless love and support, and for making me see things from new perspectives. Our lovely children Gustav and Maja, you are truly inspiring and you teach me new things every day!

This thesis was financially supported by the Faculty of Health and Society, Malmö University and the Swedish National Police Authority. 


\section{REFERENCES}

Aas, G. (2014). Familievold som et spesialfagfelt i politiet? [Should the police classify domestic violence as a special field of expertise?]. Nordisk Politiforskning, 1(1), 58-82.

Almvik, R., Woods, P., \& Rasmussen, K. (2000). The Brøset violence checklist. Sensitivity, specificity, and interrater reliability. Journal of Interpersonal Violence, 15(12), 12841296.

Anderson, K. M., Renner, L. M., \& Bloom, T. S. (2014). Rural women's strategic responses to intimate partner violence. Health Care for Women International, 35, 423-441. doi: 10.1080/07399332.2013.815757

Andrade, J. T., O’Neill, K., \& Diener, R. B. (2009). Violence risk assessment and management: A historical overview and clinical application. In J. Andrade (Ed.), Handbook of violence risk assessment and treatment. New approaches for mental health professionals (pp. 3-39). New York: Springer publishing company.

Andrews, D. A., \& Bonta, J. (2010). The psychology of criminal conduct (5th ed.). New Province, NJ: Anderson Publishing.

Andrews, D., Bonta, J., \& Wormith, J. (2004). Manual for the Level of Service/Case Management Inventory (LS/CMI). Toronto, Ontario, Canada: Multi-Health Systems.

Belfrage, H. (2005). PATRIARCH. Checklist for the assessment of risk for patriarchal violence with honour as motive. User manual. Sundsvall Forensic Psychiatric Hospital. Available: http://bit.ly/2moCZcv

Belfrage, H. (2008). Police-based structured spousal violence risk assessment: The process of developing a police version of the SARA. In A. C. Baldry, \& F. W. Winkel (Eds.), Intimate partner violence prevention and intervention. The risk assessment and management approach (pp. 33-44). New York: Nova Science Publishers.

Belfrage, H., \& Strand, S. (2008). Structured spousal violence risk assessment: Combining risk factors and victim vulnerability factors. International Journal of Forensic Mental Health, 7(1), 39-46. doi: 10.1080/14999013.2008.9914402 
Belfrage, H., \& Strand, S. (2012). Measuring the outcome of structured spousal violence risk assessments using the B-SAFER: Risk in relation to recidivism and intervention. Behavioral Sciences \& the Law, 30(4), 420-430. doi: 10.1002/bsl.2019

Belfrage, H., Strand, S., Storey, J. E., Gibas, A. L., Kropp, P. R., \& Hart, S. D. (2012). Assessment and management of risk for intimate partner violence using the spousal assault risk assessment guide. Law and Human Behaviour, 36(1), 60-67. doi: 10.1007/s10979-011-9278-0

Boyle, D. J., O’Leary, K. D., Rosenbaum, A., \& Hassett-Walker, C. (2008). Differentiating between generally and partner-only violent subgroups: Lifetime antisocial behavior, family of origin violence, and impulsivity. Journal of Family Violence, 23(1), 47-55.

Brantingham, P. J., \& Faust, F. L. (1976). A conceptual model of crime prevention. Crime and Delinquency, 22(3), 284-296. doi: 10.1177/001112877602200302

Cocozza, J. J., \& Steadman, H. J. (1978). Prediction in psychiatry: An example of misplaced confidence in experts. Social Problems, 25(3), 265-276. doi: 10.2307/800064

Dahlin, M. K., Hellner Gumpert, C, Torstensson Levander, M., Svensson, L., \& Radovic, S. (2009). International Journal of Law and Psychiatry, 32, 377-382.

Dayan, K., Fox, S., \& Morag, M. (2013). Validation of spouse violence risk assessment inventory. Journal of Family Violence, 28(8), 811-821. doi: 10.1007/s10896-013-9547-4

Douglas, K. S., Hart, S. D., Webster, C. D., \& Belfrage, H. (2013). HCR-20: Assessing Risk for Violence, third edition. Vancouver, Canada: Mental Health, Law and Policy Institute, Simon Fraser University.

Douglas, K. S., \& Kropp, R. P. (2002). A prevention-based paradigm for violence risk assessment. Clinical and Research Applications. Criminal Justice and Behavior, 29(5), 617-658. doi: 10.1177/009385402236735

Ennis, B. J., \& Litwack, T. R. (1974). Psychiatry and the presumption of expertise: Flipping coins in the courtroom. California Law Review, 62(3), 693-752. doi: 10.15779/Z38XX8W

Fuller, J., \& Cowan, J. (1999). Risk assessment in a multi-disciplinary forensic setting: Clinical judgment revisited. Journal of Forensic Psychiatry, 10(2), 276-289. doi 10.1080/09585189908403681

Garcia-Moreno, C., Pallitto, C., Devries, K., Stockl, H., Watts, C., Abrahams, N., \& Petzold, M. (2013). Global and regional estimates of violence against women: Prevalence and health effects of intimate partner violence and non-partner sexual violence. Geneva, Switzerland: World Health Organization.

Goodman, L., Dutton, M. A., Weinfurt, K., \& Cook, S. (2003). The intimate partner violence strategies index. Development and application. Violence Against Women, 9(2), 163-186. doi: 10.1177/1077801202239004

Grove, W. M., \& Meehl, P. E. (1996). Comparative efficiency of informal (subjective, impressionistic) and formal (mechanical, algorithmic) prediction procedures: The clinical-statistical controversy. Psychology, Public Policy, and Law, 2, 293-323. 
Harris G.T., Rice M.E.,\& Quincey V.L. (1993). Violent recidivism of mentally disordered offenders. The development of a statistical prediction instrument. Criminal Justice and Behavior, 20(4), 315-335.

Hart, S. D. (1998). The role of psychopathy in assessing risk for violence: Conceptual and methodological issues. Legal and Criminological Psychology, 3(1), 121-137. doi: 10.1111/j.2044-8333.1998.tb00354.x

Hart, S. D. (2008). Preventing violence: the role of risk assessment and management. In A. C. Baldry, \& F. W. Winkel (Eds.), Intimate partner violence prevention and intervention. The risk assessment and management approach (pp. 7-18). New York: Nova Science Publishers.

Hart, S., Cox, D., \& Hare, R. (1995). Manual for the Psychopathy checklist: Screening version (PCL:SV). Toronto, Ontario, Canada: MultiHealth Systems.

Hart, S., Douglas, K. S., \& Guy, L. S. (2016). The structured professional judgment approach to violence risk assessment: Origins, nature, and advances. In L. Craig, \& $\mathrm{M}$. Rettenberger (Eds.), The Wiley handbook on the theories, assessment, treatment of sexual offending: Volume II. Assessment. (pp. 1-37). New York: Wiley. doi: 10.1002/9781118574003.wattso030

Hart, S., \& Logan, C. (2011). Formulation of Violence Risk Using Evidence-Based Assessments: The Structured Professional Judgment Approach. In P. Sturmey, \& M. McMurran, (Eds.). Forensic case formulation (pp. 1-42). Chichester, United Kingdom: Wiley-Blackwell.

Heckert, A. D., \& Gondolf, E. W. (2004). Battered women's perceptions of risk versus risk factors and instruments in predicting repeat reassault. Journal of Interpersonal Violence, 19(7), 778-800. doi: 10.1177/0886260504265619

Heilbrun, K., Yasuhara, K., \& Shah, S. (2010). Violence risk assessment tools. Overview and critical analysis. In R. K. Otto, \& K. S. Douglas (Eds.), Handbook of violence risk assessment (pp. 1-17). New York: Routledge.

Heise, L., \& Garcia-Moreno, C. (2002). Violence by intimate partners. In E. G. Krug, L. L. Dahlberg, J. A. Mercy, A. B. Zwi, \& R. Lozano (Eds.), World report on violence and health (pp. 87-121). Geneva: World Health Organization.

Hendricks, B., Werner, T., Shipway, L., \& Turinetti, G. J. (2006). Recidivism among spousal abusers. Predictions and program evaluation. Journal of Interpersonal Violence, 21(6), 703-716. doi: 10.1177/0886260506287310

Hilton, N. Z., Harris, G. T., Popham, S., \& Lang, C. (2010). Risk assessment among incarcerated male domestic violence offenders. Criminal Justice and Behavior, 37(8), 815-832. doi: 10.1177/0093854810368937

Hilton, N. Z., Harris, G. T., Rice, M. E., Lang, C., Cormier, C. A., \& Lines, K. J. (2004). A brief actuarial assessment for the prediction of wife assault recidivism: The Ontario Domestic Assault Risk Assessment. Psychological Assessment, 16(3), 267-275. doi:10.1037/1040-3590.16.3.267 
Holtzworth-Munroe, A., \& Stuart, G. L. (1994). Typologies of male batterers: Three subtypes and the differences among them. Psychological Bulletin, 116(3), 476-497.

Irving, L., \& Liu, B. C. (2016). Beaten into submissiveness? An investigation into the protective strategies used by survivors of domestic abuse. Journal of Interpersonal Violence. Advance Online Publication. doi: 10.1177/0886260516682520

Jack, S. M., Ford-Gilboe, M., Wathen, C. N., Davidov, D. N., McNaughton, D. B., Coben, J. H., ... MacMillan, H. L. (2012). Development of a nurse home visitation intervention for intimate partner violence. BMC Health Services Research, 12(50), 1-14. doi:10.1186/1472-6963-12-50

Kropp, P. R. (2008). Development of the spousal assault risk assessment guide (SARA) and the brief spousal assault form for the evaluation of risk (B-SAFER). In A. C. Baldry, \& F. W. Winkel (Eds.), Intimate partner violence prevention and intervention. The risk assessment and management approach (pp. 19-31). New York: Nova Science Publishers.

Kropp, P. R., \& Hart, S. D. (2000). The spousal assault risk assessment (SARA) guide: Reliability and validity in adult male offenders. Law and Human Behavior, 24(1), 101118.

Kropp, P. R., \& Hart, S. D. (2004). The development of the brief spousal assault form for the evaluation of risk (B-SAFER): A tool for criminal justice professionals. Canada: Department of justice.

Kropp, P. R., \& Hart, S. D. (2015). SARA-V3: User guide for the third edition of the spousal assault risk assessment guide. Vancouver, Canada: Proactive Resolutions Inc.

Kropp, P. R., Hart, S. D., \& Belfrage, H. (2005). Brief spousal assault form for the evaluation of risk (B-SAFER): User manual. Australia, Canada, United States: Proactive Resolutions Inc.

Kropp, P. R., Hart, S. D., \& Belfrage, H. (2010). Brief spousal assault form for the evaluation of risk (B-SAFER), version 2: User manual. Vancouver, Canada: Proactive Resolutions Inc.

Kropp, P. R., Hart, S. D., \& Lyon, D. R. (2008). Guidelines for stalking assessment and Management (SAM). Vancouver, Canada: ProActive ReSolutions.

Kropp, P. R., Hart, S. D., Webster, C. D., \& Eaves, D. (1994). Manual for the spousal assault risk assessment guide. Vancouver, Canada: British Columbia Institute on Family Violence.

Kropp, P. R., Hart, S. D., Webster, C. D., \& Eaves, D. (1995). Manual for the spousal assault risk assessment guide (2nd ed.). Vancouver, Canada: British Columbia Institute on Family Violence.

Kropp, P. R., Hart, S. D., Webster, C. D., \& Eaves, D. (1999). Spousal assault risk assessment guide (SARA). Toronto, Canada: Multi-Health Systems, Inc. 
Lauria, I., McEwan, T. E., Luebbers, S., Simmons, M., \& Ogloff, J. R. P. (2017). Evaluating the ontario domestic assault risk assessment in an Australian frontline police setting. Criminal Justice and Behavior, 44(12): 1545-1558. doi: 10.1177/0093854817738280

Litwack, T., \& Schlesinger, L. B. (1999). Dangerousness risk assessments: research, legal, and clinical considerations. In I. B. Weiner \& A. K. Hess (Eds.), Handbook of forensic psychology (pp. 171-217). New York: Wiley.

Lundgren, E. (2004). Våldets normaliseringsprocess [The normalization process of violence]. Stockholm: Riksorganisationen för kvinnojourer och tjejjourer i Sverige (ROKS).

Lundgren, E., Heimer, G., Westerstrand, J., Kalliokoski, A-M. (2001). Slagen dam. Mäns våld mot kvinnor i jämställda Sverige - en omfängsundersökning. [Captured Queen. Men's violence against women in equality Sweden. A prevalence study]. Umeå: Åströms tryckeri AB.

MacArthur Foundation (2001). The MacArthur violence risk assessment study executive summary [Online]. Retrieved December 28, 2017. Available: http://www.macarthur.virginia.edu/risk.html

Max, W., Rice, D. P., Finkelstein, E., Bardwell, R. A., \& Leadbetter, S. (2004). The economic toll of intimate partner violence against women in the United States. Violence and Victims. 19(3), 259-272.

Maxwell, C. D., \& Robinson, A. (2013). Can interventions reduce recidivism and revictimization following adult intimate partner violence incidents? In Board on Global Health - Board on Children - Youth and Families (Ed.), Evidence for Violence Prevention Across the Lifespan and Around the World- A Workshop, Forum on Global Violence Prevention, Institute of Medicine. The Keck Center, Washington, DC, USA: National Academy of Sciences.

McEwan, T., Bateson, S., \& Strand, S. (2017). Improving police risk assessment and management of family violence through a collaboration between law enforcement, forensic mental health and academia. Journal of Criminological Research, Policy and Practice, 3(2), 119-131. doi: 10.1108/JCRPP-01-2017-0004

Mellgren, C., Svalin, K., Levander, S., \& Torstensson Levander, M. (2014a). Skånemodellen: Beskrivning och utvärdering av ett nytt verktyg för polisiär bedömning av risk för upprepat hot och våld på individnivå (Rikspolisstyrelsens utvärderingsfunktion, Rapport 2014:4) [The Police Screening Tool for Violent Crimes (PST-VC): Description and evaluation of a new tool for police employees' assessment of risk of repeated threats and violence]. Stockholm: Rikspolisstyrelsen. 
Mellgren, C., Svalin, K., Levander, S., \& Torstensson Levander, M. (2014b). Riskanalys i polisverksambet- fungerar det?: Slutrapport från ett utvärderingsprojekt (Rikspolisstyrelsens utvärderingsfunktion, Rapport 2014:6) [Violence risk assessment in police settings -Does it work? Final report from an evaluation project]. Stockholm: Rikspolisstyrelsen.

Mellgren, C., Svalin, K., Torstensson Levander, M., \& Levander, S. (2012). Riskbedömning $i$ polisverksambet [Violence risk assessment in police settings]. Malmö: Holmbergs.

Mellgren, C., Svalin, K., Torstensson Levander, M., \& Levander, S. (2014). Riskanalys $i$ polisverksambet: Utvärdering av riskanalys for våld på individnivå: Check-10(+) (Rikspolisstyrelsens utvärderingsfunktion, Rapport 2014:5) [Violence risk assessment in police settings: An evaluation of the Check-10(+) risk assessment tool]. Stockholm: Rikspolisstyrelsen.

Monahan, J. (1984). The prediction of violent behavior: Toward a second generation of theory and policy. American Journal of Psychiatry, 141(1), 10-15. doi: 10.1176/ajp.141.1.10

Monahan, J., Steadman, H., Silver, E., Appelbaum, P., Robbins, P., Mulvey, E. (2001). Rethinking risk assessment: The MacArthur Study of Mental Disorder and Violence. New York, NY: Oxford University Press.

Murray, C. E., \& Graybeal, J. (2007). Methodological review of intimate partner violence prevention research. Journal of Interpersonal Violence, 22(10), 1250-1269. doi: $10.1177 / 0886260507304293$

National Centre for Knowledge on Men's Violence against Women [NCK], (2014). Våld och hälsa. En befolkningsundersökning om kvinnors och mäns våldsutsatthet samt kopplingen till hälsa (NCK-rapport 2014:1) [Violence and health in Sweden. A national prevalence study on exposure to violence among women and men and its association to health]. Uppsala: NCK.

National Council for Crime Prevention [NCCP]. (2014). Brott $i$ nära relationer: En nationell kartläggning (Brå- rapport 2014:8) [Offences in close relationships: A national survey]. Retrieved from www.bra.se

National Council for Crime Prevention [NCCP]. (2015a). Det dödliga våldet i Sverige 1990-2014. En beskrivning av utvecklingen med särskilt fokus på skjutvapenvåldet (Brårapport 2015:24) [Lethal violence in Sweden 1990-2014. A description of trends with a special focus on firearm violence]. Retrieved from www.bra.se

National Council for Crime Prevention [NCCP]. (2015b). Larmtelefoner för hotade. Uppföljning av hur polisens larmtelefoner används och fungerar (Brå- rapport 2015:7) [Emergency phones for victims of threats. A follow-up of the use and effectiveness of the police's emergency phones]. Retrieved from www.bra.se

National Council for Crime Prevention [NCCP]. (2016). Målsägandes medverkan $i$ rättsprocessen (Brå- rapport 2016:8) [Crime victims' contacts with the justice system]. Retrieved from www.bra.se 
National Council for Crime Prevention [NCCP]. (2017). Polisiära arbetssätt för att förebygga upprepat partnervåld- med fokus på våldsutövare (Brå- rapport 2017:13) [Police approaches to prevent repeat intimate partner violence- with focus on offenders]. Retrieved from www.bra.se

Nesset, M. B., Bjørngaard, J. H., Nøttestad, J. A., Whittington, R. W., Lynum, C., \& Palmstierna, T. (2017). Factors associated with police decisions on immediate responses to intimate partner violence. Journal of Interpersonal Violence. Advance Online Publication. doi: 10.1177/0886260517706762

Nicholls, T. L., Pritchard, M. M., Reeves, K. A., \& Hilterman, E. (2013). Risk assessment in intimate partner violence: A systematic review of contemporary approaches. Partner Abuse, 4(1), 76-168. doi: 10.1891/1946-6560.4.1.76

Petersson, J., \& Strand, S. (2017). Recidivism in intimate partner violence among antisocial and family-only perpetrators. Criminal Justice and Behavior, 44(11), 1477-1495. doi: $10.1177 / 00938548177199$

Petersson, J., Strand, S., \& Selenius, H. (2016). Risk factors for intimate partner violence: A comparison of antisocial and family-only perpetrators. Journal of Interpersonal Violence. Advance Online Publication. doi: 10.1177/0886260516640547

Rettenberger, M., \& Eher, R. (2013). Actuarial risk assessment in sexually motivated intimate-partner violence. Law and Human Behavior, 37(2), 75-86. doi: $10.1037 / \mathrm{b} 0000001$

Rice, M., \& Harris, G. T. (2005). Comparing effect sizes in follow-up studies: Roc area, Cohen's d, and r. Law and Human Behavior, 29(5), 615-620. doi: 10.1007/s10979-005$6832-7$

Robinson, A. L., Pinchevsky, G. M., \& Guthrie, J. A. (2016). A small constellation: Risk factors informing police perceptions of domestic abuse. Policing and Society, 28(2), 189 204. doi: 10.1080/10439463.2016.1151881

Russell, B. (2012). Effectiveness, victim safety, characteristics, and enforcement of protective orders. Partner Abuse, 3(4), 531-552. doi: 10.1891/1946-6560.3.4.531

Salo, B., Laaksonen, T., \& Santtila, P. (2016). Construct validity and internal reliability of the Finnish risk and needs assessment form. Journal of Scandinavian Studies in Criminology and Crime Prevention, 17(1), 86-107. doi: 10.1080/14043858.2016.1161940

Sebire, J., \& Barling, H. (2016). Assessing the assessors: An analysis of the consistency of risk grading by police when conducting domestic abuse investigations. Policing, 10(4), 351-360. doi: 10.1093/police/paw012

Shepard, M., Falk, D. R., \& Elliott, B. A. (2002). Enhancing Coordinated Community Responses to Reduce Recidivism in Cases of Domestic Violence. Journal of Interpersonal Violence, 17(5), 551-569.

Skeem, J. L., \& Monahan, J. (2011). Current directions in violence risk assessment. Current directions in psychological science, 20(1), 38-42. doi: 10.1177/0963721410397271 
Skeem, J. L., \& Mulvey, E. P. (2001). Psychopathy and community violence among civil psychiatric patients: Results from the MacArthur Violence Risk Assessment Study. Journal of Consulting and Clinical Psychology, 69(3), 358-374. doi: 10.1037/0022-006X.69.3.358

Steadman, H. J., Mulvey, E. P., Monahan, J., Robbins, P. C., Appelbaum, P. S., Grisso, T., ... Silver, E. (1998). Violence by people discharged from acute psychiatric inpatient facilities and by others in the same neighborhoods. Archives of General Psychiatry, 55(5), 393-401. doi: /10.1001archpsyc.55.5.393

Steadman, H. J., \& Silver, E. (2000). Immediate precursors to violence among persons with mental illness; a return to a situational perspective. In S. Hodgins (Ed.), Effective prevention of crime and violence among the mentally ill (pp. 35-48). Dordrecht, the Netherlands: Kluwer Academic Publishers.

Steadman, H. J., Silver, E., Monahan, J., Appelbaum, P. S., Robbins, P. C., Mulvey, E. P., ... Banks, S. (2000). A classification tree approach to the development of actuarial violence risk assessment tools. Law and Human Behavior, 24(1), 83-100.

Storey, J. E., Gibas, A. L., Reeves, K. A., \& Hart, S. D. (2011). Evaluation of a violence risk (threat) assessment training program for police and other criminal justice professionals. Criminal Justice and Behavior, 38(6), 554-564. doi: $10.1177 / 0093854811403123$

Storey, J. E., Kropp, P. R., Hart, S. D., Belfrage, H., \& Strand, S. (2014). Assessment and management of risk for intimate partner violence by police officers using the brief spousal assault form for the evaluation of risk. Criminal Justice and Behavior, 41(2), 256-271. doi:10.1177/0093854813503960

Storey, J. E., \& Strand, S. (2012). The characteristics and violence risk management of women arrested by the police for intimate partner violence. European Journal of Criminology, 9(6), 636-651. doi: 10.1177/1477370812453403

Storey, J. E., \& Strand, S. (2013). Assessing violence risk among female IPV perpetrators: An examination of the B-SAFER. Journal of Aggression, Maltreatment \& Trauma, 22(9), 964-980. doi: 10.1080/10926771.2013.835015

Storey, J. E. \& Strand, S. (2017). The influence of victim vulnerability and gender on police officers' assessment of intimate partner violence risk. Journal of Family Violence, 32(1), 125-134. doi: 10.1007/s10896-016-9905-0

Stover, C. S., Poole, G., \& Marans, S. (2009). The domestic violence home-visit intervention: Impact on police-reported incidents of repeat violence over 12 months. Violence and Victims, 24(5), 591-606. doi: 10.1891/0886-6708.24.5.591

Strand, S. (2006). Violence risk assessment in male and female mentally disordered offenders - Differences and similarities. (Doctoral thesis). Sundsvall: Mid Sweden University. 
Strand, S. (2012). Using a restraining order as a protective risk management strategy to prevent intimate partner violence. Police Practice and Research, 13(3), 254-266. doi: $10.1080 / 15614263.2011 .607649$

Strand, S., Belfrage, H., Fransson, G., \& Levander, S. (1999). Clinical and risk management factors in risk prediction of mentally disordered offenders- more important than historical data? Legal and Criminological Psychology, 4, 67-76.

Sturup, J., Forsman, M., Haggård, U., Karlberg, D., \& Johansson, P. (2013). Riskbedömning $i$ kriminalvård och rättspsykiatri. Sammanfattningsrapport. (Projektnummer 2013:269) [Violence risk assessment in prison service and forensic psychiatry. A summary report]. Norrköping: Kriminalvården.

Svalin, K., Mellgren, C., Levander, S., \& Torstensson Levander, M. (2014). Utvärdering av SARA:SV: Uppsalapolisens arbete med riskbedömningar för upprepade brott $i$ nära relationer (Rikspolisstyrelsens utvärderingsfunktion, Rapport 2014:6) [An evaluation of the SARA:SV. The Uppsala police department's work with intimate partner violence risk assessments]. Stockholm: Rikspolisstyrelsen.

Svalin, K., Mellgren, C., Torstensson Levander, M., \& Levander, S. (2017). Assessing and managing risk for intimate partner violence: Police employees' use of the Police Screening Tool for Violent Crimes in Scania. Journal of Scandinavian Studies in Criminology and Crime Prevention, 18(1), 84-92. doi: 10.1080/14043858.2016.1260333

Svalin, K., Mellgren, C., Torstensson Levander, M., \& Levander, S. (2018). Police employees' violence risk assessments: The predictive validity of the B-SAFER and the significance of protective actions. International Journal of Law and Psychiatry, 56, 7179. doi: 10.1016/j.ijlp.2017.09.001

Szumilas, M. (2010). Explaining odds ratio. Journal of the Canadian Academy of Child and Adolescent Psychiatry, 19(3), 227-229.

The Swedish National Police Authority. (2012). Inspektion av polismyndigheternas hantering av det lokala personsäkerhetsarbetet (Rapport 2012:8) [Inspection of the police authorities handling of the local security work]. Stockholm: RPS Tryckeri.

Thijssen, J., \& de Ruiter, C. (2011). Identifying subtypes of spousal assaulters using the BSAFER. Journal of Interpersonal Violence, 26(7), 1307-1321. doi: $10.1177 / 0886260510369129$

Trujillo, M. P., \& Ross, S. (2008). Police response to domestic violence: Making decisions about risk and risk management. Journal of Interpersonal Violence, 23(4), 454-473. doi: $10.1177 / 0886260507312943$

Tversky, A., \& Kahneman, D. (1974). Judgment under uncertainty: Heuristics and biases. Science, 185(4157), 1124-1131.

Webster, C. D., Douglas, K. S., Eaves, D., \& Hart, S. D. (1997). HCR-20: Assessing risk for violence, version 2. Vancouver, Canada: Simon Fraser University and Forensic Psychiatric Services Commission of British Columbia. 
Webster, C. D., Eaves, D., Douglas, K. S., \& Wintrup, A. (1995). The HCR-20 scheme: The assessment of dangerousness and risk. Vancouver, Canada: Simon Fraser University and Forensic Psychiatric Services Commision of British Columbia.

Wikström, P. -O. H. (2006). Individuals, settings, and acts of crime: Situational mechanisms and the explanation of crime. In P. -O. H. Wikström, \& R. J. Sampson (Eds.), The explanation of crime: Context, mechanisms and development (pp. 61-107). Cambridge: Cambridge University Press.

Wikström, P. -O. H., \& Treiber, K. (2017). Beyond risk factors: An analytical approach to crime prevention. In B. Teasdale, \& M. S. Bradley (Eds.), Preventing crime and violence, Advances in prevention science (pp. 73-87). Switzerland: Springer International Publishing. doi: 10.1007/978-3-319-44124-5_8

Williams, K. R, \& Houghton, A. B. (2004). Assessing the risk of domestic violence reoffending: A validation study. Law and Human Behavior, 28(4), 437-455.

Winer, B. J. (1962). Statistical principles in experimental design. New York, NY: McGraw Hill.

World Health Organization/London School of Hygiene and Tropical Medicine [WHO/LSHTM]. (2010). Preventing intimate partner and sexual violence against women: taking action and generating evidence. Geneva, Switzerland: World Health Organization.

Zou, K. H., O’Malley, A. J., \& Mauri, L. (2007). Receiver-operating characteristic analysis for evaluating diagnostic tests and predictive models. Circulation, 115, 654-657. doi: 10.1161/CIRCULATIONAHA.105.594929 
ORIGINAL PAPERS I-IV 



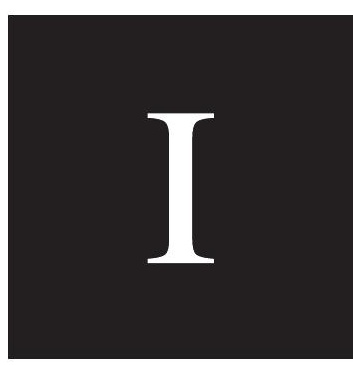





\title{
Assessing and managing risk for intimate partner violence: Police employees' use of the Police Screening Tool for Violent Crimes in Scania
}

\author{
Klara Svalin, Caroline Mellgren (D), Marie Torstensson Levander (D) and \\ Sten Levander (iD \\ Department of Criminology, Malmö University, Malmö, Sweden
}

\begin{abstract}
Relapse into intimate partner violence (IPV) can potentially be predicted and counter-measures applied. This study examines the predictive validity of a violence risk assessment tool: the Police Screening Tool for Violent Crimes (PST-VC) among a sample of 65 offenders. All PST-VC assessments regarding IPV that were conducted at the Scania police department in 2010 were included in the sample. Follow-up time was 16-28 months, and all reported incidents with the same victim and suspected offender were recorded. The PST-VC demonstrated limited effect in the ability to identify high-risk offenders and predict repeat victimization. Interventions against the offender and victim protective actions were more often recommended in highrisk cases but did not lower the number of IPV relapses. The study suggests that the PST-VC is not a promising instrument.
\end{abstract}

\section{ARTICLE HISTORY}

Received 11 January 2016 Accepted 11 October 2016

\section{KEYWORDS}

Intimate partner violence; violence risk assessment; police; crime prevention; victims; interventions

\section{Introduction}

Intimate partner violence (IPV) is a substantial problem worldwide. Victims may live with long-standing conflicts and threats from the perpetrator. Post-traumatic stress disorder and depression are common in female victims (Stein \& Kennedy, 2001). Furthermore, the risk of relapse after an IPV crime is high (Hester \& Westmarland, 2006). According to the UN declaration on the elimination of violence against women, all states should work to end violence against women (UN General Assembly, 1993). For these reasons, it is worthwhile to identify perpetrators with a particularly high risk of IPV relapse, expose them to crime preventive interventions and offer protective interventions to their potential victims. This requires that it is possible to assess the risk, and to select and implement effective interventions. Such procedures are implemented in police settings in some countries. The most commonly used IPV risk assessment instrument is the Spousal Assault Risk Assessment Guide (SARA, Kropp, Hart, Webster, \& Eaves, 1999) developed in forensic psychiatric settings. The Brief Spousal Assault Form for the Evaluation of Risk (B-SAFER, Kropp, Hart, \& Belfrage, 2010) is a version modified for use by the police. The Ontario Domestic Assault Risk Assessment (ODARA, Hilton et al., 2004) is also used by the police. However, the research basis for the quite extensive 
use of such tools in some police settings is meagre. Most of the studies have focused SARA and B-SAFER (summed up in Svalin, Mellgren, Torstensson Levander, \& Levander, 2014).

\section{Predictive validity of risk assessment tools}

Three studies have a main focus on IPV recidivism and predictive validity of police officers' violence risk assessments (Belfrage \& Strand, 2012; Belfrage et al., 2012; Storey, Kropp, Hart, Belfrage, \& Strand, 2014). Belfrage et al. (2012) and Storey et al. (2014) studied whether risk assessment is associated with the risk-based recommendations of interventions and with IPV recidivism, and if the relationship between risk assessment and recidivism is mediated by the recommended interventions. The assessments were followed-up in terms of recommended interventions, IPV recidivism reported to the police and additional assessments and recommended interventions. In these studies, the rate of IPV recidivism was almost the same; $21 \%$ in the former and $24 \%$ in the latter.

Belfrage et al. (2012) found the SARA assessments and the associated risk management procedures to prevent violence. The recommended interventions were based on the risk assessment and mediated the relationship between the risk assessment and the outcome: IPV recidivism. The results of the B-SAFER evaluation (Storey et al., 2014) were partly in line with those of the previous study by being related to risk management and to IPV recidivism, but the recommended interventions did not mediate the association between the risk and IPV recidivism. However, the risk assessment interacted with the recommended protective actions when predicting IPV recidivism. In both studies, the rate of IPV recidivism was lower in high-risk cases with many recommended protective actions. In low-risk cases, it was the other way around; the rate of repeat IPV was higher in cases with many protective actions (cf. Andrews \& Bonta, 2010).

In another Swedish study, the predictive validity of the B-SAFER was found to be poor (Belfrage \& Strand, 2012). The data consisted of 216 assessments of IPV cases conducted by police officers and a follow-up of crime preventive/victim protective interventions, legal sanctions and IPV recidivism. The recidivism rate was high (42\%). A high level of protective interventions was initiated in $68 \%$ of the cases. Aware of the confounding problem, the authors interpreted the outcome as a positive effect of interventions which in turn corrupted the prediction of relapse in the high-risk group (those who were at high risk were exposed to effective interventions and therefore did not relapse).

We have not been able to find any studies in which police officers use general violence risk assessment tools to evaluate the risk of IPV recidivism. This issue has however been studied in other settings. Grann and Wedin (2002) compared the predictive validity of the SARA to that of three general risk assessment instruments, the Psychopathy Checklist Revised (PCL-R) (Hare, 1991), the 10 actuarial items (H10) of the Historical-Clinical-Risk-20 instrument (Webster, Douglas, Eaves, \& Hart, 1997) and the Violence Risk Assessment Guide (VRAG) (Harris, Rice, \& Quinsey, 1993), in a population of violent offenders, assessed psychiatrically by a court order. All offenders were diagnosed with a personality disorder and most of them had an extensive criminal history and high PCL-R, H-10 and VRAG scores. SARA ratings were performed retrospectively, without knowledge of the general risk instrument scores. All general tools did predict IPV recidivism better than the IPV-specific SARA during the following year. The characteristics of the sample differed from that of male IPV offenders 
(Holtzworth-Munroe \& Stuart, 1994) which might explain the higher predictive validity of the general tools compared to the SARA.

\section{Aims}

The current study evaluated whether the Police Screening Tool for Violent Crimes (PST-VC), a general tool for assessing and managing the risk of different types of crime, can be used by police employees to identify high-risk cases of repeat intimate partner violence (IPV). The accuracy was measured as the ability to predict IPV reoffending. The aim was also to discuss the preventive effect of the recommended crime preventive and victim protective interventions and whether these interventions create a confounding problem with respect to predictive validity.

\section{The Police Screening Tool for Violent Crimes (PST-VC)}

Within the county of Scania police department, the person who receives a report of threats or violence considers the risk of recidivism. There are neither instruments available to aid the police to make an assessment of the risk in this initial screening phase, nor any specific training. When a case has been assessed as indicating a heightened risk of recidivism, the PST-VC is used to assess the risk further. A specific group of police employees (both police officers and professionals with other education and/or work experience) conduct the risk assessments. The PST-VC is a general tool for assessing and managing the risk of different types of crime, ranging from threats by an unknown offender to intimate partner violence. The tool was developed by the Scania police department in 2009.

The PST-VC lists headings under which the assessor is required to summarize information about present offender risk factors (e.g. previous IPV, other criminality, substance abuse) and victim vulnerability factors (e.g. fear of the offender and psychosocial situation). These factors are similar to those included in the other tools used by the Swedish police. PST-VC is not a checklist; it only provides guidelines and formulates questions related to headings, for example, whether the victim has been exposed to threats, violence or other crimes, and how the suspected offender's psychosocial situation can be described.

Thus, the risk and victim vulnerability factors are not strictly defined in the tool, leaving room for different interpretations of a factor, as well as the threshold determining whether a specific factor is present or not. The assessors also have to identify which factors are particularly relevant to the assessment of a specific case. The assessment is based on information from the police registers and, in most of the cases, a meeting with the victim.

The risk of recidivism is scored on a 5 -level scale, from no risk (1) to high risk (5). Based on the risk assessment, the assessor recommends crime preventive interventions directed towards the offender and protective actions directed towards the victim. These include (a) victim support (e.g. contact information for victim support agencies, victim support coordinators at the police, etc.), (b) security and/or victim support talk with the police (conversations regarding, for instance, strategies that the victim can apply to reduce the risk of revictimization), (c) filing for a restraining order, (d) contacting a victim shelter, (e) protecting the identity of the victim (i.e. helping the victim to apply for new personal data), (f) providing an alarm (portable and directly linked to the police) and (g) contacting a special security group at the police working with high-risk cases. 


\section{Method}

\section{Procedure and data}

The data consist of all the PST-VC assessments regarding IPV conducted at the Scania police department in $2010(N=65)$ and information about recommended crime preventive and victim protective interventions. Some of these interventions had been implemented prior to the assessment (e.g. a restraining order was issued or the police had already contacted the victim) while most of the interventions were recommended after the assessment phase. The police database does not contain information regarding implementation of a recommended intervention, which is a common limitation for this kind of studies. Items a and b (see above) were categorized as low-level interventions and c to $g$ as high-level interventions. Thirty-eight per cent of the victims were recommended low-level interventions and $62 \%$ high-level interventions.

IPV was defined as all kinds of crime (physical and psychological) between current or former intimate partners. We retrieved information on repeat police reports for each case to control for repeat IPV. All reported incidents with the same victim and suspected offender were included in the follow-up (e.g. unlawful threat, assault, violation of a woman's integrity and violation of a restraining order), which ranged from the date of risk assessment until April 2012 (range 16-28 months). Thus, the time-at-risk was quite variable. However, more than half of the repeat IPV tend to occur within four months after the index crimes (Gondolf, 1997; Svalin et al., 2014), which makes the differences in time at risk less problematic. Both the initially reported IPV offence and instances of repeated IPV involved suspected offences, i.e. we do not know whether or not the offenders were convicted. Repeat IPV does not need to involve the same type of offence as the initially reported IPV offence.

The assessments were conducted according to the police department's routines. The assessors were blind to possible repeat IPV, in line with the prospective design recommended by Belfrage et al. (2012). A total of 71 PST-VC assessments regarding IPV were conducted in 2010 in Scania. Three cases lacked risk level and two cases lacked information regarding repeat IPV. These cases were excluded from the sample. In one case, two assessments had been conducted over the course of 2010. Only the first was included in the sample. The low number of cases (65) was probably because the tool and the assessment routines were new, and, most importantly, no routines for the initial screening were established.

The 65 offenders were all male (mean age 34, range 18-74). Victims were 64 women and one man (mean age 33, range 19-68). Only 5\% of the offenders had no police record of previous criminality prior to the index crime; i.e. the offence which led to the risk assessment. The victim had been abused or threatened by the suspected offender prior to the index crime in $80 \%$ of the cases. Eight police employees conducted the assessments; not all of the assessors were police officers. The assessors' professional knowledge (time of employment at the police department and type of assignments) and experience of assessing violence risk varies, but is overall quite limited. The study was approved by the Ethical Review Board in South Sweden and the Scania police department.

\section{Statistical methods}

In order to analyse the data, a number of statistical methods were conducted: bivariate correlations (Kendall's tau), a Receiver operating characteristics (ROC) analysis and logistic regression analyses. 


\section{Results}

Repeat victimization, divided into violence or other crimes, is presented in Table 1 for four of the five risk levels. Risk level 5 was never used; risk levels 1 and 4 only in a few cases. In the following analyses, cases belong to a low-risk (risk levels $1-2, N=37$ ) or a high-risk group (risk levels $3-4, N=28$ ). Repeat victimization was reported in $48 \%$ of the cases at least once during the follow-up period. In half of the cases, victims were subjected to direct violence, and in the remaining cases, to other kinds of crime (e.g. unlawful threat, violation of a restraining order, interference in a judicial matter).

\section{Predictive validity}

Data relevant to the predictive values of the PST-VC for relapse are shown in Table 2, separately for the high-risk group (positive predictive value, PPV) and the low-risk group (negative predictive value, NPV) and associated values of sensitivity (failure to identify a high-risk offender as a high-risk) and specificity (failure to recognize a low-risk offender as a low-risk one).

Repeat victimization occurred in 19 high-risk cases and 13 low-risk cases. The sensitivity of the model was .59 and the specificity was .73 , i.e. there were a substantial number of misclassifications. A Receiver operating characteristics (ROC) analysis illustrates the tradeoff between sensitivity and specificity (Zou, O'Malley, \& Mauri, 2007) when moving the threshold for identifying an offender as a high-risk case: between 1 and 2, between 2 and 3 and between 3 and 4 (Table 2). The overall predictive validity of the PST-VC for IPV relapse (all crimes) was measured as the Area Under the Curve (AUC) in the ROC analysis. This value was marginal $(.66, S E=.068)$, i.e. the risk level was a fairly weak predictor of repeat IPV. The AUC for violent revictimization was similar $(.67, S E=.078)$. The assessed risk (low/high) correlated significantly with both repeat IPV and repeat violence $(\tau=.324, p<.01$ and $\tau=.296, p<.05)$.

Table 1. Repeat IPV (violence and other crimes) by risk level $(\%, n)$.

\begin{tabular}{lcccc}
\hline Risk level & No & Violence & Other crimes & Repeat IPV in total \\
\hline $1: 3 \%(2)$ & $6 \%(2)$ & $0 \%$ & $0 \%$ & $0 \%$ \\
$2: 54 \%(35)$ & $67 \%(22)$ & $31 \%(5)$ & $50 \%(8)$ & $41 \%(13)$ \\
$3: 39 \%(25)$ & $21 \%(7)$ & $63 \%(10)$ & $50 \%(8)$ & $56 \%(18)$ \\
$4: 5 \%(3)$ & $6 \%(2)$ & $6 \%(1)$ & $0 \%$ & $3 \%(1)$ \\
Total $(\mathrm{N}=65)$ & $52 \%(33)$ & $24 \%(16)$ & $24 \%(16)$ & $48 \%(32)$ \\
\hline
\end{tabular}

Table 2. Sensitivity, specificity, positive (PPV) and negative (NPV) predictive values in three different risk classifications.

\begin{tabular}{|c|c|c|c|c|}
\hline \multirow[b]{2}{*}{ Risk level } & Sensitivity & Specificity & PPV & NPV \\
\hline & \multicolumn{2}{|c|}{ Repeat IPV } & \multicolumn{2}{|c|}{ Repeat IPV } \\
\hline 1 vs. $2,3,4$ & 1.00 & .061 & 50.8 & 0 \\
\hline 1,2 vs. 3,4 & .594 & .727 & 67.9 & 35.1 \\
\hline $1,2,3$ vs. 4 & .031 & .939 & 33.3 & 50.0 \\
\hline
\end{tabular}

Notes: Sensitivity: the proportion of cases that are considered high-risk cases and in which repeat IPV occurs. Specificity: the proportion of cases that are considered low-risk cases and in which repeat IPV does not occur. 
Table 3. Risk level, level of protective actions and repeat IPV.

\begin{tabular}{lcc}
\hline Risk level & Level of protective actions & Repeat IPV $(\%, n)$ \\
\hline Low (1-2) & Low (19) & $31.6 \%(6)$ \\
High (3-4) & High (18) & $38.9 \%(7)$ \\
& Low (6) & $66.7 \%(4)$ \\
\hline
\end{tabular}

\section{Risk level, crime preventive and victim protective interventions, and repeat victimization}

In the next step, we constructed a contingency table for risk, recommended crime preventive and victim protective actions, and the interactions of these factors on IPV recidivism. Data were analysed using logistic regression (only presented in text). The risk-level (low/high) was significantly associated with repeat IPV $(\mathrm{OR}=3.5, p<.05)$, but the recommended interventions were not $(\mathrm{OR}=1.3, \mathrm{~ns})$.

In $62 \%$ of the cases, a high level of interventions was recommended. The risk level (low/ high) and the level of interventions (low/high) correlated significantly ( $\tau=.305, p<.05$ ), but the recommended interventions were neither associated with repeat IPV in general $(\tau=.15)$ nor with repeat violence $(\tau=.01)$ (only presented in text).

In the high-risk group, the majority of cases had a high level of recommended interventions, while high and low levels of interventions were equally distributed among the low-risk cases (Table 3). Repeat victimization was not associated with interventions in any of the two risk groups.

In order to study the interaction between summarized risk and recommended crime preventive and victim protective actions on victimization, we categorized the risk and the interventions as four dummy variables. The low-risk group with a high level of interventions and the two high-risk groups were compared with the low-risk group with a low level of interventions, i.e. the reference category. Only the high-risk group with a high level of interventions displayed a significantly higher frequency of repeat victimization $(\mathrm{OR}=4.6, p<.05)$ (only presented in text). Because of the low $N$, this unexpected finding (that interventions increased relapse) should be considered preliminary.

\section{Discussion}

The use of risk instruments has become common in police settings, but the scientific support for the predictive validity of police employees' risk assessments is meagre, and different police authorities use different assessment instruments and procedures (Mellgren, Svalin, Levander, \& Torstensson Levander, 2014). In this study, we analysed one of these instruments, the PST-VC. We limited our analysis to cases of IPV. The number of cases, which had been assessed during one year, was unexpectedly low $(N=65)$ signalling that the initial screening process does not seem to work.

Risk can be rated on a 5-point Likert scale, but the assessors actually used only two of the five categories (risk level 2 or 3 were used in $92 \%$ of the cases). We classified the cases into a low and a high-risk group. The predictive validity of the PST-VC for relapse into repeat victimization was rather poor, and the recommendations of crime preventive and protective interventions were not associated with IPV recidivism in any of the risk groups, except among 
the high-risk cases with a high level of interventions, being unexpectedly associated with increased relapses.

Some of the results are in line with previous studies and some are not. One of the main similarities between studies is the weak to moderate association between the risk assessment and recidivism (Belfrage \& Strand, 2012; Belfrage et al., 2012; Storey et al., 2014). Belfrage et al. (2012) found a significant association between recommended interventions and IPV recidivism. Neither we, nor Storey et al. (2014), were able to confirm this finding. Both Belfrage et al. (2012) and Storey et al. (2014) found, in contrast to us, that the higher the risk and the more interventions that were recommended, the lower was the risk of recidivism. Belfrage et al. (2012), unlike Storey et al. (2014), found that interventions had a mediating effect on the association between risk and recidivism. Summing up, the literature is not consistent and calls for more studies.

There are almost no empirical studies on the issue whether interventions are effective in IPV cases. Strand (2012) examined the effectiveness of the use of a restraining order as a protective intervention. Cases assessed as high risk by the police were more often subject to a restraining order compared to low- and medium-risk cases. Paradoxically, however, this intervention was better suited to the low and medium risk groups than to the high-risk group. The high rate of unreported IPV (Gracia, 2004) complicates the interpretation of such findings still further.

Another problem is to what extent recommended interventions are implemented. Unlike Belfrage et al. (2012), Storey et al. (2014) and the present study, Belfrage and Strand (2012) examined implemented interventions. Unfortunately, they do not provide information regarding differences in the proportion of recommended and implemented ones, and if certain interventions were implemented more often than others. Such information would have contributed to the interpretation of the significance of the interventions in, for instance, the aforementioned studies. In a recent evaluation of the predictive validity of 320 assessments using the B-SAFER, conducted by police employees, only just over half of the recommended interventions were implemented (Svalin et al., 2014).

The lack of information regarding the actual implementation of interventions is a limitation in this study and in most similar studies. Some of the interventions require decisions from other authorities and the police can therefore not guarantee that recommended actions are implemented. For instance, prosecutors decide on restraining orders, and the availability of safe houses largely depends on municipalities. This practical reality becomes a methodological weakness, which has to be addressed in future studies. Furthermore, although all IPV cases assessed with the PST-VC in 2010 were included in the study, the actual number of assessments was small (but represents a 'population' rather than a sample). This carries some limitations with respect to the generalizability of our findings.

The PST-VC differs in a number of ways from the other IPV risk assessment instruments used by the Swedish police, the SARA and the B-SAFER, by being a general violence risk assessment tool designed by police employees on the basis of tacit knowledge. It does not include a checklist and assigns more weight to subjective judgements than the structured tools. Head-to-head comparisons between PST-VC and other instruments are needed before any firm conclusions can be drawn - but the PST-VC is not a promising instrument. 


\section{Acknowledgement}

The authors thank the Scania police department.

\section{Disclosure statement}

No potential conflict of interest was reported by the authors.

\section{Funding}

This work was supported by the National Swedish Police Board [grant number A202.590/2013].

\section{ORCID}

Caroline Mellgren (D) http://orcid.org/0000-0001-5375-0065

Marie Torstensson Levander (iD) http://orcid.org/0000-0002-8595-4502

Sten Levander (iD) http://orcid.org/0000-0002-9227-8987

\section{References}

Andrews, D. A., \& Bonta, J. (2010). The psychology of criminal conduct (5th ed.). New Province, NJ: Anderson Publishing.

Belfrage, H., \& Strand, S. (2012). Measuring the outcome of structured spousal violence risk assessments using the B-SAFER: Risk in relation to recidivism and intervention. Behavioral Sciences and the Law, 30, 420-430. doi:10.1002/bsl.2019

Belfrage, H., Strand, S., Storey, J. E., Gibas, A. L., Kropp, P. R., \& Hart, S. D. (2012). Assessment and management of risk for intimate partner violence using the Spousal Assault Risk Assessment Guide. Law and Human Behaviour, 36, 60-67. doi:10.1007/s10979-011-9278-0

Gondolf, E. W. (1997). Patterns of reassault in batterer programs. Violence and Victims, 12, 373-387.

Gracia, E. [Editorial]. (2004). Unreported cases of domestic violence against women: Towards an epidemiology of social silence, tolerance, and inhibition. Journal of Epidemiology and Community Health, 58, 536-537.

Grann, M., \& Wedin, I. (2002). Risk factors for recidivism among spousal assault and spousal homicide offenders. Psychology, Crime \& Law, 8, 5-23. doi:10.1080/10683160208401806

Hare, R. D. (1991). Manual for the Revised Psychopathy Checklist (1 st ed.). Toronto: Multi Health Systems.

Harris, G. T., Rice, M. E., \& Quinsey, V. L. (1993). Violent recidivism of mentally disordered offenders: The development of a statistical prediction instrument. Criminal Justice and Behavior, 20, 315-335.

Hester, M., \& Westmarland, N. (2006). Domestic violence perpetrators. Criminal Justice Matters, 66, 34-35. doi:10.1080/09627250608553400

Hilton, N. Z., Harris, G. T., Rice, M. E., Lang, C., Cormier, C. A., \& Lines, K. J. (2004). A brief actuarial assessment for the prediction of wife assault recidivism: The Ontario Domestic Assault Risk Assessment. Psychological Assessment, 16, 267-275. doi:10.1037/1040-3590.16.3.267

Holtzworth-Munroe, A., \& Stuart, G. L. (1994). Typologies of male batterers: Three subtypes and the differences among them. Psychological Bulletin, 116, 476-497.

Kropp, P. R., Hart, S. D., \& Belfrage, H. (2010). Brief Spousal Assault Form for the Evaluation of Risk (B-SAFER), Version 2: User manual. Vancouver: Proactive Resolutions Inc.

Kropp, P. R., Hart, S. D., Webster, C. D., \& Eaves, D. (1999). Spousal Assault Risk Assessment Guide (SARA). Toronto: Multi-Health Systems.

Mellgren, C., Svalin, K., Levander, S., \& Torstensson Levander, M. (2014). Riskbedömning i polisverksamhetfungerar det? Slutrapport från ett utvärderingsprojekt [Violence risk assessment in police settings - Does it work? Final report from an evaluation project]. (Rikspolisstyrelsens utvärderingsfunktion, Rapport Nr. 2014:7). Stockholm: RPS Tryckeri. 
Stein, M. B., \& Kennedy, C. (2001). Major depressive and post-traumatic stress disorder comorbidity in female victims of intimate partner violence. Journal of Affective Disorders, 66, 133-138.

Storey, J. E., Kropp, P. R., Hart, S. D., Belfrage, H., \& Strand, S. (2014). Assessment and management of risk for intimate partner violence by police officers using the Brief Spousal Assault Form for the Evaluation of Risk. Criminal Justice and Behavior, 41, 256-271. doi:10.1177/0093854813503960

Strand, S. (2012). Using a restraining order as a protective risk management strategy to prevent intimate partner violence. Police Practice \& Research, 13, 254-266. doi:10.1080/15614263.2011.607649

Svalin, K., Mellgren, C., Torstensson Levander, M., \& Levander, S. (2014). Utvärdering av SARA:SV. Uppsalapolisens arbete med riskbedömningar för upprepade brott i nära relationer [An evaluation of the SARA:SV. The Uppsala police department's work with intimate partner violence risk assessments]. (Rikspolisstyrelsens utvärderingsfunktion, Rapport Nr. 2014:6). Stockholm: RPS Tryckeri.

UN General Assembly. (1993, December 20). Declaration on the Elimination of Violence against Women, A/RES/48/104. Retrieved September 22, 2016, from http://www.refworld.org/docid/3b00f25d2c.html Webster, C. D., Douglas, K. S., Eaves, D., \& Hart, S. D. (1997). HCR-20: Assessing risk for violence, Version 2. Vancouver: Simon Fraser University and Forensic Psychiatric Services Commission of British Columbia.

Zou, K. H., O'Malley, A. J., \& Mauri, L. (2007). Receiver-operating characteristic analysis for evaluating diagnostic tests and predictive models. Circulation, 115, 654-657. doi:10.1161/ CIRCULATIONAHA.105.594929 

II 



\title{
The Inter-Rater Reliability of Violence Risk Assessment Tools Used by Police Employees in Swedish Police Settings
}

\author{
Klara Svalin \\ PhD-student, Corresponding author, Department of Criminology, Malmö University, Sweden \\ klara.svalin@mah.se
}

\section{Caroline Mellgren}

Senior lecturer/PhD, Department of Criminology, Malmö University, Sweden

caroline.mellgren@mah.se

Marie Torstensson Levander

Professor, Department of Criminology, Malmö University, Sweden

marie.torstensson.levander@mah.se

\section{Sten Levander}

Professor, Department of Criminology, Malmö University, Sweden

stenlevander@gmail.com

\section{ABSTRACT}

Risk assessments are used by the police in order to identify the need for victim protection. The aim of this study was to examine the inter-rater reliability of two violence risk assessment tools; the Police Screening Tool for Violent Crimes (PST-VC) and the Brief Spousal Assault Form for the Evaluation of Risk (B-SAFER), used by police employees in two different police authorities in Sweden. The inter-rater agreement was evaluated for both tools, with respect to global risk assessments, recommended protective actions and risk- and victim vulnerability factors. The main results showed that the inter-rater agreement was highest for the global assessments and widely varying, from very low to fairly high, for the structured variables. The fairly high reliability for the global risk assessments was most likely due to shared assumptions (heuristics, tacit knowledge) among the assessors rather than being based on the information obtained by the tools. 


\section{INTRODUCTION}

Violence risk assessment tools have been used in the Swedish police organization since the late 1990s (National Swedish Police Board, 2010). Their use began with the introduction of an intimate partner violence (IPV) risk assessment tool, the Spousal Assault Risk Assessment guide (SARA; Kropp, Hart, Webster \& Eaves, 1994, 1995, 1999), in a couple of police authorities. Thereafter, a number of other tools have been introduced in more or less all Swedish police authorities. Most of these tools are variants of structured instruments developed in the forensic psychiatric context (e.g. SARA). In addition, there is a general violence risk assessment tool denoted the Police Screening Tool for Violent Crimes (PSTVC), which has been designed at one of Sweden's regional police authorities. This tool is different, in that it assigns more weight to subjective judgements than the structured instruments.

The number of studies regarding violence risk assessment and management in police settings has increased in the recent years. For instance, areas of interest have been the applicability of psychiatric tools in police settings (e.g. Belfrage \& Strand, 2009; Kropp, 2008; Kropp \& Hart, 2004; Storey \& Strand, 2012a); the development/adaptation of assessment tools (e.g. Belfrage, 2008; Belfrage \& Strand, 2008; Belfrage, Strand, Ekman \& Hasselborg, 2012; Dayan, Fox \& Morag, 2013); the predictive validity of IPV assessments (e.g. Belfrage \& Strand, 2012; Belfrage et al., 2012a; Storey, Kropp, Hart, Belfrage \& Strand, 2014); police officers' decision making in the risk assessment and management procedure (e.g. Robinson, Pinchevsky \& Guthrie, 2016; Trujillo \& Ross, 2008), and the inter-rater reliability/consistency of police officers risk assessments (e.g. Sebire \& Barling, 2016).

The main findings of these studies can be summarized in the following statements. The majority of risk- and victim vulnerability factors employed in various assessment tools are useful in police settings, in particular in male offender samples (Belfrage, 2008; Belfrage \& Strand, 2008, 2009). However, police officers have difficulty assessing psychiatric risk factors, because information regarding these factors is difficult to access and police officers in general lack training in psychiatry (Belfrage, 2008). This was one of the problems that motivated the development of the Brief Spousal Assault Form for the Evaluation of Risk (BSAFER; Kropp, Hart \& Belfrage, 2005, 2010), which is a police version of the SARA guide (see Belfrage, 2008 and Kropp, 2008). Another assessment tool developed to guide professionals in the law enforcement and social authorities is the PATRIARCH (Belfrage, 2005). It is a structured instrument, like the SARA and the B-SAFER, and focuses on the assessment of honor-based crime (see Belfrage et al., 2012b). Studies on risk assessment and management in female offender samples are still limited. However, a recent study examined police officers' use of the B-SAFER instrument in a female offender sample (Storey \& Strand, $2012 \mathrm{a}^{1}$ ). Some of the B-SAFER factors were found to be useful in assessing female IPV offenders, but there seem to be some gender-related factors also, that are not included in the tool. Additional studies are required to identify these factors.

1. Storey and Strand (2012b) have also conducted a study aiming to describe characteristics of female IPV offenders and male IPV victims, as well as risk management strategies recommended by the police. In approximately half the sample, the violence risk was assessed using the B-SAFER and in the other half the SARA was used. The BSAFER sample was the same as in Storey and Strand (2012a), except that there were two additional cases included in the sample in Storey and Strand (2012b). 
Further, the number of risk factors/the total score of the risk factors has been found to be positively associated with the summarized risk assessment (Belfrage et al., 2012a; Kropp \& Hart, 2004; Storey et al., 2014). A relationship between the summarized risk assessment and recommended protective actions has also been found in a number of studies. Taken together, these studies show that a higher number/level of protective actions or specific protective actions are more often recommended in cases assessed as being high risk (Belfrage \& Strand, 2012; Belfrage et al., 2012a; Kropp, 2008; Storey et al., 2014). The predictive validity of IPV assessments was found to be low to moderate, which was mainly thought to be a consequence of effective protective actions preventing repeat IPV in high-risk cases (Belfrage \& Strand, 2012; Belfrage et al., 2012a; Storey et al., 2014). However, Trujillo and Ross (2008) found police officers to be biased in their summarized IPV risk assessments. They also found, in line with Robinson et al. (2016) that police officers tend to put the greatest emphasis on a small number of risk factors in their assessments. This suggests that the poor predictive accuracy might also be due to the quality of the summarized risk assessments themselves, and thus not merely a result of the effect of interventions. Some other possible reasons for the low accuracy, such as an underestimation of the risk, are also addressed in Belfrage and Strand (2012).

Moreover, it has been found that there is a relationship between the inter-rater agreement and the predictive validity of violence risk assessments (McNeil, Lam \& Binder, 2000). Clinical assessments administered by nurses at a short-term psychiatric inpatient unit were compared with assessments administered by physicians. The cases were also followed up in terms of violent behavior. The main results showed that predictive validity was higher in cases in which the nurse and the physician agreed on the level of risk. In line with these results, Kropp and Hart (2000) state the importance of a high inter-rater agreement as follows: "If raters cannot agree on the presence of individual risk factors or the implications that can be drawn from them, there is little point in conducting risk assessments" (p. 109).

According to the National Swedish Police Board (2010), inter-rater agreement and the quality of risk assessments conducted in police settings increase with the use of assessment tools, which thus creates a firmer foundation for the recommendation of protective actions across different cases. This assumption is not motivated by any results from previous studies and to our knowledge, it has not yet been tested in a police setting. However, the stability of police officers' SARA, B-SAFER and DASH (Domestic Abuse, Stalking, Harassment and Honor-Based Violence) ratings has been studied previously (Belfrage et al., 2012a; Storey et al., 2014; Sebire \& Barling, 2016). In the first two studies, the first and the second assessment in cases of repeat IPV were compared. The stability of the total score of the risk assessment was high (ICC $=.76^{2}$ in both studies) and for the global risk assessment it was fair in the first study (SARA, ICC = .45) and low in the second study (B-SAFER, ICC= .32). Both measures increased over time and the changes were statistically significant. Belfrage et al. (2012a) also measured the stability of the police officers' assessments of items related to symptoms of mental disorder (recent suicidal or homicidal ideation/intent, recent psychotic and/or manic symptoms and personality disorder with anger, impulsivity, or behavioral instability), and

2. According to Ciccetti and Sparrow (1981), a reliability coefficient between $.60-.74$ indicates the clinical significance to be good, while a coefficient in the ranges .75-1.00 indicates the clinical significance to be excellent. 
found the ICC coefficients $(.56, .68$, and .59$)$ to be of moderate size. The stability of 38 specialist investigating police officers' domestic violence risk assessments using the DASH risk assessment tool was recently examined (Sebire \& Barling, 2016). All participants assessed the risk (low, medium or high) in four cases at two different points in time. Between the two occasions, the participants were reminded of the national risk grading definitions. The consistency of the first-time risk assessments was weak (ICC $=.182, p<.05)$. The second assessments were somewhat more consistent $(\mathrm{ICC}=.283, p<.001)$. Further, 66 percent of the police officers' assessments were similar at the two occasions. Officers working in areas with a comparatively high rate of domestic violence cases more often used lower risk steps in their assessments compared to officers working in areas with a lower rate of such cases.

The current risk assessment tradition dates back to the new conception of psychopathy advanced by Hare and Schalling (1978), and the construction of a psychopathy checklist (Levander, 1979). Such a checklist was used in the 1980s (the Penetanguishene project) as part of the VRAG risk assessment instrument (Harris, Rice \& Quinsey, 1993), which outperformed contemporary actuarial risk assessment instruments with respect to predictive accuracy. Most of the follow-up work of this ground-breaking study was done in North American correctional settings, by psychologists/behavioral scientists. HCR-20 (Webster, Eaves, Douglas \& Wintrup, 1995) marks the beginning of the current generation of risk assessments, the items of which are strongly loaded with psychopathy-related personality/ behavioral factors. Used in correctional settings by properly educated and trained staff, the inter-rater reliability is impressive (around .90).

Kropp and Hart (2000), for example, compared IPV assessments (SARA; Kropp et al., 1994, 1995, 1999) conducted by staff from correctional settings with assessments conducted by a clinical psychologist. The clinical significance of the SARA total score was good to excellent (the total score, $\mathrm{ICC}=.84$, Part $1, \mathrm{ICC}=.68$ and Part $2, \mathrm{ICC}=.87$ ). The inter-rater reliability for the summary risk assessment was somewhat lower (ICC= .63). Grann and Wedin (2002) presented similar results in a study in which the SARA instrument was used in an actuarial manner by a B.A.-level psychology student and a psychology researcher. In this case, however, the intra-class correlation score for part 1 of the instrument was higher than that for part 2 (total score, ICC $=.85$, Part $1, \mathrm{ICC}=.88$ and Part 2, ICC $=.74)$. Finally, a violence risk assessment tool called the Spouse Violence Risk Assessment Inventory (SVRA-I) was recently evaluated (Dayan et al., 2013). As a part of the evaluation, the inter-rater reliability was examined, including 19 cases assessed by one investigator and two psychology graduate students per case. Assessments conducted by the students were compared both to each other and to the assessments conducted by investigators (correlations were computed). The results were fair $(r=.68, .73$ and $.75(p<.01)$.

Given these results and the police authorities' duty to prevent violence and protect victims, the use of violence risk assessment and management methods in police settings is reasonable. The fact that these methods were implemented widely in the Swedish police organization without being fully tested in this specific context may be questioned. Thus, in the present study we aim to fill this knowledge gap by examining two violence risk assessment tools used in the Swedish police, the B-SAFER and the PST-VC. The first one is the tool that is used to the greatest extent among Swedish police, and the latter differs from this and most other tools used by the police, in that it is a general tool, allows more weight for 
subjective judgements and is developed by police employees. The tools will be evaluated separately with some comparisons when possible.

The present study is based on a broader evaluation regarding the use of violence risk assessment tools in the Swedish police authority, which was conducted on behalf of the National Swedish Police Board between the years 2012 and $2014 .^{3}$ The overall aim of the evaluation was to examine police employees' use of violence risk assessment tools and particularly whether these tools can be useful in identifying high-risk cases for repeat crime, and if different assessors examine the same cases coherently. All empirical data used in this study was collected for the evaluation.

\section{AIMS}

The main aim of this study was to examine the inter-rater reliability of the Police Screening Tool for Violent Crimes (PST-VC) and the Brief Spousal Assault Form for the Evaluation of Risk (B-SAFER), as used by police employees in two different police authorities in Sweden.

\section{METHODS}

\section{I. The Police Screening Tool for Violent Crimes (PST-VC)}

The PST-VC was designed at one of Sweden's regional police authorities, and is used to assess all types of cases (e.g. intimate partner violence, honor-based violence and stalking) that are identified as high risk on the basis of the initial police report. The PST-VC is structured on the basis of a number of headings under which important risk/vulnerability and contextual factors should be noted. In order to help the assessor to choose which risk- and victim vulnerability factors to include in the assessment, there is a guideline with questions: e.g. Does the suspected offender has access to weapons? The main sources of information used by the assessor are police records, police reports and information provided by the victim. However, speaking to victims is not mandatory. The assessor decides on how to collect information in each individual case. In the second part of the assessment, a global risk assessment is conducted, based on the information collected and the assessor's experiencebased judgment (tacit knowledge, see Polanyi, 1983). The PST-VC risk scale ranges from no risk (1) to high risk (5). As a part of the risk assessment and management procedure, the assessor is required to recommend interventions ${ }^{4}$ to address the risks identified.

\subsubsection{Procedure}

Seventeen cases were evaluated by ten police employees ${ }^{5}$. The majority of these were trained police officers. Hereafter we refer to these individuals as police employees or asses-

3. The results of the evaluation are presented in five reports (Mellgren, Svalin, Levander \& Torstensson Levander, 2012, 2014a, 2014b; Mellgren, Svalin, Torstensson Levander \& Levander, 2014c; Svalin, Mellgren, Torstensson Levander \& Levander, 2014).

4. The police are responsible for the implementation of some of the protective measures that they recommend (e.g., conducting safety dialogues with victims and providing safety alarms) while others are the responsibility of other actors restraining orders are granted by prosecutors, for example. However, the primary responsibility for implementing protective measures and providing support to the victims of crime lies with the municipalities (SFS 2001:453).

5. These individuals each assessed between one and five cases. 
sors. The level of training regarding violence risk assessment and management among the assessors was overall low.

Each case was evaluated by two assessors who were paired at random and were blind to one another's assessments. All cases ${ }^{6}$ were authentic cases and had therefore been assessed previously, at the time of the initial police report, thus producing a total of 51 PST-VC assessments. In order to avoid the assessors becoming aware of, e.g. repeat victimization, they were instructed to use only information from the period prior to a specified date. Another difference in the new assessments compared to the original assessments was that the assessors did not have the possibility to collect information by speaking to victims. However, since the assessors did not list which sources of information they used, neither in the original nor in the new assessments, we do not know to which extent victims were contacted originally. But it seems that contacting victims was rare, since answers to those variables included in this study (described below) were mainly based on information found in police reports and records. Otherwise, the new assessments were conducted according to the assessors' normal assessment routines. The new assessments (Assessors 1 and 2) were compared both to each other and to the original assessment (Assessor 3).

All of the cases related to threats and/or violence (e.g. intimate partner violence, honorbased violence and gang-related violence). In five cases, more than one offender ${ }^{7}$ was involved and in one case, there was more than one victim. However, only one offender and victim per case were included in the study data (either the offender/victim first mentioned in the assessment or a key victim/offender, if identified). In all but one case, the offenders were men. ${ }^{8}$ Their ages at the time of the risk assessment varied between 15 and 64 (mean age: 29). The age of the victims varied between 17 and 98 (mean age: 32 ). Ten of the victims were men, seven were women.

\subsubsection{Variables}

The raw data of 51 PST-VC assessments were coded by the first author (KS) using SPSS (version 23). At first, nine risk- and seven victim vulnerability factors were identified for examination (see Table 1), on the basis of the PST-VC guidelines. All factors except threats and/or violence were coded as either present, absent or missing. Factors with more than 50 percent missing values were excluded from further analysis. Finally, the inter-rater agreement was examined for five offender risk factors: access to weapons, previous violence, previous offences other than violence, threats and/or violence against the victim and social problems; and for three victim vulnerability factors: fear of the offender, violence and offences other than violence.

6. The cases were selected by the police. A comparison with a larger PST-VC sample (see Mellgren, Svalin, Torstensson Levander \& Levander, 2012) showed the distribution of risk levels in the cases selected for the current study to be fairly similar. Original cases: risk level $1(n=4), 2(n=7), 3(n=4), 4(n=2), 5(n=0)$.

7. Both the PST-VC and the B-SAFER assessments were conducted prior to a possible court hearing, which means that the offenders were suspected offenders. We nonetheless refer to them as offenders in this study.

8. In one case the offender was not identified by the police. 
The offenders' previous violence and offences other than violence, as well as the victims' violence and offences other than violence were coded as present/absent based on the information from police reports included in the assessment. If neither the presence nor absence of previous offences was mentioned, the item was considered missing. In some of the cases, it was noted that the victim had been registered by the police, but not for what type of offence. In these cases, we coded "missing" on violence and "present" on offences other than violence. The offenders' previous threats and violence against the victim included both previous incidents and the current incident, which meant that threats and/or violence had occurred in all cases. We coded this item on the basis of three categories; "threats", "violence" or "threats and violence". The offenders were considered to have access to weapons if such information was mentioned in the assessment. A "no" was coded if access to weapons was not mentioned in the assessment (and police records had been searched). The item was coded as "missing" if there was no information on access to weapons in the assessment and the police records had not been searched. Offender social problems included various kinds of problems: antisocial peers, family problems and homelessness. If any of these problems were mentioned in the assessment, the factor was considered present, and vice versa; if there was information stating these factors not to be problematic, a "no" was coded. In cases which lacked any information of this kind, the item was considered missing. The same principle was applied when coding whether or not the victim feared the offender.

The risk level (1-5), and the level of recommended protective actions were also examined. For both data sets, the protective actions were divided into three categories of protective actions, on the basis of the type of action: (1) information/support (contact with a victim support agency, the social services, a police employee, forward a case to the personal security group at the police and victim information) (2) victim protective actions (contact a victim shelter, protect identity of victim, provide an alarm, safety inspection of victim's home and security and/or victim support talk with a police employee) (3) offender prevention actions (applying for a restraining order and offender dialogue with a police employee). However, not all actions were recommended by police employees in both settings. If a combination of protective actions from different categories were recommended, this was noted in the coding procedure.

In addition to the standardized information supplied to all victims, the information/ support category included contacts with different types of victim support staff or authorities. In the PST-VC sample, there was a small number of high-risk cases in which a recommendation was made for the case to be forwarded to a personal security group within the police for further investigation. This action was also classified under the heading information/support. The other two protective action categories included actions more directly focused on either the victim (e.g. safety inspection of the victim's home) or the offender (e.g. an offender dialogue with a police officer). Protective actions were recommended in all assessments, but we have no information on whether they were implemented. 
Table I. Presence of offender risk- and victim vulnerability factors in the PST-VC $(\mathrm{N}=5 \mathrm{I})$. Percent (frequency).

\begin{tabular}{|c|c|c|c|}
\hline Offender risk factors & Yes & No & Missing values \\
\hline Access to weapons & $35(18)$ & $51(26)$ & $14(7)$ \\
\hline Aggressivity & $14(7)$ & $2(1)$ & $84(43)$ \\
\hline Escalation of crime & $2(1)$ & $12(6)$ & $86(44)$ \\
\hline Previous offences (not violence) & $61(31)$ & $22(11)$ & $18(9)$ \\
\hline Previous violence & $53(27)$ & $29(15)$ & $18(9)$ \\
\hline Psychiatric problems & $4(2)$ & 0 & $96(49)$ \\
\hline Social problems & $53(27)$ & 0 & $47(24)$ \\
\hline \multirow[t]{2}{*}{ Substance abuse } & $37(19)$ & 0 & $63(32)$ \\
\hline & Violence & Threats & Violence and threats \\
\hline Violence/threats against the victim & $43(22)$ & $18(9)$ & $39(20)$ \\
\hline Victim vulnerability factors & Yes & No & Missing values \\
\hline Violence & $8(4)$ & $59(30)$ & $33(17)$ \\
\hline Offences other than violence & $37(19)$ & $31(16)$ & $31(16)$ \\
\hline Fear of the offender & $49(25)$ & $6(3)$ & $45(23)$ \\
\hline Social problems & $10(5)$ & 0 & $90(46)$ \\
\hline Social support & $6(3)$ & 0 & $94(48)$ \\
\hline Substance abuse & $14(7)$ & 0 & $86(44)$ \\
\hline Take own protective actions & $22(11)$ & $2(1)$ & $77(39)$ \\
\hline
\end{tabular}

In order to control for bias, we summed the scores of the risk- and victim vulnerability factors in all cases, and compared the means of Assessors 1, 2 and 3. All factors that were present were coded 2 , absent factors were coded 0 and missing values 1 . Due to the open structure of the PST-VC, it is not known whether a missing value in the PST-VC means that a specific item is not present in the actual case or whether it has been missed because the assessor for some other reason decided not to include it in the assessment. This was why we coded missing values with the middle option (1). The alternative proceeding was to use listwise deletion. However, due to the high rate of missing cases a large amount of the data would then have been excluded from the analyses.

\subsection{The Brief Spousal Assault Form for the Evaluation of Risk (B-SAFER)}

The B-SAFER instrument (Kropp et al., 2005, 2010) was developed (based on the SARA guidelines) for the assessment and management of IPV risk in police settings, and consists of a checklist comprising ten offender risk factors and five victim vulnerability factors (see 
Table 2). On the basis of information from multiple sources: police reports, police records and information from the victim, the offender, witnesses if any, and the victims' relatives. Each factor is assessed as either "present", "partly present", "not present" or as impossible to assess due to a "lack of information". The risk factors are assessed based on both the current situation (the last four weeks) and the background (before the last four weeks) to the cases. Case-specific factors should also be included in the assessment. Finally, all the information, together with the assessor's professional judgment, is summarized into a global risk assessment. Both the risk of severe/fatal violence, imminent/acute violence and continued violence are assessed on a three-level risk scale; "low", "medium" or "high". The second part of the assessment procedure involves the formulation of a risk management plan.

\subsubsection{Procedure}

Three police employees who had been hired to conduct violence risk assessments at a Swedish police department conducted the B-SAFER assessments. Altogether they conducted 23 pairwise B-SAFER-assessments ${ }^{9}$ of cases that were about to be evaluated in the context of their everyday work. Thus, in these cases there was an original assessment (Assessor 2) and one additional assessment (Assessor 1). All possible pairs of assessors were represented: the first pair conducted six pairwise assessments, the second pair eight, and the third pair nine assessments. The original cases had all been identified as high-risk cases by a screening procedure conducted at the time of police report. The B-SAFER risk factors were assessed both in the current situation and in terms of the background to the case, ${ }^{10}$ but as a result of a high rate of missing values in the background assessments (48-87\% in the original assessments) these were not included in further analyses.

The global risk scale used by the assessors in this study differed somewhat from the original B-SAFER manual, in terms of both the definition of risk and the nature of the scale employed; both the likelihood and the severity of IPV was assessed on a 5-point Likert scale. ${ }^{11}$ Another difference was that the police authority under study had decided that the assessors should not speak to victims prior to assessing the risk, because they did not want the assessments to be influenced by the victims. Thus, just as the new PST-VC assessments, the B-SAFER assessments were mainly based on information found in police reports and records. Further, the cases were coded according to the directions contained in the B-SAFER manual (Kropp et al., 2005, 2010): present (2), partly present (1), not present (0). In addition to these coding options, we included missing values in the analysis of percentage agreement, but not in the correlations (the analytical strategy is described in more detail below). The B-SAFER assessments $(N=46)$ were coded by the second author $(\mathrm{CM})$ using SPSS (version 23). In the same way as with the PST-VC, the means of the B-SAFER total scores were compared to control for bias.

9. The distribution of risk levels in the cases: IPV likelihood: $1(n=7), 2(n=10), 3(n=5), 4(n=1)$. IPV Severity: $1(n=3), 2(n=16), 3(n=4)$. The distribution of risk levels was compared to a larger sample of B-SAFER assessments conducted at the same police department (see Svalin, Mellgren, Levander \& Torstensson Levander, 2014). The risk levels of IPV severity were similar to the larger sample, whereas the cases in this study were assessed as having somewhat lower levels of IPV likelihood.

10. The victim vulnerability factors were only assessed in the current situation.

11. $1=$ (low risk/no threat $)-5=$ (high risk/significant threat). 
Table 2. Presence of offender risk- and victim vulnerability factors in the B-SAFER ( $N=46)$. Percent (frequency).

\begin{tabular}{|c|c|c|c|c|}
\hline & Yes & Partly present & No & Missing values \\
\hline \multicolumn{5}{|l|}{ Perpetrator risk factors } \\
\hline 1. Violent acts & $72(33)$ & $22(10)$ & $4(2)$ & $2(1)$ \\
\hline 2. Violent threats or thoughts & $52(24)$ & $15(7)$ & $28(13)$ & $4(2)$ \\
\hline 3. Escalation & $35(16)$ & $50(23)$ & $7(3)$ & $9(4)$ \\
\hline 4. Violations of court orders & 0 & 0 & $98(45)$ & $2(1)$ \\
\hline 5. Violent attitudes & $35(16)$ & $13(6)$ & $30(14)$ & $22(10)$ \\
\hline \multicolumn{5}{|l|}{ Psychosocial adjustment } \\
\hline 6. General criminality & $22(10)$ & $15(7)$ & $54(25)$ & $9(4)$ \\
\hline 7. Intimate relationship problems & $39(18)$ & $17(8)$ & $28(13)$ & $15(7)$ \\
\hline 8. Employment problems & $28(13)$ & $2(1)$ & $46(21)$ & $24(11)$ \\
\hline 9. Substance use problems & $37(17)$ & $24(11)$ & $24(11)$ & $15(7)$ \\
\hline 10. Mental health problems & $9(4)$ & $4(2)$ & $35(16)$ & $52(24)$ \\
\hline \multicolumn{5}{|l|}{ Victim vulnerability factors } \\
\hline $\begin{array}{l}\text { 11. Inconsistent behavior and/or } \\
\text { attitude toward perpetrator }\end{array}$ & $37(17)$ & $15(7)$ & $37(17)$ & $11(5)$ \\
\hline 12. Extreme fear of perpetrator & $17(8)$ & $26(12)$ & $52(24)$ & $4(2)$ \\
\hline 13. Inadequate access to resources & $7(3)$ & $17(8)$ & $63(29)$ & $13(6)$ \\
\hline 14. Unsafe living situation & $9(4)$ & $11(5)$ & $39(18)$ & $41(19)$ \\
\hline 15. Personal problems & $30(14)$ & $9(4)$ & $33(15)$ & $28(13)$ \\
\hline
\end{tabular}

Note: B-SAFER, Brief Spousal Assault Form for the Evaluation of Risk (Kropp, Hart, \& Belfrage, 2005, 2010).

\subsection{Analysis}

The pairwise assessments were compared by computing correlations (Kendall's tau, see Kendall, 1938) and percentage agreement for each risk factor, the global assessments and the recommended protective actions. The Kendall's tau was chosen as the statistical method because it is the most powerful and robust non-parametric bivariate correlation statistic (Winer, 1962). The results of the percentage agreement analysis should be interpreted with caution, since the agreement that would be expected on the basis of chance is not taken into account and the level of agreement is therefore overestimated (Hallgren, 2012). Paired sample $t$-tests were conducted in order to control for bias in both datasets ( $t$-tests are robust vs. violations of normality, Winer, 1962). We prefer to go safe because of doubts concerning whether requirements for an analysis of variance (ICC) was fulfilled. All analysis was computed in SPSS.

The study was approved by the Ethical Review Board in south Sweden. The assessors consented to participate in the study. Only the authors had access to data, which was stored in a safe. 


\section{RESULTS}

\section{I. The PST-VC}

The percentage agreement results for the PST-VC are presented in Table 3, and the correlations are presented in Table 4. The inter-rater agreement for the global risk assessments was moderate to high. Assessor 1 and Assessor 2 agreed in 59 percent of the cases (10/17). The agreement between Assessors 1 and 2 and the original assessment (Assessor 3) was even higher; here the different assessors arrived at the same risk level in 82 and 76 percent of the cases respectively (14 and 13/17). In those cases where the assessors did not agree on the global risk assessment, the size of the difference was a single risk level. In all cases but two, the assessors specified risk levels $1 / 2$ or $2 / 3$.

The level of agreement regarding previous violence and other criminal behavior varied across the assessment pairs. Compared to the other factors, the assessment pairs agreed to a relatively large extent as to whether there was information regarding previous offences (other than violence). On the other hand, there were no significant correlations with regard to this item. The evaluations of Assessors 1 and 3 and of Assessors 2 and 3 with regard to the offenders' previous violence correlated significantly ( $\tau=.67$ and .66$)$. However, in some cases one of the assessors rated previous violence to have occurred while the other assessor did not.

The level of agreement regarding threats and/or violence against the victim was equally high for all pairs. This risk factor was coded as "violence", "threats" and "violence and threats", with the current incident included. Thus, there were no missing values. Some assessors only included the most serious offence, violence, in cases of both threats and violence, which may explain the differences that were nonetheless identified.

Assessors 2 and 3 were relatively coherent in their assessments of both the offenders' social problems and the victims' fear of the offender, whereas the other assessment pairs did not agree to the same extent. It should be noted that in approximately half of the cases, the assessors agreed that there was not enough information available. For the items victims'violence and offences other than violence, we evaluated whether the assessors reported whether the victim had criminal records. All assessment pairs agreed in 53 percent of the cases $(9 / 17)$ regarding the victims' violence and in 53 and 47 percent of the cases respectively ( 9 and $8 /$ 17), regarding offences other than violence. However, the assessment pairs did not agree to the same extent as to whether there was information present on which these assessments could be based. They agreed in less than 30 percent of the cases $(0-5 / 17)$ for these two items.

Assessors 1 and 2 and Assessors 1 and 3 agreed on recommended protective actions in 59 percent of the cases (10/17). Assessors 2 and 3 agreed in 41 percent of the cases $(7 / 17)$. Both Assessor 1 and Assessor 2 recommended more protective actions than Assessor 3 (the original assessment). This can probably be explained by the limited police resources available for protective actions and differences in the level of access to information (Assessor 3 had the opportunity to contact the victim to discuss the need for protective actions).

In summary, the inter-rater agreement was moderate to high for the global risk assessments. For the offender risk factors, it was highest for previous violence (with the exception of the level of agreement between Assessors 1 and 2) and threats and/or violence against the victim. All psychosocial factors except the offenders' social problems had too many missing values to be included in the analyses. Further, the victim vulnerability factors had a high rate of missing values and for those factors that were included, the inter- 
rater agreement was low overall (with the exception of the level of agreement between Assessors 2 and 3 regarding the victim's fear of the offender). The agreement for the recommended protective actions was also low.

Table 3. Percentage agreement among the PST-VC assessments in ten police employees in a Swedish police setting (Pairs=17).

\begin{tabular}{|c|c|c|c|c|c|c|}
\hline & \multicolumn{2}{|c|}{ Assessor 1-2 } & \multicolumn{2}{|c|}{ Assessor 1-3 } & \multicolumn{2}{|c|}{ Assessor 2-3 } \\
\hline & $\begin{array}{l}\text { Percentage } \\
\text { agreement }\end{array}$ & $\begin{array}{c}\text { Percentage } \\
\text { agreement in } \\
\text { cases assessed } \\
\text { as present }\end{array}$ & $\begin{array}{l}\text { Percentage } \\
\text { agreement }\end{array}$ & $\begin{array}{c}\text { Percentage } \\
\text { agreement in } \\
\text { cases assessed } \\
\text { as present }\end{array}$ & $\begin{array}{l}\text { Percentage } \\
\text { agreement }\end{array}$ & $\begin{array}{c}\text { Percentage } \\
\text { agreement in } \\
\text { cases assessed } \\
\text { as present }\end{array}$ \\
\hline Risk level & 59 & - & 82 & - & 76 & - \\
\hline Protective actions & 59 & - & 59 & - & 41 & - \\
\hline \multicolumn{7}{|c|}{ Offender risk factors } \\
\hline Access to weapons & 59 & 24 & 59 & 24 & 65 & 18 \\
\hline Previous violence & 59 & 29 & 76 & 53 & 71 & 35 \\
\hline $\begin{array}{l}\text { Previous offences } \\
\text { (not violence) }\end{array}$ & 65 & 47 & 65 & 53 & 53 & 35 \\
\hline $\begin{array}{l}\text { Threats and/or } \\
\text { violence }\end{array}$ & 76 & - & 76 & - & 76 & - \\
\hline Social problems & 71 & 35 & 65 & 35 & 82 & 47 \\
\hline \multicolumn{7}{|c|}{ Victim vulnerability factors } \\
\hline Fear of the offender & 47 & 24 & 65 & 41 & 82 & 41 \\
\hline Violence & 53 & 0 & 53 & 0 & 53 & 12 \\
\hline $\begin{array}{l}\text { Offences other } \\
\text { than violence }\end{array}$ & 53 & 29 & 47 & 12 & 47 & 24 \\
\hline
\end{tabular}

Table 4. Kendall's tau-b for PST-VC assessments in ten police employees in a Swedish police setting (Pairs=17).

\begin{tabular}{|c|c|c|c|}
\hline & Assessor 1-2 & Assessor 1-3 & Assessor 2-3 \\
\hline & Kendall's tau-b & Kendall's tau-b & Kendall's tau-b \\
\hline Risk level & $.70^{\star * \star}$ & $.87^{\star * *}$ & $.85^{\star * *}$ \\
\hline Protective actions & $.52^{*}$ & $.43, \mathrm{~ns}$ & $.41, \mathrm{~ns}$ \\
\hline \multicolumn{4}{|l|}{ Offender risk factors } \\
\hline Access to weapons & $.41, \mathrm{~ns}$ & $.27, \mathrm{~ns}$ & $.36, \mathrm{~ns}$ \\
\hline Previous violence & $.41, \mathrm{~ns}$ & $.67^{\star *}$ & $.66^{\star *}$ \\
\hline Previous offences (not violence) & $.41, \mathrm{~ns}$ & $46, \mathrm{~ns}$ & $.14, \mathrm{~ns}$ \\
\hline Threats and/or violence & $.57^{\star}$ & $.61^{\star *}$ & $.61^{\star *}$ \\
\hline Social problems & $.42, \mathrm{~ns}$ & $.31, \mathrm{~ns}$ & $.65^{\star \star}$ \\
\hline \multicolumn{4}{|l|}{ Victim vulnerability factors } \\
\hline Fear of the offender & $.23, \mathrm{~ns}$ & $.54^{*}$ & $.75^{\star *}$ \\
\hline Violence & $.29, \mathrm{~ns}$ & $.39, \mathrm{~ns}$ & $.32, \mathrm{~ns}$ \\
\hline Offences other than violence & $.52^{\star}$ & $.38, \mathrm{~ns}$ & $.41, \mathrm{~ns}$ \\
\hline
\end{tabular}

$*_{p}<.05 . * *_{p}<.01 . * * * p<.001 . \mathrm{ns}=$ not significant. 


\subsection{The B-SAFER}

The percentage agreement results for the B-SAFER are presented in Table 5 and the correlations are presented in Table 6. Overall, the level of agreement was highest for the global assessments; agreement varied between 70 and 83 percent of the cases respectively (16 and 19/23). The correlations for both the likelihood- and the severity of risk was good $(\tau=.72$ and .69). In cases where the risk assessments differed, levels $1 / 2$ and $2 / 3$ were specified in all but one case.

The percentage agreement for offender risk factors varied between 22-96 percent, with the lowest level of agreement being found for intimate relationship problems and mental health problems and the highest for violations of court orders. This latter finding was probably due to the fact that few of the offenders had been subjected to court orders; in 96 percent of the cases $(22 / 23)$ both the assessors had rated this factor as a "no". The inter-rater agreement was satisfactory for the assessments of violent threats and thoughts and for item 3 "escalation" it was fair. No significant correlations were found in relation to either the assessments of the offenders' previous violent acts or the assessments of their violent attitudes.

The level of agreement in relation to general criminality was satisfactory and it was fair in relation to substance use problems. However, the assessors only agreed that general criminality had occurred in 13 percent of the cases (3/23) and that substance use problems existed in 22 percent of the cases (5/23).

The inter-rater agreement for the victim vulnerability factors was poor; there were no significant correlations in relation to any of these items and the percentage agreement scores were low overall. Compared to the analysis of PST-VC risk management, the level of agreement on recommended protective actions was higher in the B-SAFER risk management analysis. However, a closer examination of the pairwise assessments revealed that in a majority of the cases, information/support was the only recommended intervention.

To sum up the B-SAFER results, the inter-rater agreement for the global risk assessments were somewhat lower for the B-SAFER compared to the PST-VC. However, it was still good. The agreement for the offender risk factors was highest for violent threats and thoughts and for general criminality. Among the psychosocial adjustment items, the only significantly correlated factors were general criminality and substance use problems. The inter-rater agreement for the victim vulnerability factors was low and for the protective actions, it was fair. 
Table 5. Percentage agreement among the B-SAFER assessments in three police employees in a Swedish police setting (Pairs=23).

\begin{tabular}{|c|c|c|}
\hline & Percentage agreement & $\begin{array}{l}\text { Percentage agreement in } \\
\text { cases assessed as present }{ }^{\star}\end{array}$ \\
\hline \multicolumn{3}{|l|}{ Risk level } \\
\hline The IPV likelihood & 70 & - \\
\hline The IPV severity & 83 & - \\
\hline Protective actions & 74 & - \\
\hline \multicolumn{3}{|l|}{ Perpetrator risk factors } \\
\hline 1. Violent acts & 61 & 52 \\
\hline 2. Violent threats or thoughts & 70 & 43 \\
\hline 3. Escalation & 57 & 26 \\
\hline 4. Violations of court orders & 96 & 0 \\
\hline 5. Violent attitudes & 26 & 22 \\
\hline \multicolumn{3}{|l|}{ Psychosocial adjustment } \\
\hline 6. General criminality & 70 & 13 \\
\hline 7. Intimate relationship problems & 22 & 13 \\
\hline 8. Employment problems & 35 & 13 \\
\hline 9. Substance use problems & 43 & 22 \\
\hline 10. Mental health problems & 22 & 0 \\
\hline \multicolumn{3}{|l|}{ Victim vulnerability factors } \\
\hline $\begin{array}{l}\text { 11. Inconsistent behavior/attitude toward per- } \\
\text { petrator }\end{array}$ & 43 & 22 \\
\hline 12. Extreme fear of perpetrator & 39 & 9 \\
\hline 13. Inadequate access to resources & 43 & 0 \\
\hline 14. Unsafe living situation & 26 & 0 \\
\hline 15. Personal problems & 39 & 13 \\
\hline
\end{tabular}

B-SAFER, Brief Spousal Assault Form for the Evaluation of Risk, adapted from (Kropp, Hart, \& Belfrage, 2005, 2010). Note 2: *present= assessed according to the B-SAFER guidelines. 
Table 6. Kendall's tau-b for B-SAFER assessments in three police employees in a Swedish police setting.

\begin{tabular}{|c|c|c|}
\hline & Kendall's tau-b & Pairs \\
\hline \multicolumn{3}{|l|}{ Risk level } \\
\hline The IPV likelihood & $.72^{\star * \star}$ & 23 \\
\hline The IPV severity & $.69^{* * *}$ & 23 \\
\hline Protective actions & $.58^{\star * *}$ & 22 \\
\hline \multicolumn{3}{|l|}{ Perpetrator risk factors } \\
\hline 1. Violent acts & $.17, \mathrm{~ns}$ & 22 \\
\hline 2. Violent threats or thoughts & $.66^{* * *}$ & 21 \\
\hline 3. Escalation & $.56^{\star}$ & 19 \\
\hline 4. Violations of court orders & - & - \\
\hline 5. Violent attitudes & $.21, \mathrm{~ns}$ & 13 \\
\hline \multicolumn{3}{|l|}{ Psychosocial adjustment } \\
\hline 6. General criminality & $.71^{* * *}$ & 20 \\
\hline 7. Intimate relationship problems & $-.34, \mathrm{~ns}$ & 17 \\
\hline 8. Employment problems & $.16, \mathrm{~ns}$ & 13 \\
\hline 9. Substance use problems & $.55^{\star}$ & 16 \\
\hline 10. Mental health problems & - & - \\
\hline \multicolumn{3}{|l|}{ Victim vulnerability factors } \\
\hline $\begin{array}{l}\text { 11. Inconsistent behavior/attitude toward per- } \\
\text { petrator }\end{array}$ & $.36, \mathrm{~ns}$ & 18 \\
\hline 12. Extreme fear of perpetrator & $.12, \mathrm{~ns}$ & 21 \\
\hline 13. Inadequate access to resources & $.17, \mathrm{~ns}$ & 18 \\
\hline 14. Unsafe living situation & - & - \\
\hline 15. Personal problems & $.42, \mathrm{~ns}$ & 12 \\
\hline
\end{tabular}

$*_{\mathrm{p}}<.05 . * *_{\mathrm{p}}<.01 . * * *_{\mathrm{p}}<.001 . \mathrm{ns}=$ not significant.

Note I: B-SAFER, Brief Spousal Assault Form for the Evaluation of Risk, adapted from (Kropp, Hart, \& Belfrage, 2005, 2010). Note 2: Factor 4 was excluded due to lack of variation. Factors 10 and I 4 were excluded due to the high rate of missing values. Note 3: The number of cases for each item varies, because if an item was omitted for one of the assessors or for both, the case was excluded from the analysis.

The $t$-tests revealed no significant differences between the mean values of the total scores for the assessments, for either of the tools, which indicates that the assessors were not biased in their assessments. 


\section{DISCUSSION}

The level of inter-rater agreement varied substantially for different types of factors in both samples. Overall, the assessors agreed regarding the global assessments, particularly when the percentage agreement was examined allowing for a one-step difference in the assessments. Even though one of the tools was a general violence risk assessment tool and the other was an IPV assessment tool, the overall results were similar. Sebire and Barling (2016) on the other hand, found a low consistency in police officers' summarized risk assessments. However, it is problematic to compare the results since the tools under study were different, as were the procedures of the evaluations. There was a high rate of missing values and a low inter-rater agreement for most of the risk- and vulnerability factors, which may be explained by two different shortcomings: lack of training and lack of access to information. The overall level of training regarding violence risk assessment, management and key risk/victim vulnerability factors, was low among the assessors. Some of them had not had any training in how to assess and manage violence risk, meaning they might not even know which factors to include in the PST-VC assessment, or how to assess such factors. The latter has also been found in a previous study. Belfrage (2008) found that police officers had difficulty assessing psychiatric risk factors in IPV cases; they chose to omit risk factors rather than including information that was uncertain. One way to improve the way these instruments are used in a police setting would thus be to provide a basic education with respect to personality and mental health factors: a recommendation that is justified by the fact that male offenders who commit lethal violence on a female intimate partner suffer from a psychiatric disorder in almost 90 percent of the cases ${ }^{12}$ (Rying, 2007).

The level of omitted factors varies greatly in previous studies (from less than $1 \%$ in Storey et al. (2014) up to 39\% in Belfrage (2008)). We can only speculate on the reasons for the large differences. However, the level of omitted factors was reduced in Belfrage's (2008) study, after the assessors had received additional information on how to conduct the assessments. The assessors in the present study did not have any training related to the study, which may be one of the reasons to the large number of omitted factors in the study.

Storey, Gibas, Reeves and Hart (2011) evaluated a violence risk assessment training program for staff working in criminal justice settings, about 50 percent of whom were police officers. Overall, the results were promising, e.g. the participants' global risk assessments and recommended protective actions were more consistent with the experts' assessments when the training had been completed. They also improved their skills in identifying the presence of risk factors, and the level of agreement among the participants' assessments increased. On the negative side, the number of irrelevant risk factors included in the participants' assessments did not decrease after training and an even greater number of irrelevant protective actions were recommended in the assessments following training as compared to the situation prior to the training program.

Aas (2014) highlights whether working with cases of domestic violence should be a specialty in Norwegian police settings, due to the complexity in such cases. The findings of the present study motivate consideration of the corresponding question, regarding the work

12. The results refer to those offenders who had undergone a forensic psychiatric evaluation ( $78 \%$ of the cases). 
with violence risk assessments in Swedish police settings. Should violence risk assessment be a task for police employees in general or a specialty for a dedicated group?

The lack of access to information noted in the current study was due to both case-specific factors and to factors that were common to all of the assessors. In one case, neither the police nor the victim had been able to identify the offender and in some other cases, the offender was unknown to the victim and this limited the level of access to information. Another case-specific factor relates to the victims' participation in the legal process. The victim is a key informant in risk assessments, which means that crucial information may be lost if the victim refuses to participate. Thus, the decision not to gather information for the B-SAFER assessments by speaking to victims probably contributed to the high rate of missing values and the low inter-rater agreement found in relation to those B-SAFER factors that could not be answered by only checking the police records/reports. The same explanation could probably be applied to the PST-VC results, since victims were not involved in the new assessments and rarely, as it seems, in the original assessments. The other reason to the lack of information was related to the lack of access to information regarding psychiatric risk factors among police employees in general (see Belfrage, 2008).

The fact that the assessors did not use the structured variables in the risk assessment process leaves too much space for subjective judgements, which in previous research has shown to be associated with heuristics and biases (Tversky \& Kahneman, 1974). The researchers describe three different heuristics that people often use in doing such judgements: representativeness (comparisons with similar cases), availability (associations to instances close at hand) and adjustment and anchoring (adjustments from a starting point). Of these, primarily the first two can be linked to the violence risk assessments described in this study. For instance, the representativeness heuristic is used in classifying different cases to certain groups and the availability heuristics in assessing the probability of an event occurring. However, both representativeness and availability are affected by biases. E.g. in the use of representativeness, people seldom take the base-rate of the phenomenon under study into account and the base-rate is not related to the representativeness (called insensitivity to prior probability of outcomes by Tversky \& Kahneman [1974, p. 1124]). In the case of subjective violence risk assessments this can be exemplified by an assessor's use of his/her professional experiences regarding similar cases/situations. Thus, a case that resembles a previous high-risk case may be assessed as high risk, without taking the base-rate of such cases into account.

The availability heuristics are associated with a kind of bias called illusory correlation (Tversky \& Kahneman, 1974, p. 1128), which is described as the influence of our perceptions regarding the association between different events. If we consider two events to be closely linked, these will more often be assessed as co-occurring. In the context of violence risk assessments, illusory correlations between for instance offender or victim characteristics and the risk of repeat IPV could lead to incorrect judgements.

The fairly high reliability for the global risk assessments was most likely due to shared assumptions (heuristics, tacit knowledge) among the assessors rather than being based on the information obtained by the tools. One reason for this among the PST-VC assessors was probably that they meet occasionally to discuss and compare their risk assessments. Although one of the tools (B-SAFER) is commonly used by police forces within and out- 
side Europe the assessments seem to be flawed. Still, the actual assessments might nonetheless be relevant for risk predictions and selection of protective measures - an issue which we have not addressed in this study.

\section{I. Limitations}

A limitation of the study is that there were only three police employees conducting the BSAFER assessments. To compensate for this, they assessed a relatively large number of cases. However, the results would of course have been more robust and possible to generalize with a larger number of assessors. Furthermore, the open structure of the PST-VC complicated the coding of risk- and victim vulnerability factors. If a factor was not mentioned, we do not know whether this was because the factor did not exist in the actual case (cf. "no" in the B-SAFER), or whether it was to be considered a missing value. Thus, the rate of missing values may appear to be larger than it actually was, as may the level of percentage agreement. This high rate of missing values constitutes the main limitation associated with the study, and it made a validation of the tools impossible. Additional evaluations are therefore needed of the inter-rater agreement for various violence risk assessment tools in police settings. However, despite the limitations, the study contributes to knowledge on how violence risk assessment and management works and what might be done in order to improve the methods.

Finally, one must keep in mind that prediction of human behavior is difficult. In order to identify "true" high-risk cases, many victims will be recommended protective actions unnecessarily. Their personal integrity will be limited and the society will be burdened monetarily. To ensure the quality of future violence risk assessments and the effect of the subsequent protective actions, it is important to continue to follow up and evaluate this work.

\section{REFERENCES}

Aas, G. (2014). Familievold som et spesialfagfelt i politiet? [Domestic violence as a special area of policing?]. Nordisk politiforskning, 1(1), 58-82.

Belfrage, H. (2005). Patriark: Bedömning av risk för patriarkalt våld med hedern som motiv: Användarmanual (version 5) [Patriarch: Assessment of risk for honour based violence: User guide (version 5)]. Sundsvall: Rättspsykiatriska regionkliniken. Retrieved from: http://bit.ly/2moCZcv

Belfrage, H. (2008). Police-based structured spousal violence risk assessment: The process of developing a police version of the SARA. In A. C. Baldry \& F. W. Winkel (Eds.), Intimate partner violence prevention and intervention: The risk assessment and management approach (pp. 33-44). Hauppauge, NY: Nova Science

Belfrage, H., \& Strand, S. (2008). Structured spousal violence risk assessment: Combining risk factors and victim vulnerability factors. International Journal of Forensic Mental Health, 7(1), 39-46. doi: 10.1080/14999013.2008.9914402

Belfrage, H., \& Strand, S. (2009). Validation of the Stalking Assessment and Management checklist (SAM) in law enforcement: A prospective study of 153 cases of stalking in two Swedish police counties. International Journal of Police Science and Management, 11(1), 67-76. doi: 10.1350/ ijps.2009.11.1.110

Belfrage, H., \& Strand, S. (2012). Measuring the outcome of structured spousal violence risk assessments using the B-SAFER: Risk in relation to recidivism and intervention. Behavioral Sciences and the Law, 30(4), 420-430. doi: 10.1002/bsl.2019 
Belfrage H., Strand S., Ekman L., \& Hasselborg A-K. (2012b). Assessing risk of patriarchal violence with honour as a motive. Six years' experience using the PATRIARCH checklist. International Journal of Police Science and Management, 14(1), 20-29. doi: 10.1350/ijps.2012.14.1.250

Belfrage, H., Strand, S., Storey, J. E., Gibas, A. L., Kropp, P. R., \& Hart, S. D. (2012a). Assessment and management of risk for intimate partner violence using the Spousal Assault Risk Assessment Guide. Law and Human Behaviour, 36(1), 60-67. doi: 10.1007/s10979-011-9278-0

Dayan, K., Fox, S., \& Morag, M. (2013). Validation of spouse violence risk assessment inventory. Journal of Family Violence, 28(8), 811-821. doi: 10.1007/s10896-013-9547-4

Cicchetti, D. V., \& Sparrow, S. S. (1981). Developing criteria for establishing interrater reliability of specific items: Applications to assessment of adaptive behavior. American Journal of Mental Deficiency, 86(2), 127-137.

Grann, M., \& Wedin, I. (2002). Risk factors for recidivism among spousal assault and spousal homicide offenders. Psychology, Crime and Law, 8(1), 5-23. doi: 10.1080/10683160208401806

Hallgren, K. A. (2012). Computing inter-rater reliability for observational data: An overview and tutorial. Tutorials in Quantitative Methods for Psychology, 8(1), 23-34. doi: 10.20982/tqmp.08.1.p023

Hare, R. D., \& Schalling, D. (Eds.). (1978). Psychopathic behaviour: Approaches to research. Chichester: Wiley.

Harris, G. T., Rice, M. E., \& Quinsey, V. L. (1993). Violent recidivism of mentally disordered offenders: The development of a statistical prediction instrument. Criminal Justice and Behavior, 20(4), 315335. doi: $10.1177 / 0093854893020004001$

Kendall, M. (1938). A new measure of rank correlation. Biometrika, 30(1/2), 81-93. doi: 10.2307/ 2332226

Kropp, P. R. (2008). Development of the spousal assault risk assessment guide (SARA) and the brief spousal assault form for the evaluation of risk (B-SAFER). In A. C. Baldry \& F. W. Winkel (Eds.), Intimate partner violence prevention and intervention: The risk assessment and management approach (pp. 33-44). Hauppauge, NY: Nova Science.

Kropp, P. R., \& Hart, S. D. (2000). The spousal assault risk assessment (SARA) guide: Reliability and validity in adult male offenders. Law and Human Behavior, 24(1), 101-118. doi: 10.1023/ A:1005430904495

Kropp, P. R., \& Hart, S. D. (2004). The development of the brief spousal assault form for the evaluation of risk (B-SAFER): A tool for criminal justice professionals. Ottawa, Canada: Department of Justice. Retrieved from http://www.justice.gc.ca/eng/rp-pr/fl-lf/famil/rr05_fv1-rr05_vf1/rr05_fv1.pdf

Kropp, P. R., Hart, S. D., \& Belfrage, H. (2005). Brief spousal assault form for the evaluation of risk (B-SAFER): User manual. Vancouver, Canada: Proactive Resolutions.

Kropp, P. R., Hart, S. D., \& Belfrage, H. (2010). Brief spousal assault form for the evaluation of risk (B-SAFER): User manual (version 2). Vancouver, Canada: Proactive Resolutions.

Kropp, P. R., Hart, S. D., Webster, C. D., \& Eaves, D. (1994). Manual for the spousal assault risk assessment guide. Vancouver, Canada: British Columbia Institute on Family Violence.

Kropp, P. R., Hart, S. D., Webster, C. D., \& Eaves, D. (1995). Manual for the spousal assault risk assessment guide (2nd ed.). Vancouver, Canada: British Columbia Institute on Family Violence.

Kropp, P. R., Hart, S. D., Webster, C. D., \& Eaves, D. (1999). Spousal assault risk assessment guide (SARA). Toronto, Canada: Multi-Health Systems.

Levander, S. (1979). Psychophysiological differentiation within criminal groups: an approach to the study of psychopathy. (Unpublished doctoral dissertation). Karolinska Institutet, Sweden.

McNeil, D. E., Lam, J. N., \& Binder, R. L. (2000). Relevance of interrater agreement to violence risk assessment. Journal of Consulting and Clinical Psychology, 68(6), 1111-1115. doi: 10.1037//0022006X.68.6.1111

Mellgren, C., Svalin, K., Levander, S., \& Torstensson Levander, M. (2012). Riskbedömning $i$ polisverksamhet [Violence risk assessment in police settings]. Malmö: Holmbergs. 
Mellgren, C., Svalin, K., Levander, S., \& Torstensson Levander, M. (2014a). Skånemodellen: Beskrivning och utvärdering av ett nytt verktyg för polisiär bedömning av risk för upprepat hot och våld på individnivå [The Police Screening Tool for Violent Crimes (PST-VC): Description and evaluation of a new tool for police employees assessment of risk of repeated threats and violence].

(Rikspolisstyrelsens utvärderingsfunktion, Rapport 2014:4). Stockholm: Rikspolisstyrelsen.

Mellgren, C., Svalin, K., Levander, S., \& Torstensson Levander, M. (2014b). Riskanalys i polisverksamhet - fungerar det?: Slutrapport från ett utvärderingsprojekt [Violence risk assessment in police settings Does it work? Final report from an evaluation project]. (Rikspolisstyrelsens utvärderingsfunktion, Rapport 2014:6). Stockholm: Rikspolisstyrelsen.

Mellgren, C., Svalin, K., Torstensson Levander, M., \& Levander, S. (2014c). Riskanalys i polisverksamhet: Utvärdering av riskanalys för våld på individnivå: Check-10(+) [Violence risk assessment in police settings: An evaluation of the Check-10(+) risk assessment tool]. (Rikspolisstyrelsens utvärderingsfunktion, Rapport 2014:5). Stockholm: Rikspolisstyrelsen.

National Swedish Police Board. (2010). Riktlinjer för polisiära riskanalyser vid våld på individnivå [Guidelines for police employees assessment of risk for violence]. (Rapport 2010:8). Stockholm: Rikspolisstyrelsen.

Polanyi, M. (1983). The tacit dimension. Gloucester, MA: Peter Smith.

Robinson, A. L., Pinchevsky, G. M., \& Guthrie, J. A. (2016). A small constellation: Risk factors informing police perceptions of domestic abuse. Policing and Society, 1-16. Online before print. doi: 10.1080/ 10439463.2016.1151881

Rying, M. (2007). Utvecklingen av dödligt våld mot kvinnor i nära relationer [Lethal violence against women in intimate relationships]. (Rapport 2007:6). Stockholm: Brottsförebyggande rådet.

Sebire, J., \& Barling, H. (2016). Assessing the assessors: An analysis of the consistency of risk grading by police when conducting domestic abuse investigations. Policing, 10(4), 351-360. doi: 10.1093/police/paw012

SFS 2001:453. (2001). Socialtjänstlag [The Social Services Act]. Stockholm: Socialdepartementet.

Storey, J. E., Gibas, A. L., Reeves, K. A., \& Hart, S. D. (2011). Evaluation of a violence risk (threat) assessment training program for police and other criminal justice professionals. Criminal Justice and Behavior, 38(6), 554-564. doi: 10.1177/0093854811403123

Storey, J. E., Kropp, P. R., Hart, S. D., Belfrage, H., \& Strand, S. (2014). Assessment and management of risk for intimate partner violence by police officers using the Brief Spousal Assault Form for the Evaluation of Risk. Criminal Justice and Behavior, 41(2), 256-271. doi: 10.1177/0093854813503960

Storey, J. E., \& Strand, S. (2012a). Assessing violence risk among female IPV perpetrators: An examination of the B-SAFER. Journal of Aggression, Maltreatment \& Trauma, 22(9), 964-980. doi: 10.1080/10926771.2013.835015

Storey, J. E., \& Strand, S. (2012b). The characteristics and violence risk management of women arrested by the police for intimate partner violence. European Journal of Criminology, 9(6), 636-651. doi: $10.1177 / 1477370812453403$

Svalin, K., Mellgren, C., Levander, S., \& Torstensson Levander, M. (2014). Utvärdering av SARA:SV: Uppsalapolisens arbete med riskbedömningar för upprepade brott $i$ nära relationer [An evaluation of the SARA:SV. The Uppsala police department's work with intimate partner violence risk assessments]. (Rikspolisstyrelsens utvärderingsfunktion, Rapport 2014:6). Stockholm: Rikspolisstyrelsen.

Trujillo, M. P., \& Ross, S. (2008). Police response to domestic violence: Making decisions about risk and risk management. Journal of Interpersonal Violence, 23(4), 454-473. doi: 10.1177/0886260507312943

Tversky, A., \& Kahneman, D. (1974). Judgment under uncertainty: Heuristics and biases. Science, 185(4157), 1124-1131.

Webster, C. D., Eaves, D., Douglas, K. S., \& Wintrup, A. (1995). The HCR-20 scheme: The assessment of dangerousness and risk. Vancouver, Canada: Simon Fraser University and Forensic Psychiatric Services Commission of British Columbia.

Winer, B. J. (1962). Statistical principles in experimental design. New York, NY: McGraw Hill. 


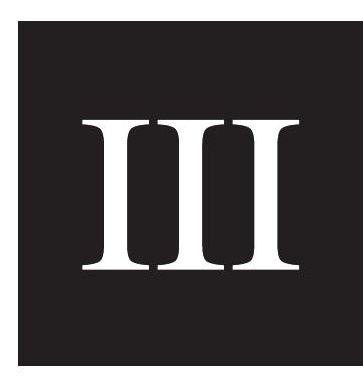





\title{
Police employees' violence risk assessments: The predictive validity of the B-SAFER and the significance of protective actions
}

\author{
Klara Svalin *, Caroline Mellgren, Marie Torstensson Levander, Sten Levander \\ Department of Criminology, Malmö University, 20506 Malmö, Sweden
}

\section{A R T I C L E I N F O}

\section{Article history:}

Received 8 August 2016

Received in revised form 4 July 2017

Accepted 5 September 2017

Available online 24 September 2017

\section{Introduction}

The first violence risk assessment tools were developed in forensic psychiatric settings and were used in order to predict future violence. In the early 1990s, a new approach to violence risk assessment was introduced known as the structured professional judgement (SPJ) approach, and a number of risk assessment tools were launched (e.g. the HCR-20, Webster, Eaves, Douglas, \& Wintrup, 1995; Webster, Douglas, Eaves, \& Hart, 1997 and the SARA, Kropp, Hart, Webster, \& Eaves, 1994, 1995, 1999). With the introduction of these new tools, risk management was introduced as a part of the risk assessment procedure and the focus shifted from violence prediction to violence prevention (Heilbrun, 2003).

During the late 1990 s/early 2000 s, the use of SPJ tools was implemented in police settings. Since then the use of such tools to assess and manage violence risk has increased among police authorities around the world. Today, the SARA guide and the B-SAFER (Kropp, Hart, \& Belfrage, 2005, 2010), both of which are employed to assess and manage the risk of intimate partner violence (IPV), are two of the most frequently used tools in police settings. These are also the most well-evaluated tools in this specific context (e.g. Belfrage, 2008; Belfrage et al., 2012; Belfrage \& Strand, 2008, 2012; Kropp, 2008; Kropp \& Hart, 2004; Storey, Kropp, Hart, Belfrage, \& Strand, 2014).

Evaluations of risk assessment and management tools are important for practical, ethical and scientific reasons (Salo, Laaksonen, \& Santtila, 2016). When evaluating violence risk assessment tools, there are primarily two important aspects that should be studied, the interrater reliability (including bias) and the predictive validity. In the

\footnotetext{
* Corresponding author.

E-mail addresses: klara.svalin@mah.se (K. Svalin), caroline.mellgren@mah.se (C. Mellgren), marie.torstensson.levander@mah.se (M.T. Levander), stenlevander@gmail.com (S. Levander).
}

present study, we will focus on the latter. However, the study of risk predictions is complicated by the fact that high risk cases are often exposed to risk reducing interventions (see for instance Belfrage, 2008). Previous studies (Belfrage et al., 2012; Belfrage \& Strand, 2012 Storey et al., 2014) have discussed recommended/initiated protective actions as possible mediators of the relationship between the global risk assessment and the outcome variable (repeat IPV), but the problem has not been fully addressed.

\subsection{The SARA and the B-SAFER}

The SARA guide was developed in forensic psychiatric settings and was revised to become the B-SAFER, in order to make it better suited to the legal context (see Belfrage, 2008Kropp, 2008). For instance, to simplify the assessment procedure the number of offender risk factors was reduced from 20 in the SARA to 10 in the B-SAFER (Belfrage, 2008). This was mainly done by merging a number of risk factors together, e.g. items 8 (recent suicidal or homicidal ideation/intent), 9 (recent psychotic and/or manic symptoms) and 10 (personality disorder with anger, impulsivity, or behavioral instability) in the SARA are all included in B-SAFER item 10 (mental disorder). However, despite the lower number of risk factors, the same amount of training is still needed to use the B-SAFER, if not more extensive training due to the comprehensiveness of the merged items (Belfrage, 2008). The revision also included an adaptation of the definitions of the B-SAFER items to better suit the legal setting and a modification of the global risk assessment into three dimensions; imminent risk, long-term risk and severity of the potential violence. Another difference between the SARA and the B-SAFER (version 2), is that the latter includes victim vulnerability factors. Ideally the assessments should be based on information from police registers and interviews with the suspected offender, the victim, his/her relatives and/or witnesses (if any). All factors (in both tools) are 
assessed as either present (coded as 2), partly present (coded as 1) or absent (coded as 0 ). Factors that cannot be assessed due to lack of information are marked with "- -". When all factors have been assessed and case -specific factors have been reviewed, a global risk assessment and a risk management plan are formulated. A number of studies conducted in police settings have found positive and significant associations between the number of risk factors or the total score of the risk factors, or the values of specific risk factors, and the global risk assessment, for both the B-SAFER (Belfrage \& Strand, 2008, 2012; Kropp \& Hart, 2004; Storey et al., 2014; Storey \& Strand, 2012a) and the SARA (Belfrage, 2008; Belfrage et al., 2012).

\subsection{The accuracy of police officers' B-SAFER and SARA assessments}

The predictive validity of police officers' B-SAFER and SARA assessments has to date been evaluated in three studies (Belfrage et al., 2012; Belfrage \& Strand, 2012; Storey et al., 2014). In the first two, the SARA guide was evaluated and in the latter, the B-SAFER guide was examined. All were conducted in Swedish police settings.

Belfrage et al. (2012) and Storey et al. (2014) examined the same hypothesis, namely: The police officers' risk assessments will 1) be positively associated with recommended protective actions and 2 ) predict recidivism. Furthermore, the recommended protective actions will 3) mediate the association between risk management and recidivism. However, the influence of the recommended protective actions on recidivism was assumed to vary depending on the level of risk, in line with Andrews and Bonta's (2010) RNR model of correctional assessment and treatment.

In both studies, the data consisted of IPV risk assessments and their associated recommended protective actions, IPV recidivism reported to the police (involving the same offender and victim) and subsequent risk assessments and their related recommended protective actions. The follow-up time regarding repeat IPV, risk assessments and additional recommended protective actions was 18 months from the initial police response in Belfrage et al. (2012) and eleven months from the initial police contact in Storey et al. (2014). The studies included all risk assessments involving suspected male offenders aged 18 and over that were conducted during a specific period of time. The SARA sample consisted of 429 cases and the B-SAFER sample of 249. The rates of repeat IPV were 21\% (Belfrage et al., 2012) and 24\% (Storey et al., 2014) respectively.

The first hypothesis was supported in both studies; i.e. global risk assessments and total scores were positively associated with the total number of recommended protective actions. Further, risk assessments and IPV recidivism were associated in both studies, which thereby also confirmed the second hypothesis. However, the strength of the associations varied for the different measures of risk assessment (global risk assessment and total score) for both tools.

The SARA total score, the number of recommended protective actions and the interaction between these two, were all found to significantly predict IPV recidivism (Belfrage et al., 2012). In order to examine the RNR model, the SARA total score and the number of recommended protective actions were dichotomized. The rate of repeat IPV was lower in the high risk group with a high number of protective actions, compared to the high risk group with a low number of protective actions, and the reverse was found among the low risk cases. Thus, the RNR approach was supported. Finally, a Sobel test (Sobel, 1982) was conducted, which confirmed that the number of recommended protective actions mediated the association between the SARA total score and repeat IPV.

Storey et al. (2014) dichotomized both measures of risk assessment (global risk assessment and total score) and the number of recommended protective actions, in order to compare the results of the test of the third hypothesis with findings from Belfrage et al. (2012). The global risk assessment and the B-SAFER total score were found to significantly predict IPV recidivism. The number of recommended protective actions, on the other hand, did not. The predictive accuracy of the interaction between risk assessment and protective actions for IPV recidivism varied; the B-SAFER total score and the protective actions did not predict IPV recidivism significantly, whereas the B-SAFER global risk assessment and the protective actions did, although the relationship was weak. The results of the examination of the RNR model showed similar patterns to those reported by Belfrage et al. (2012). The mediating analysis, on the other hand, did not replicate their findings, i.e. there was no mediating effect of the recommended protective actions on the association between risk assessment and IPV recidivism.

To summarize then, risk assessment predicted the number of recommended protective actions and IPV recidivism. At the same time an interaction effect was observed in both studies between risk assessment (total score in Belfrage et al., 2012 and global risk assessment in Storey et al. (2014)) and the number of recommended protective actions, in relation to IPV recidivism. Additionally, Belfrage et al. (2012) found the number of recommended protective actions to predict IPV recidivism and to mediate the association between risk assessment and IPV recidivism. None of these results, however, were replicated by Storey et al. (2014). In both studies, it was concluded that the tools were useful for the assessment and management of IPV in police settings. In addition, Belfrage et al. (2012) stated that the SARA was an effective tool for preventing repeat IPV. Storey et al. (2014), however, concluded that the B-SAFER tool was in some ways better suited to this specific context than the SARA. For instance, there was a lower rate of missing values for individual risk factors and a stronger association between global risk assessments and IPV recidivism.

Belfrage and Strand (2012) examined similar questions to those considered in the studies described above. The aim was to examine the predictive validity of the B-SAFER and to discuss how to interpret the results with respect to the accuracy issue. The data consisted of all B-SAFER risk assessments conducted with male offenders over the course of a specific period of time (ranging over 20 months, $N=216$ ). In cases where more than one B-SAFER assessment had been conducted during the specified time period, the first assessment was included in the sample. Compared to the studies described above, the follow-up time was significantly longer (28-48 months) and in addition to information regarding IPV recidivism, this study also included information on sentences and implemented (i.e. not only recommended) protective actions.

The protective actions were dichotomized according to the type of action. For one third (32\%) of the cases, a low level of protective actions was implemented, for the remaining cases a high level. The global risk assessments (imminent and acute violence risk) were positively correlated with the level of protective actions.

The overall rate of repeat IPV was $42 \%$, i.e. approximately twice as high as in the studies described earlier (Belfrage et al., 2012; Storey et al., 2014). In order to examine predictive validity, the study compared the rates of repeat IPV in the different risk groups (low, medium, high). No significant differences were found with regard to either imminent/ acute- or severe/fatal violence. However, when only repeat IPV cases were included in the analysis, significant differences were found with regard to severe/fatal violence; the higher the assessed risk, the lower was the rate of repeat IPV. These differences were assumed to be due to the implementation of effective protective actions in the most severe cases. Further, the overall high rate of repeat IPV in the population was assumed to be due to: 1) the geographical area under study, which is described as an area with a relatively high level of social problems, 2) the level of implemented protective actions, which is said to be generally low, and 3) the B-SAFER, which is assumed to underestimate the global risk. The same conclusion (as in the previously cited studies) was drawn with respect to the usefulness of the tool in police settings, but the authors emphasized the need for further studies.

Previous studies have also identified some weaknesses associated with the use of violence risk assessment and management tools in police settings. An Australian study examined the predictive effect of 
the most important factors in a violence risk assessment tool called the Family Violence Risk Assessment and Management Report (L17A. In addition, information from the Family Incident Report (L17) and the Standard Incident Report (L1) was used) on global risk assessments (Trujillo \& Ross, 2008). The results showed that more than half of the variance in the assessments was explained by factors other than those included in the analysis. This problem was also highlighted in another study, which evaluated police officers' use of the SARA guide (Belfrage, 2008). The results showed high rates of missing values, especially regarding factors related to the offenders' mental health status. This finding was explained as being due to the police officers' limited access to information regarding psychiatric risk factors and their lack of training in psychiatry. Thus, previous findings indicate that the tools include factors that, for various reasons, are not included in police officers' global risk assessments and also that global risk assessments are based on factors other than those included in the tool to a relatively large extent. In line with these findings, a recent study found the predictive validity of police officers L17 assessments to be poor (McEwan, Bateson, \& Strand, 2017). These findings highlight the importance of further studies of the validity of police officers' violence risk assessments.

\subsection{Aims}

The aim of the current study was to examine to what extent the riskand victim vulnerability factors in the B-SAFER predicted the global risk assessments, and to evaluate the predictive accuracy of both the individual B-SAFER factors and the global risk assessments with regard to repeat IPV. The aim was also to study to what extent recommended protective actions were implemented, an issue that has only rarely been addressed in previous studies, and to examine the preventive effect of the implemented protective actions on repeat IPV.

\section{Method}

\subsection{Population and drop-outs}

The data consists of all B-SAFER assessments conducted at a Swedish police department from March 2011 until December 2012. However, due to a lack of information, 20 assessments were excluded; in 11 of these cases, none of the B-SAFER risk- and victim vulnerability factors had been assessed and in nine other cases, there was insufficient information (for example, cases where the victim is said to be a man, but where the reported repeat IPV is "violation of a woman's integrity") regarding repeat victimization at Time 1,2 or 3 (we followed- up a maximum of three occasions of re-victimization (Time 1-3). This will be described further in the method sections). Thus, 301 assessments were finally included, of which 114 were conducted in year 2011 and 185 in 2012. In two cases, information regarding whether the assessment was conducted in 2011 or 2012 was lacking. All cases had been identified as high risk cases by a screening procedure conducted at the time of the police report (by the person who received the police report), and had therefore been evaluated with the B-SAFER.

The population consisted of 288 female victims and 11 male victims. Among the female victims, there were 285 male offenders, two female offenders and in one case, information regarding the sex of the offender was missing. Among the male victims, there were nine female offenders and two male offenders. In two cases the sex of both the offender and the victim was missing. The age of the victims ranged between 16 and 69 years, while the mean age was 37 . In three cases, information regarding the victim's age was missing. The age of the offenders ranged between 18 and 77 years, with a mean age of 41 . Information regarding the offender's age was missing in six cases.

\subsection{Procedure and data}

Three police employees, who carried out risk assessments in their daily work, conducted the B-SAFER assessments. In this study, we used the three main parts of the assessments: 1) the risk- and victim vulnerability factors, 2) the global risk assessments and 3) the recommended protective actions. An important difference in the way the B-SAFER was used in the current study was that the assessors did not gather information for the assessments by speaking to victims, meaning the assessments mainly were based on police reports and records. This decision was based on the assessors' preference to conduct assessments independently of the victims' stories, to avoid being influenced by a story that may be biased.

The raters assessed the risk- and victim vulnerability factors in line with the B-SAFER manual: present (2), partly present (1) and not present $(0)$ (the numerical coding was conducted by the research team). All factors that were not assessed with any of these options were considered as missing. Further, the global risk assessments in this study were measured in a way different to that described in the B-SAFER instructions. The police employees assessed the likelihoodand the severity of repeat IPV on a five-point Likert scale $(1=$ low risk/no threat $-5=$ high risk/significant threat).

In order to examine the significance of IPV protective actions, the study included information on both recommended and implemented protective actions. The recommended protective actions were reported in the risk assessments, and thus relate only to the time prior to the first possible re-victimization (Time 1). Information on implemented protective actions, on the other hand, is more comprehensive. It includes protective measures undertaken after the risk assessment (Time 1), the first re-victimization (Time 2) and the second revictimization (Time 3) (see Fig. 1).

Seven different protective actions were used by the police employees to prevent re-victimization; victim shelter, safety inspection of victim's home, security talk with a police employee, offender dialogue with a police employee, alarm, victim identity protection and restraining order. It is reasonable to assume that the majority of the victims were also the subject of some form of information-oriented protective measures, such as the provision of contact information to victim support agencies. However, protective measures of this kind were not reported in a majority of the cases. This is probably because information on victim support is routinely communicated in more or less all cases. Because of these presumed deficiencies in reporting, we chose not to include information-oriented protective actions in the analysis. In cases involving children under the age of 18 , it is mandatory for the police to contact the social services. However, we chose not to include this intervention as a protective measure, since it is not primarily focused on protecting the victim.

In addition to the B-SAFER assessments and the implemented protective actions, we retrieved information from the police registers regarding repeat victimization, which was defined as all kinds of police reported crime towards the same victim. The follow-up time ranged from the date of the risk assessment until October 2013, i.e. 1032 months, with up to three repeat IPV offences included (Time 1-3).

\subsection{Statistics}

A number of different statistical analyses were conducted to answer the aims of the study. Initially, the relationships between the riskvictim vulnerability factors and the global risk assessments were computed by bivariate correlations.

Linear regression analyses were conducted thereafter, to evaluate the predictive validity of the risk- and victim vulnerability factors (both in the current and in the past situation) with regard to repeat IPV/violence. However, due to the high rate of missing values, we started by replacing missing vales with the modal value for each item (i.e. the most common value: 0,1 or 2 ). For items with a higher rate of 


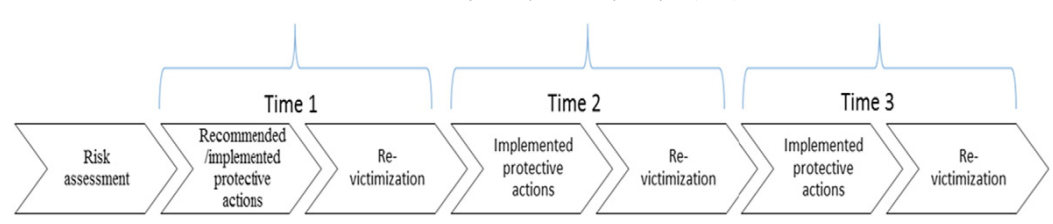

Fig. 1. Follow-up data. The follow-up data were collected at three different points of time.

missing values than one third, or items that lacked clear modal values (current situation: item 10, past situation: items 3, 5, 7 and 9), new values were estimated using stepwise linear regression analyses. The rate of missing values on items 8 and 10 (past situation) was too high for these items to be included in further analysis, but all other items (current and past situation) were included. Risk/victim vulnerability factors with replaced values for missing items were used as predictors and the outcome variable was the actual factor whose missing values were going to be replaced. Predictive values obtained from the analysis were saved and used to determine which new replacement values would be employed. The same distribution of 0,1 and 2 was used as far as possible.

In order to examine the predictive accuracy of the B-SAFER items on the global risk assessments (likelihood and severity), we conducted linear regressions using the stepwise and enter methods both for the risk factors in the past together with the victim vulnerability factors and for the risk factors in the current situation together with the victim vulnerability factors.

The predictive validity with regard to repeat IPV/violence was examined in several ways. The accuracy of the B-SAFER risk/victim vulnerability factors was evaluated by means of independent samples $t$-tests, and the global risk assessments by means of bivariate correlations and ROC-analyses. The outcome of the ROC-analysis is measured as the area under the curve of the receiver operating characteristics (AUC of ROC) and illustrates the balance between the sensitivity and the specificity of the model (Hajian-Tilaki, 2013). ROC-analyses were also conducted using predictive values as test variables, with these being obtained by means of linear regression analyses. Stepwise- and enter linear regression models were specified to examine to what extent B-SAFER items (risk- and victim vulnerability factors in the current/past situation) predicted repeat IPV/violence. These predictive values were used in the ROC-analyses.

Finally, stepwise logistic regression and Cox regression analyses were computed to examine the predictive effect of the implemented protective actions on repeat IPV/violence.

\subsection{Ethical considerations}

The study was approved by the Ethical Review Board in South Sweden.

\section{Results}

The presence of offender risk- and victim vulnerability factors in the B-SAFER is presented in Table 1. Overall, there was a high rate of missing values in the assessments. The highest rate was found for the offender risk factors in the past (14-52\%). Risk factor 10, mental health problems, was the single factor with the highest rate of missing values (39\% in the current situation and $52 \%$ in the past). The rate of missing values for the victim vulnerability factors ranged between 7 and $33 \%$.

Table 1

Presence of offender risk- and victim vulnerability factors in the B-SAFER $(N=301)$. Frequency (percent)

\begin{tabular}{|c|c|c|c|c|c|}
\hline Risk- and victim vulnerability factors & & Yes & Partly present & No & Missing values \\
\hline \multicolumn{6}{|l|}{ Perpetrator risk factors } \\
\hline \multirow[t]{2}{*}{ 1. Violent acts } & Currently & $201(66.8)$ & $51(16.9)$ & $47(15.6)$ & $2(0.7)$ \\
\hline & Past & $187(62.1)$ & $30(10.0)$ & $43(14.3)$ & $41(13.6)$ \\
\hline \multirow[t]{2}{*}{ 2.Violent threats or thoughts } & Currently & $164(54.5)$ & $42(14.0)$ & $80(26.6)$ & $15(5.0)$ \\
\hline & Past & $132(43.9)$ & $24(8.0)$ & $63(20.9)$ & $82(27.2)$ \\
\hline \multirow[t]{2}{*}{ 3. Escalation } & Currently & $64(21.3)$ & $118(39.2)$ & $96(31.9)$ & $23(7.6)$ \\
\hline & Past & $24(8.0)$ & $85(28.2)$ & $85(28.2)$ & $107(35.5)$ \\
\hline \multirow[t]{2}{*}{ 4. Violations of court orders } & Currently & $9(3.0)$ & 0 & $283(94.0)$ & $9(3.0)$ \\
\hline & Past & $14(4.7)$ & 0 & $219(72.8)$ & $68(22.6)$ \\
\hline \multirow[t]{2}{*}{ 5. Violent attitudes } & Currently & $69(22.9)$ & $39(13.0)$ & $147(48.8)$ & $46(15.3)$ \\
\hline & Past & $32(10.6)$ & $21(7.0)$ & $138(45.8)$ & $110(36.5)$ \\
\hline \multicolumn{6}{|l|}{ Psychosocial adjustment } \\
\hline \multirow[t]{2}{*}{ 6. General criminality } & Currently & $76(25.2)$ & $23(7.6)$ & $184(61.1)$ & $18(6.0)$ \\
\hline & Past & $65(21.6)$ & $18(6.0)$ & $142(47.2)$ & $76(25.2)$ \\
\hline \multirow{2}{*}{ 7. Intimate relationship problems } & Currently & $65(21.6)$ & $43(14.3)$ & $145(48.2)$ & $48(15.9)$ \\
\hline & Past & $35(11.6)$ & $21(7.0)$ & $123(40.9)$ & $122(40.5)$ \\
\hline \multirow[t]{2}{*}{ 8. Employment problems } & Currently & $49(16.3)$ & $11(3.7)$ & $150(49.8)$ & $91(30.2)$ \\
\hline & Past & $21(7.0)$ & $9(3.0)$ & $125(41.5)$ & $146(48.5)$ \\
\hline \multirow[t]{2}{*}{ 9. Substance use problems } & Currently & $133(44.2)$ & $28(9.3)$ & $74(24.6)$ & $66(21.9)$ \\
\hline & Past & $96(31.9)$ & $22(7.3)$ & $61(20.3)$ & $122(40.5)$ \\
\hline \multirow[t]{2}{*}{ 10. Mental health problems } & Currently & $32(10.6)$ & $24(8.0)$ & $127(42.2)$ & $118(39.2)$ \\
\hline & Past & $18(6.0)$ & $14(4.7)$ & $114(37.9)$ & $155(51.5)$ \\
\hline \multicolumn{6}{|l|}{ Victim vulnerability factors } \\
\hline 11. Inconsistent behavior and/or attitude towards perpetrator & Currently & $48(15.9)$ & $43(14.3)$ & $160(53.2)$ & $50(16.6)$ \\
\hline 12. Extreme fear of perpetrator & Currently & $63(20.9)$ & $79(26.2)$ & $138(45.8)$ & $21(7.0)$ \\
\hline 13. Inadequate access to resources & Currently & $31(10.3)$ & $61(20.3)$ & $176(58.5)$ & $33(11.0)$ \\
\hline 14. Unsafe living situation & Currently & $84(27.9)$ & $38(12.6)$ & $95(31.6)$ & $84(27.9)$ \\
\hline 15. Personal problems & Currently & $60(19.9)$ & $26(8.6)$ & $116(38.5)$ & $99(32.9)$ \\
\hline
\end{tabular}


In all but 26 cases (9\%), global risk assessments had been conducted. Most of the cases were assessed as corresponding to risk levels 2 and 3 , both with regard to the likelihood of IPV (risk level $2=43 \%$, risk level $3=30 \%$ ) and the level of severity (risk level $2=56 \%$, risk level $3=27 \%$ ). In $15 \%$ of the cases, the likelihood of repeat IPV was assessed to be low (risk level 1) and in 4\% to be high (risk level 4). The severity of violence were assessed as low (risk level 1) in $8 \%$ of the cases and high (risk level 4 ) in $0.3 \%$ of the cases. None of the cases were ascribed risk level 5 with regard to either the likelihood or the severity of repeat IPV. The summed total score of the offender risk factors (current situation) and the victim vulnerability factors ranged between 1 and 25 , with a median value of 9

Because of the restricted range associated with the use of risk levels, both regarding IPV likelihood and severity, we merged the cases into two risk groups (risk level 1 and $2=$ low risk, risk level 3 and $4=$ high risk). The likelihood/severity of repeat IPV was assessed to be low in $58 \% / 64 \%$ of the cases and high in $34 \% / 28 \%$ of the cases. Global risk assessments were missing in $9 \%$ of the cases.

3.1. To what extent did the raters use the risk- and victim vulnerability factors in the global risk assessments?

In order to examine the significance of the risk- and victim vulnerability factors in the B-SAFER, we evaluated 1) whether there was a relationship between each factor and the global risk assessments and 2 ) the predictive accuracy of the risk- and victim vulnerability factors with regard to the global risk assessments.

Most of the factors correlated significantly both with the likelihood of repeat IPV and with the severity of repeat IPV, although the relationships were rather weak overall (see Table 2 ). The single risk factor with the strongest relationship to the severity of repeat IPV in the current and past situation was risk factor 6 , general criminality. This factor also

Table 2

Correlations between offender risk-, victim vulnerability factors and global risk assessment (low/high)

\begin{tabular}{|c|c|c|c|c|}
\hline \multirow{2}{*}{$\begin{array}{l}\text { Risk- and victim } \\
\text { vulnerability factors } \\
\text { Perpetrator risk factors }\end{array}$} & & \multirow[b]{2}{*}{$\mathrm{n}^{\mathrm{a}}$} & \multicolumn{2}{|c|}{$\begin{array}{l}\begin{array}{l}\text { Correlation } \\
\text { (Kendall's tau-b) }\end{array} \\
\end{array}$} \\
\hline & & & Likelihood & Severity \\
\hline \multirow[t]{2}{*}{ 1. Violent acts } & Currently & 273 & $0.20^{* * *}$ & $0.15^{*}$ \\
\hline & Past & 239 & $0.25^{* * *}$ & $0.25^{* * *}$ \\
\hline \multirow[t]{2}{*}{ 2. Violent threats or thoughts } & Currently & 265 & $0.20^{* * *}$ & $0.26^{* * *}$ \\
\hline & Past & 204 & $0.26^{* * *}$ & $0.25^{* * *}$ \\
\hline \multirow[t]{2}{*}{ 3. Escalation } & Currently & 259 & $0.16^{* *}$ & $0.20^{* * *}$ \\
\hline & Past & 181 & $0.20^{* *}$ & $0.23^{* * *}$ \\
\hline \multirow[t]{2}{*}{ 4. Violations of court orders } & Currently & 267 & $0.16^{* *}$ & $0.15^{*}$ \\
\hline & Past & 215 & $0.21^{* *}$ & $0.15^{*}$ \\
\hline \multirow{2}{*}{ 5. Violent attitudes } & Currently & 235 & $0.23^{* * *}$ & $0.15^{*}$ \\
\hline & Past & 179 & $0.20^{* *}$ & $0.08 \mathrm{~ns}$ \\
\hline \multicolumn{5}{|l|}{ Psychosocial adjustment } \\
\hline \multirow[t]{2}{*}{ 6. General criminality } & Currently & 262 & $0.34^{* * *}$ & $0.30^{* * *}$ \\
\hline & Past & 208 & $0.35^{* * *}$ & $0.30^{* * *}$ \\
\hline \multirow{2}{*}{ 7. Intimate relationship problems } & Currently & 233 & $0.31^{* * *}$ & $0.24^{* * *}$ \\
\hline & Past & 170 & $0.36^{* * *}$ & $0.26^{* * *}$ \\
\hline \multirow[t]{2}{*}{ 8. Employment problems } & Currently & 197 & $0.28^{* * *}$ & $0.23^{* * *}$ \\
\hline & Past & 147 & $0.30^{* * *}$ & $0.26^{* * *}$ \\
\hline \multirow[t]{2}{*}{ 9. Substance use problems } & Currently & 220 & $0.26^{* * *}$ & $0.23^{* * *}$ \\
\hline & Past & 171 & $0.25^{* * *}$ & $0.25^{* * *}$ \\
\hline \multirow{2}{*}{ 10. Mental health problems } & Currently & 173 & $0.25^{* * *}$ & $0.18^{*}$ \\
\hline & Past & 140 & $0.26^{* * *}$ & $0.18^{*}$ \\
\hline \multicolumn{5}{|l|}{ Victim vulnerability factors } \\
\hline $\begin{array}{l}\text { 11. Inconsistent behavior and/or } \\
\text { attitude towards perpetrator }\end{array}$ & Currently & 232 & $0.02 \mathrm{~ns}$ & $-0.07 \mathrm{~ns}$ \\
\hline 12. Extreme fear of perpetrator & Currently & 260 & $0.25^{* * *}$ & $0.20^{* * *}$ \\
\hline 13. Inadequate access to resources & Currently & 248 & $0.20^{* * *}$ & $0.09 \mathrm{~ns}$ \\
\hline 14. Unsafe living situation & Currently & 204 & $0.31^{* * *}$ & $0.12 \mathrm{~ns}$ \\
\hline 15. Personal problems & Currently & 190 & $0.15^{*}$ & $0.01 \mathrm{~ns}$ \\
\hline
\end{tabular}

${ }^{a} \mathrm{n}$ was the same for likelihood and severity for each risk/victim vulnerability factor. presented the strongest correlation with the likelihood of repeat IPV in the current situation. Risk factor 7, intimate relationship problems, correlated most strongly with the likelihood of repeat IPV in the past situation. Bivariate correlations between each B-SAFER factor and the global risk assessments were also conducted using factors with replaced missing values. No significant differences were found by comparison with the results presented in Table 2 . Hereafter, all analyses were based on data with replaced missing values.

The stepwise regressions in which we tested the predictive accuracy of the risk factors in the past/victim vulnerability factors (outcome likelihood and severity) and the risk factors in the current situation/ victim vulnerability factors (outcome severity) resulted in a mode in which 4 out of 15 items were included. The stepwise regression that tested the predictive accuracy of the risk factors in the current situation/victim vulnerability factors on the likelihood of repeat IPV, produced similar results, with 6 out of 15 items being included. The shared variance in all regressions (enter- and stepwise models, past and current items, both outcomes) varied between 0.14 and 0.26 ; i.e. approximately $75-85 \%$ of the shared variance could not be explained by the B-SAFER items.

3.2. To what extent did the risk/victim vulnerability factors predict repeat IPV?

In 93 cases (31\%), repeat IPV occurred at least once. In some cases, the offenders committed more than one offense on the same occasion. In total, the repeat victimization (at Time 1) consisted of 114 offences (in two cases information regarding number of offences was missing, and for these cases we tallied one offense per case).

The different types of repeat IPV committed at Time 1 were categorized into two groups; violent offences and other offences. The following types of repeat violent offences were committed at Time 1: lethal violence, physical abuse, rape, molestation, gross violation of a woman's integrity, unlawful coercion, interference in a judicial matter, unlawful appropriation, and unlawful persecution. Repeat offences other than violence reported at Time 1 were: unlawful threat, theft, illegal encroachment, fraud, damage, false incrimination, embezzlement, defamation, violation of a restraining order and arbitrary handling of a child. $60 \%$ of the repeat offences (at Time 1) consisted of violent crimes, $34 \%$ consisted of offences other than violence and in $5 \%$ of the cases (five cases), information regarding the type of offense was missing. In the following repeat IPV/ repeat victimization/IPV recidivism includes all kinds of repeat crimes (violent offences and other offences), whereas repeat violence only includes violent offences. Both categories with the same offenders towards the same victims, committed at Time 1 (if nothing else is specified).

The results of the $t$-tests showed that the mean values of the risk/ victim vulnerability factors differed significantly between, the nonrepeat IPV group and the repeat IPV group with regard to one of the items in the B-SAFER, risk factor 9 (substance use problems, in the current situation). The mean values of risk factor 9 (current and past situation) also differed significantly between the non-repeat violence group and the repeat violence group. The same applied to victim vulnerability factor 11 (inconsistent behavior and/or attitude towards perpetrator) and 15 (personal problems).

\subsection{To what extent did the global assessments predict repeat IPV?}

The likelihood of IPV was significantly correlated with repeat IPV, although the association was weak $(\tau=0.13, p<0.05)$. IPV severity, on the other hand, was not significantly related to repeat IPV. The same applied to the results regarding the associations between the global risk assessment measures and repeat violence; no significant relationships were found.

The AUC values for the likelihood and severity of repeat IPV were similar (repeat IPV: AUC 0.57 and 0.55 , respectively and repeat violence: 
Table 3

Recommended and implemented protective actions at Time 1 .

\begin{tabular}{|c|c|c|}
\hline & $\begin{array}{l}\text { Recommended } \\
\text { protective actions }^{a}\end{array}$ & $\begin{array}{l}\text { Implemented } \\
\text { protective actions } s^{\mathrm{b}}\end{array}$ \\
\hline Victim shelter & $10(3.3)$ & $9(3.0)$ \\
\hline Safety inspection of victims home & $66(21.9)$ & $15(5.0)$ \\
\hline Security talk with a police employee & $76(25.2)$ & $33(11.0)$ \\
\hline $\begin{array}{l}\text { Offender dialogue with a police } \\
\text { employee }\end{array}$ & $9(3.0)$ & $3(1.0)$ \\
\hline Providing an alarm & $2(0.7)$ & $1(0.3)$ \\
\hline Protect identity of victim & $12(4.0)$ & $3(1.0)$ \\
\hline Restraining order & $82(27.2)$ & $37(12.3)$ \\
\hline
\end{tabular}

Note.

a In the parenthesis: percent recommended protective actions of total number of cases. ${ }^{\mathrm{b}}$ In the parenthesis: percent implemented protective actions of total number of cases. Some of the implemented protective actions were not recommended prior to their implementation.

AUC 0.54 and 0.50 , respectively), i.e. the global risk assessments were not much better predictors of repeat IPV and repeat violence than chance. For all but two of the test variables that were based on predictive values, the predictive accuracy was similar and somewhat higher (repeat IPV: AUC 0.51-0.63 and repeat violence: AUC 0.51-0.67). The two test variables that differed from the others predicted repeat violence with an AUC of just over 0.70 ( 0.71 and 0.73 ). Both these variables were based on predictive values from enter models with repeat violence as the outcome variable. Test variables were 1) risk factors in the current situation and victim vulnerability factors and 2) risk factors in the past situation and victim vulnerability factors. By performing split-half analyses on randomly selected cases and obtaining almost identical AUCs, we found that it was unlikely that these rather high AUCs were statistical artefacts.

\subsection{To what extent were the recommended protective actions implemented?}

The number of recommended protective actions contained in the risk assessments was generally small (see Table 3 ). The most frequently recommended protective action was a restraining order, which was recommended in $27 \%$ of the cases. The assessors recommended a security talk with a police employee or a safety inspection of the victim's home slightly less often. All of the other protective actions, i.e. victim shelter, offender dialogue with a police employee, alarm and victim identity protection, were recommended in $<5 \%$ of the cases.

In $70(23 \%)$ of the 301 cases, at least one protective action was implemented at Time 1 and thus no protective actions were implemented in 231 cases $(77 \%)$. In 152 of these cases in which no protective actions had been implemented, the risk assessment included no recommendations for risk reducing measures, while in the remaining 79 cases, one to four protective actions had been recommended.

In 16 of these 70 cases in which at least one protective action had been implemented at Time 1 , no risk reducing interventions had been recommended in the assessment. In 19 cases, the exact same preventive measure(s) that had been recommended were later implemented, and in five of these 19 cases, at least one further intervention was also implemented in addition to the recommended measures. In 23 cases, one or a few of the recommended protective actions were implemented. In 17 of these 23 cases, no additional protective measures were implemented, while in the remaining six cases, at least one additional action was implemented. Finally, in 12 cases, other protective measures than those recommended in the assessment were implemented.

In order to study whether there were any patterns in the distribution of protective actions in relation to repeat victimization, we produced a flowchart (see Fig. 2). The rate of repeat IPV (at Time 1) was higher among cases in which at least one protective action had been

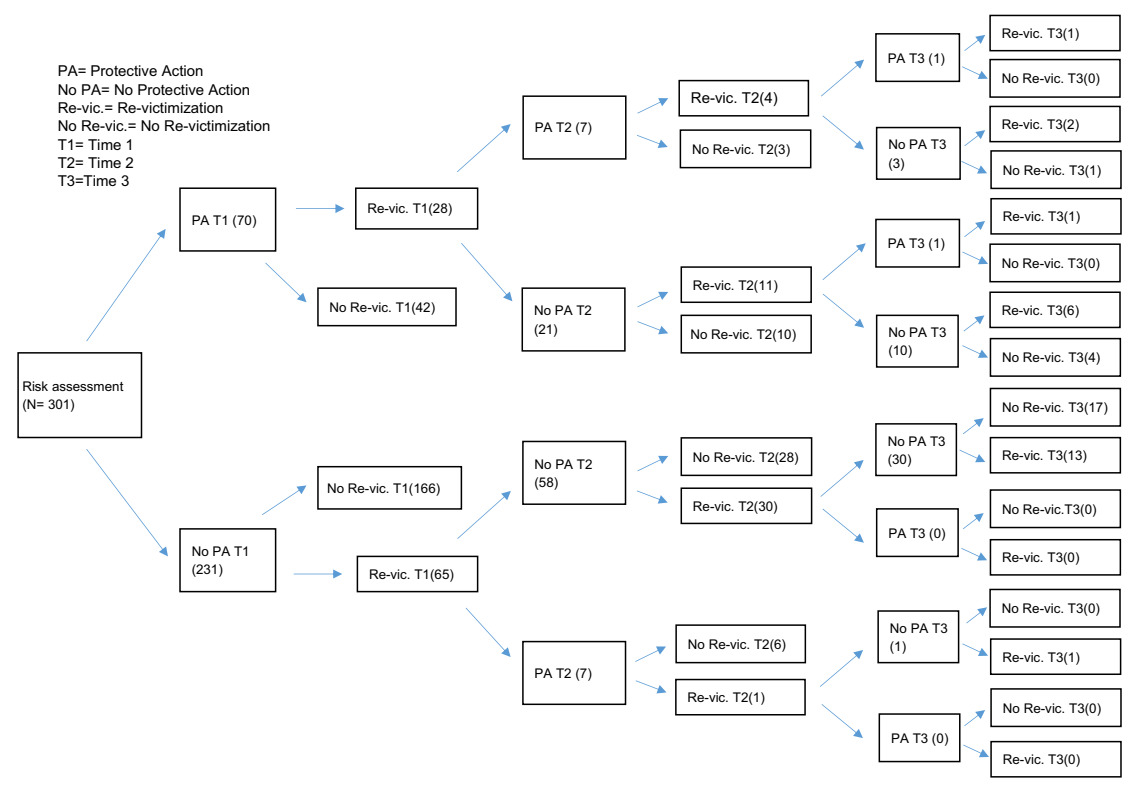

Fig. 2. Flowchart. Distribution of protective actions in relation to repeat victimization at Time 1, 2 and 3 . 
implemented (40\%) by comparison with cases where no protective actions had been implemented (28\%).

Following these groups further, we found that overall a small number of new protective actions were implemented subsequent to an instance of repeat IPV. Among repeat IPV cases in which protective actions had been implemented at Time 1 (T1), new protective actions were implemented in 7 of 28 cases (25\%). In the other group, where no protective actions had been implemented at Time 1 (T1), at least one protective action was implemented following re-victimization in 7 of 65 cases (11\%).

In the next part of the flowchart, four groups are examined: cases that had had an intervention at Time 1, relapsed into IPV and then either been the focus of new protective actions at Time 2 (Group 1 ) or not (Group 2). The other two groups were those that had not had any interventions at Time 1, relapsed into IPV and then either been the focus of protective actions at Time 2 (Group 4 ) or not (Group 3). In approximately $50 \%$ of the cases in Groups $1-2$, repeat IPV occurred at Time 2. In Group 4, somewhat fewer cases experienced repeat IPV, although this group only included 7 cases (as was also the case with Group 1).

Of the total population, 46 offenders (15\%) relapsed into IPV at least twice. Thus $49 \%$ of the offenders who relapsed at Time 1 also relapsed at Time 2. Among these 46 offenders, only two were subjected to an intervention at Time 3 (T3) and both these offenders later relapsed into repeat IPV. Among the remaining 44 cases, i.e. those left with no interventions at Time 3, half of the group relapsed (22 cases) and the other half did not (22 cases).

\subsection{Did the protective actions prevent repeat IPV?}

The predictive effect of the implemented protective actions on repeat IPV/violence was examined in stepwise logistic regression analyses. In the first step, the global risk assessments were examined (see Tables 4 and 5). The results showed that IPV likelihood was the only risk measure that significantly predicted IPV recidivism (OR $\left.\left(e^{\mathrm{B}}\right)=1.80, p<0.05\right)$, and none of the global risk assessments significantly predicted repeat violence. Thus, the previous results regarding the predictive validity of the global risk assessments were confirmed.

In step two, we added protective actions (coded: no protective actions/at least one protective action) to the regression model in order to examine whether these measures predicted IPV/violence recidivism. No significant predictive effects were found, however. These results were confirmed by results of bivariate correlations between implemented protective actions (Time 1$)$ and repeat IPV $(\tau=0.108, p<$ $0.1) /$ repeat violence $(\tau=-0.018, \mathrm{p}=\mathrm{ns})$.

Finally, four dummy variables were created to examine whether the combination of global risk assessments and implemented protective actions predicted repeat IPV/violence; 1 ) low likelihood/severity and no implemented protective actions, 2) low likelihood/severity and at least one implemented protective action, 3) high likelihood/severity and no implemented protective actions, 4) high likelihood/severity and at least one implemented protective action. Both of the groups assessed to have a high likelihood of repeat IPV demonstrated a higher frequency of repeat IPV by comparison with the reference category (low risk/no protective actions) (see Table 6). However, cases assessed to have a low likelihood of repeat IPV did not differ significantly with regard to repeat IPV by comparison with the reference category. The same was found in the analysis of the severity risk assessments regarding repeat IPV and in both of the predictive models (likelihood/severity) focused on repeat violence (see Table 7); in these analyses, however, none of the three groups (low risk/protective actions, high risk/no protective actions and high risk/protective actions) significantly differed from the reference category. We also conducted survival analyses (Cox regression analyses). The date of the risk assessment constituted the starting date in the analyses and repeat IPV (Time 1) or the last date for the follow-up constituted the end date. Those cases with missing/incorrect dates for the risk assessment or the repeat IPV were excluded. We also excluded cases with missing data regarding repeat IPV or global risk assessments. In total 257 cases were included. However, the analyses were conducted separately for each group i.e. not all cases were included in the analyses at the same time. The analyses produced results similar to those of the logistic regression analyses. There were no significant effects of the protective actions on repeat IPV.

\section{Discussion}

The cases were generally assessed to low risk cases. The police employees primarily used the two lower middle steps ( 2 and 3 ) on the five-step global risk scale (restriction of range). The highest step (5) was not used in any of the cases. The majority of the B-SAFER items were significantly related to the global risk assessments. However, the relationships were weak overall. The predictive accuracy of the risk factors (current/past situation) together with the victim vulnerability factors was also weak. The shared variance was $0.20-0.26$ for the likelihood and $0.14-0.21$ for the severity of repeat IPV, which means that 75$85 \%$ of the variance was unexplained by the B-SAFER items in both cases. Thus, the police employees mainly used other information than the B-SAFER items in their global risk assessments, which may explain why most of the risk- and victim vulnerability factors were not related to repeat victimization. These results are in line with Trujillo and Ross's (2008) findings; the assessors in their study also based their global risk assessments to a large extent, on other factors than those included in the tool under study. However, the stepwise regression method to estimate "best" models, which was used in this study, is associated with limitations. For instance, Akinwande, Dikko, and Gulumbe (2015) showed that by including a variable with a nonecorrelation or weak correlation with a dependent variable, but which correlated with other independent variables, the predictive accuracy of a model may be improved.

The global risk assessments were not much better predictors of repeat IPV/violence than chance. However, it was possible to construct algorithms that better predicted the outcome than the global risk assessments; the predictive validity was significantly better (AUC > 0.70 ) for some combinations of risk- and victim vulnerability factors.

Table 4

Logistic regression predicting repeat IPV from global risk assessment severity/likelihood and protective actions $(N=275)$.

\begin{tabular}{|c|c|c|c|c|c|}
\hline \multicolumn{3}{|l|}{ Step 1} & \multicolumn{3}{|l|}{ Step 2} \\
\hline & $\mathrm{OR}\left(e^{B}\right)$ & $p$ & & $\mathrm{OR}\left(e^{B}\right)$ & $p$ \\
\hline \multirow[t]{2}{*}{ Global risk assessment: severity } & 1.563 & 0.109 & Global risk assessment: severity & 1.458 & 0.185 \\
\hline & & & Protective actions (low/high) & 1.481 & 0.197 \\
\hline \multicolumn{3}{|c|}{ Note: $\chi^{2}=2.544, p=\mathrm{ns}, \mathrm{df}=1$, Nagelkerke $R^{2}=0.013$} & \multicolumn{3}{|c|}{ Note: $\chi^{2}=4.182, p=\mathrm{ns}, \mathrm{df}=2$, Nagelkerke $R^{2}=0.021$} \\
\hline & $\mathrm{OR}\left(e^{B}\right)$ & $p$ & & $\mathrm{OR}\left(e^{B}\right)$ & $p$ \\
\hline \multirow[t]{2}{*}{ Global risk assessment: likelihood } & 1.803 & 0.028 & Global risk assessment: likelihood & 1.729 & 0.043 \\
\hline & & & Protective actions (low/high) & 1.487 & 0.189 \\
\hline \multicolumn{3}{|c|}{ Note: $\chi^{2}=4.827, p=\mathrm{ns}, \mathrm{df}=1$, Nagelkerke $R^{2}=0.025$} & \multicolumn{3}{|c|}{ Note: $\chi^{2}=6.524, p=0.038, \mathrm{df}=2$, Nagelkerke $R^{2}=0.033$} \\
\hline
\end{tabular}


Table 5

Logistic regression predicting repeat violence from global risk assessment severity/likelihood and protective actions $(N=270)$.

\begin{tabular}{|c|c|c|c|c|c|}
\hline \multicolumn{3}{|l|}{ Step 1} & \multicolumn{3}{|l|}{ Step 2} \\
\hline & $\mathrm{OR}\left(e^{B}\right)$ & $p$ & & $\mathrm{OR}\left(e^{B}\right)$ & $p$ \\
\hline \multirow{2}{*}{ Global risk assessment: severity } & 1.036 & 0.918 & Global risk assessment: severity & 1.077 & 0.833 \\
\hline & & & Protective actions (low/high) & 0.800 & 0.573 \\
\hline \multicolumn{3}{|c|}{${ }^{1}$ Note: $\chi^{2}=0.011, p=\mathrm{ns}, \mathrm{df}=1$, Nagelkerke $R^{2}=0.000$} & \multicolumn{3}{|c|}{ Note: $\chi^{2}=0.338, p=\mathrm{ns}, \mathrm{df}=2$, Nagelkerke $R^{2}=0.002$} \\
\hline & $\mathrm{OR}\left(e^{B}\right)$ & $p$ & & $\mathrm{OR}\left(e^{B}\right)$ & $p$ \\
\hline \multirow[t]{2}{*}{ Global risk assessment: likelihood } & 1.403 & 0.292 & Global risk assessment: likelihood & 1.445 & 0.257 \\
\hline & & & Protective actions (low/high) & 0.768 & 0.501 \\
\hline \multicolumn{3}{|c|}{ Note: $\chi^{2}=1.095, p=\mathrm{ns}, \mathrm{df}=1$, Nagelkerke $R^{2}=0.007$} & \multicolumn{3}{|c|}{ Note: $\chi^{2}=1.563, p=0.458, \mathrm{df}=2$, Nagelkerke $R^{2}=0.009$} \\
\hline
\end{tabular}

Either the police employees were not able to use the actual information to the full extent, or, irrelevant factors had corrupted the ratings. Such factors may be personal ("gut feeling"), local or linked to the police culture, and are possible to control by means of education/training.

The recommendation/implementation of effective protective measures in high risk cases has been referred to as the main explanation for why violence risk assessments have been rather poor predictors of repeat IPV (Belfrage et al., 2012; Belfrage \& Strand, 2012; Storey et al., 2014). Based on the results of our study, we find no support for a similar conclusion. Protective actions had been implemented in only $23 \%$ of all cases and no association was found between protective actions and repeat IPV/violence. The latter was also the case when we conducted separate analysis in the low and high risk groups, with one exception; cases assessed as highly likely to be subjected to repeat IPV, with or without implemented protective actions, were at higher risk of repeat IPV by comparison with cases assessed to be low risk without implemented protective actions. However, comparisons with previous studies must be made with caution, since studies have focused on the evaluation of different tools/versions of tools and have employed different follow-up periods, analytical methods and definitions of protective actions/levels of protective actions. Another important difference is that two of the previous studies (Belfrage et al., 2012; Storey et al., 2014) examined recommended protective actions and not implemented protective actions. Our results show that there was a large discrepancy between the proportions of recommended and implemented protective actions. In addition, the risk assessments did not seem to guide the implementation of protective actions; some of the implemented measures had not been recommended in the assessments.

In this study, the protective actions did not prevent repeat IPV. However, this does not necessarily mean that the protective actions are ineffective in general. Such a conclusion was drawn in an evaluation of restraining orders (Strand, 2012). There the results showed that restraining orders were most effective in medium and low risk cases and that prosecutors more often granted restraining orders in high risk cases. Due to the fact that IPV-offenders consist of a diverse group containing different subtypes of offenders (Holtzworth-Munroe \&

Table 6

Logistic regression predicting repeat IPV from global risk assessment severity/likelihood and protective actions (reference category low likelihood or severity/no protective actions).

\begin{tabular}{lll}
\hline Likelihood & $\mathrm{OR}\left(e^{B}\right)$ & $p$ \\
\hline Low likelihood/protective actions & 1.769 & 0.165 \\
High likelihood/no protective actions & 1.916 & 0.041 \\
High likelihood/protective actions & 2.342 & 0.040 \\
\hline Note: $\chi^{2}=6.900, p=\mathrm{ns}, \mathrm{N}=275, \mathrm{df}=3$, Nagelkerke $R^{2}=0.035$ \\
Severity & \\
\hline Low severity/protective actions & 1.476 \\
High severity/no protective actions & 1.455 & 0.330 \\
High severity/protective actions & 2.164 & 0.273 \\
\hline Note: $\chi^{2}=4.182, p=\mathrm{ns}, \mathrm{N}=275, \mathrm{df}=3$, Nagelkerke $R^{2}=0.021$.
\end{tabular}

\section{Table 7}

Logistic regression predicting repeat violence from global risk assessment severity likelihood and protective actions (reference category low likelihood or severity/no protective actions).

\begin{tabular}{lll}
\hline Likelihood & $\mathrm{OR}\left(e^{B}\right)$ & $p$ \\
\hline Low likelihood/protective actions & 0.901 & 0.845 \\
High likelihood/no protective actions & 1.552 & 0.230 \\
High likelihood/protective actions & 1.009 & 0.987 \\
\hline Note: $\chi^{2}=1.737, p=\mathrm{ns}, \mathrm{N}=270, \mathrm{df}=3$, Nagelkerke $R^{2}=0.010$ \\
Severity & \\
\hline Low severity/protective actions & \\
High severity/no protective actions & 0.972 & 0.954 \\
High severity/protective actions & 1.217 & 0.622 \\
\hline Note: $\chi^{2}=0.707, p=\mathrm{ns}, \mathrm{N}=270, \mathrm{df}=3$, Nagelkerke $R^{2}=0.004$. &
\end{tabular}


B-SAFER assessments were only conducted in cases identified as high risk in an initial screening procedure, and unfortunately we have no knowledge regarding the cases that were not identified as high risk. In order to develop a clearer picture of how the B-SAFER works, the initial screening procedure should be examined. It would also be interesting to conduct a comparative study, in which assessments conducted as a part of an ongoing project will be compared with assessments conducted according to ordinary routines such as in the present study. Further, in addition to the police, there are a number of actors involved in the implementation of protective actions (e.g. prosecutors, social services and municipalities). In this study, implemented protective actions were those actions that the police knew had been implemented. Thus, interventions implemented by the victim him/herself or by other actors, without involvement from the police or without the police being informed were not included.

The number of cases in which repeat violence occurred was small. Therefore, the interpretation of the results of the logistic regressions predicting repeat violence from global risk assessments and protective actions (see Table 7) should be made with caution. Finally, it is widely known that the number of unreported IPV cases in general is large, which of course complicates the interpretation of the results. Does the lack of reported IPV in the follow-up mean that no repeat IPV has occurred? Or did incidents occur without being reported to the police? This is a common problem in studies of this kind and to overcome it, we need to speak to victims.

\section{Conclusions}

Our results indicate that there are problems already in the first step of the risk assessment procedure, i.e. the assessment of the individual items included in the tool. This is probably due to a lack of information and a lack of education/training in how to assess violence risk and mental health/psychosocial risk factors in particular. Important information is thus neglected, and it is likely that police employees compensate for this by using their professional knowledge (tacit knowledge) in the global risk assessments. This in turn leads to the global risk assessments having low predictive accuracy and providing a weak basis for the recommendation of protective actions. In this study, only a small proportion of the recommended protective actions were implemented. Moreover, new protective measures were not implemented to a greater extent in cases in which repeated victimization occurred (at Times 1 and 2 ). In order to improve the work conducted with violence risk assessment and management in police settings, continuous education and training for assessors is required, along with continuous evaluations of the ongoing work and the introduction of improvements to the assessment tools. Finally, studies regarding the effect of different types of protective actions are needed and should preferably include interviews with IPV victims regarding their experiences of such measures.

\section{Funding sources}

This work was supported by the National Swedish Police Board under Grant A202.590/2013 and the Department of Criminology, Malmö University.

\section{Disclosure statement}

The authors declared no potential conflicts of interest with respect to the authorship and/or publication of this article.

Parts of these results have previously been published in two Swedish reports, see Mellgren, Svalin, Levander, and Torstensson Levander (2014) and Svalin, Mellgren, Levander, and Torstensson Levander (2014).

\section{References}

Akinwande, O. M., Dikko, H. G., \& Gulumbe, S. K. (2015). Identifying the limitation of stepwise selection for variable selection in regression analysis. American Journal of Theoretical and Applied Statistics, 4, 414-419. https://doi.org/10.11648/j.ajtas. 20150405.22.

Andrews, D. A., \& Bonta, J. (2010). The psychology of criminal conduct ( $5^{\text {th }}$ ed.). New Province, NJ: Anderson Publishing

Belfrage, H. (2008). Police-based structured spousal violence risk assessment: The proces of developing a police version of the SARA. In A. C. Baldry, \& F. W. Winkel (Eds.), Intimate partner violence prevention and intervention. The risk assessment and management approach (pp. 33-44). Hauppauge, NY: Nova Science.

Belfrage, H., \& Strand, S. (2008). Structured spousal violence risk assessment: Combining risk factors and victim vulnerability factors. International Journal of Forensic Mentel Health, 7, 39-46. htps.//doi.org/10.1080/14999013.2008.9914402.

Belfrage, H., \& Strand, S. (2012). Measuring the outcome of structured spousal violence risk assessments using the B-SAFER: Risk in relation to recidivism and interve
Behavioral Sciences \& the Law, 30, 420-430. https://doi.org/10.1002/bsl.2019.

Behavioral Sciences \& the Law, 30, 420-430. https://doi.org/10.1002/bsl.2019.
Belfrage, H., Strand, S., Storey, J. E., Gibas, A. L., Kropp, P. R., \& Hart, S. D. (2012). Assess-

Belfrage, H., Strand, S., Storey, J. E., Gibas, A. L., Kropp, P. R., \& Hart, S. D. (2012). Assess-
ment and management of risk for intimate partner violence using the spousal assaul ment and management of risk for intimate partner violence using the spousal assault
risk assessment guide. Law and Human Behaviour, 36, 60-67. https://doi.org/10.1007, risk assessment guid
s10979-011-9278-0.

Hajian-Tilaki, K. (2013). Receiver operating characteristic (ROC) curve analysis for medical diagnostic test evaluation. Caspian Journal of Internal Medicine, 4, 627-635.

Heilbrun, K. (2003). Violence risk: From prediction to management. In D. Carlson, \& R Bull (Eds.), Handbook of psychology in legal contexts (pp. 127-143) $\left(2^{\text {nd }}\right.$ ed.) Chichester: Wiley \& Sons.

Holtzworth-Munroe, A., \& Stuart, G. L. (1994). Typologies of male batterers: Three subtypes and the differences among them. Psychological Bulletin, 16, 476-497.

Hoyle, C. (2008). Will she be safe? A critical analysis of risk assessment in domestic violence cases. Children and Youth Services Review, 30, 323-337. https://doi.org/10. 1016/J.childyouth.2007.10.009.

Kropp, P. R. (2008). Development of the spousal assault risk assessment guide (SARA) and the brief spousal assault form for the evaluation of risk (B-SAFER). In A. C. Baldry, \& F W. Winkel (Eds.), Intimate partner violence prevention and intervention. The risk

assessment and management approach (pp. 19-31). Nova Science: Hauppauge, NY. the R., \& Hart, S. D. (2004). The development of the brief spousal assault form for the evaluation of risk (B-SAFER): A tool for criminal justice professionals. Canada: Department of justice.

(2005). Brief spousal assault form for the evaluation of risk (B-SAFER): User manual. Vancouver, Canada: Proactive Resolutions Inc.

Kropp, P. R., Hart, S. D., \& Belfrage, H. (2010). Brief spousal assault form for the evaluation of risk (B-SAFER), version 2: User manual. Vancouver, Canada: Proactive Resolutions Inc risk assessment Duide Vancouver, BC: British Columbia Institute on the spousal assault risk assessment guide. Vancouver, BC. British Columbia Institute on Family Violence. Kropp, P. R., Hart, S. D., Webster, C. D., \& Eaves, D. (1995). Manual for the spousal assault risk assessment guide (2nd ed.). Vancouver, BC. British Columbia Institute on Family Violence. guide (SARA). Toronto: Multi-Health Systems, Inc.

McEwan, T., Bateson, S., \& Strand, S. (2017). Improving police risk assessment and management of family violence through a collaboration between law enforcement forensic mental health and academia. Journal of Criminological Research, Policy and Practice, 3. https://doi.org/10.1108//CRPP-01-2017-0004.

Mellgren, C., Svalin, K., Levander, S., \& Torstensson Levander, M. (2014). Riskanalys $i$ polisverksamhet- fungerar det? Slutrapport frän ett utvärderingsprojekt.

(2016), Raptrits o, B., Laaksonen, I., \& Santtila, P. (2016). Construct validity and internal reliability of the Finnish risk and needs assessment form. Journal of Scandinavian Studies in Criminology and

Sobel, M. E. (1982). Asymptotic intervals for indirect effects in structural equations models. In S. Leinhart (Ed.), Sociological methodology 1982 (pp. 290-312). San
mold Francisco: Jossey-Bass.

Francisco: Jossey-Bass.
Storey, J. E., Kropp, P. R., Hart, S. D., Belfrage, H., \& Strand, S. (2014). Assessment and management of risk for intimate partner violence by police officers using the brief
mand management of risk for intimate partner violence by police officers using the brief
spousal assault form for the evaluation of risk. Criminal Justice and Behavior, 41 , spousal assault form for the evaluation of risk. Crimina
256-271. https://doi.org/10.1177/0093854813503960.

Storey, J. E., \& Strand, S. (2012a). Assessing violence risk among female IPV perpetrators: An examination of the B-SAFER. Journal of Aggression, Maltreatment \& Trauma, 22, An examination of the B-SAFER. Journal of Aggression, M
964-980. https://doi.org/10.1080/10926771.2013.835015.

Storey, J. E., \& Strand, S. (2012b). The characteristics and violence risk management of women arrested by the police for intimate partner violence. European Journal of
woment J. E. \& Strand, S. (2012b). The characteristics and violence risk management of women arrested by the police for intimate partner violence. Europe
Criminology, 9, 636-651. https://loi.org/10.1177/1477370812453403.

Strand, S. (2012). Using a restraining order as a protective risk management strategy to prevent intimate partner violence. Police Practice and Research, 13, 254-266. to prevent intimate partner violence. Police $P r$
https://doi.org/10.1080/15614263.2011.607649.

Svalin, K., Mellgren, C., Levander, S., \& Torstensson Levander, M. (2014). Utvärdering av SARA: SV. Uppsalapolisens arbete med riskbedömningar för upprepade brott $i$ nära relationer (Rikspolisstyrelsens utvärderingsfunktion, Rapport 2014:6). Stockholm: RPS Tryckeri.

Trujillo, M. P., \& Ross, S. (2008). Police response to domestic violence: Making decisions about risk and risk management. Journal of

Webster, C. D., Douglas, K. S., Eaves, D., \& Hart, S. D. (1997). HCR-20: Assessing risk for violence, version 2. Vancouver, Canada: Simon Fraser University and Forensic
valis Psychiatric Services Commission of British Columbia.

Webster, C. D., Eaves, D., Douglas, K. S., \& Wintrup, A. (1995). The HCR-20 scheme: The assessment of dangerousness and risk. Vancouver: Simon Fraser University and Forensic Psychiatric Services Commision of British Columbia. 

IV 



\section{The predictive validity of intimate partner violence risk assessments conducted by practitioners in different settings - A review of the literature}

Klara Svalin, Department of criminology, Malmö University, 20506 Malmö

Practitioners in different settings worldwide are using tools to assess and manage violence risk, and tools have been developed and adapted to suit different contexts. In a study with the aim of evaluating the use of violence risk assessment tools among nurses, psychologists and psychiatrists in mental health settings on six continents, a survey was conducted among mental health professionals in 44 countries (Singh et al., 2014). The number of respondents was 2135 and together they reported using over 400 assessment tools.

Another practitioner group that uses assessment tools to assess and manage violence risk are police employees. Examples include police authorities in the USA (e.g. Storey, Gibas, Reeves, \& Hart, 2011), Canada (e.g. Kropp \& Hart, 2004), Sweden (e.g. Belfrage, Strand, Ekman, \& Hasselborg, 2012), Norway (e.g. Nesset, Bjørngaard, Nøttestad, Whittington, Lynum, \& Palmstierna, 2017), Italy (e.g. Baldry, 2008), Spain (e.g. Echeburúa, FernándezMontalvo, Corral, \& López-Goñi, 2009), England (e.g. Almond, McManus, Brian, \& Merrington, 2017), Australia (McEwan, Bateson, \& Strand, 2017) and the Netherlands (e.g. van de Put \& Stams, 2013). The Ontario Domestic Assault Risk Assessment (ODARA, Hilton, Harris, Rice, Lang, Cormier, \& Lines, 2004) and the Brief Spousal Assault Form for the Evaluation of Risk (B-SAFER, Kropp, Hart, \& Belfrage, 2005; 2010) are examples of tools that have been developed for use in this specific context. However, tools have not only been adapted for use in specific settings, there are also different tools for different types of violence. Both the ODARA and the B-SAFER are specifically intended to assess the risk of intimate partner violence (IPV). In addition, there are specific tools to assess the risk of stalking, e.g. Stalking Assessment and Management (SAM, Kropp, Hart, \& Lyon, 2008), youth crime, e.g. Structured Assessment of Violence Risk in Youth (SAVRY, Borum, Bartel, \& Forth, 2006), general violence, e.g. HCR-20 (Webster, Douglas, Eaves, \& Hart, 1997; Webster, Douglas, \& Wintrup, 1995) and honor-related violence, e.g. PATRIARCH (Belfrage, 2005), to mention a few.

IPV is a type of violence that is often faced by practitioners in criminal justice and health contexts, and many practitioners meet victims of IPV soon after the violence has occurred. 
Since repeat IPV victimization usually occur close to previous IPV exposure (Mele, 2009), they have the potential to play a significant role in victim protection. It may even be a matter of saving lives. For instance, practitioners working in emergency departments meet victims of IPV, and they not only play an important role in the immediate situation, but also in identifying the risk for repeat IPV. In some emergency departments, screening tools are used to make decisions about interventions in IPV cases (e.g. Koziol-McLain et al., 2010). Further, social workers meet victims of IPV in many different situations, which Danis (2003) has argued gives them an opportunity to identify those at high risk of IPV and to intervene in those cases.

The risk assessment procedure has been suggested by some to be a cornerstone in IPV prevention (Kropp, 2004). However, this suggestion assumes that the violence risk assessments are accurate, i.e. that cases in which interventions are needed/not needed can be identified. A key aspect to study in examining the accuracy of violence risk assessments is their predictive validity, and according to Messing and Thaller (2013) this is the most important of the efficacy measures. Knowledge on the predictive validity of IPV risk assessments has been examined and summarized in a number of recent review studies, e.g. Helmus and Bourgon (2011), Messing and Thaller (2013) and Nicholls, Pritchard, Reeves and Hilterman (2013), all of which are described below. However, I have not been able to find any previous reviews examining the predictive validity of IPV assessments conducted by practitioners in different settings specifically, and this will be the focus of the present study. The following questions will be examined: How accurate are practitioners' intimate partner violence risk assessments with regard to repeat IPV? Which practitioner groups had conducted the assessments in the studies under review, and what were their characteristics in terms of violence risk assessment education/training? An important part of the violence risk assessment procedure usually involves the implementation of interventions to protect victims and prevent offenders from engaging in repeat violence. Since such interventions are intended to prevent re-victimization, they should be considered in the evaluation of predictive validity in relation to repeat violence (see Belfrage, 2008). This is thus the next question examined by the study: the role of protective measures in the examination of predictive validity. Finally, a number of previous studies have highlighted the fact that tools are not always used as recommended in the guidelines (e.g. Wong \& Hisashima, 1998). These findings will be described in more detail below, and the question of whether the tools evaluated in the studies were used as recommended will also be studied in this review. By reviewing the knowledge 
regarding practitioners' IPV risk assessments, we will hopefully learn more about the usefulness of such assessments and find guidance regarding the work that remains to be done in the fields of both practice and research.

\section{Previous studies of the predictive validity of IPV violence risk assessments}

A recent study examined the average predictive validity of five different IPV risk assessment tools (ODARA, SARA, DA, DVSI, K-SID) and victim assessments (Messing \& Thaller, 2013). The data were based on results obtained in ten previous studies, all of which examined the accuracy of the tools by measuring the area under the curve (AUC) of the Receiver Operating Characteristic (ROC). Results from analyses in which protective actions were controlled for were not included, and nor were studies of risk assessment tools that had only been evaluated once. The ODARA produced the highest average AUC score $(=.67)$ and the effect size (of the average AUC) was medium. The average AUCs of the other tools and victim assessments varied between .54 and .63 , and the effect sizes were small.

The predictive/postdictive validity of IPV risk assessment tools was also examined in another recent review study, which was based on 39 publications identified by means of a systematic literature review (Nicholls et al., 2013). These studies represented all English-language publications on the subject from western nations written between 1990 and 2011. For most of the tools, ROC-analyses had been conducted and the AUC values varied substantially (.48.92). A closer look at the studies with the highest AUC values showed that the tools used were actuarial tools based on victim/offender questionnaires or interviews. In addition, some of the risk measures were based on victim appraisals.

Finally, Helmus \& Bourgon (2011) reviewed 15 years of the use of the SARA tool. At the time of the study, 11 studies on the predictive accuracy of the SARA tool had been published and were included in the review. The AUCs (for total score or global risk assessment) varied between .59 and .87 . The highest AUC value was found in a study conducted in Spain, based on 102 provincial court cases (Andrés-Pueyo, López, \& Álvarez, 2008). The assessments were produced in retrospect and the follow-up period was 12 months (outcome: IPV recidivism). The AUC of the SARA total score/global risk assessment was $.77 / .87$. The study with the second highest AUC values (a conference presentation, Gibas, Kropp, Hart, \& Stewart, 2008) was conducted in Canada, based on a federal treatment sample $(\mathrm{N}=108)$ with 
correctional staff conducting the assessments. The predictive accuracy (AUC) of the SARA total score/global risk assessment (with IPV recidivism as the outcome measure) was .70/.76.

In summary, all three review studies included a mix of risk raters, i.e. in some of the studies risk was assessed by practitioners, in others by researchers. There was an overlap of four studies that were included in all three reviews. ${ }^{1}$ The AUCs in both Nicholls et al. (2013), and Helmus and Bourgon (2011) varied greatly, whereas the range of the AUC values (average AUC values) was smaller in Messing and Thaller (2013). The tool associated with the highest AUC value in Nicholls et al. (2013) was the Danger Assessment scale (DA, AUC = .92) and in Messing and Thaller (2013) it was the ODARA (.67). The highest AUC value in the SARA studies reported by Helmus and Bourgon (2011) was specified at .87. There are many factors that influence predictive validity, e.g. information sources (for the assessment and for recidivism), definitions of IPV, length of follow-up times and outcome measures (Nicholls et al., 2013), which means that the variety of such factors complicates comparisons between different studies. Nicholls et al. (2013) suggest the examination of more than one tool in the same study as a means of, at least in part, overcoming this issue.

Previous studies have highlighted a number of problems related to practitioners' use of violence risk assessment tools. One such issue is related to the fact that the tools are not administered in the recommended ways (Her Majesty's Inspectorate of Constabulary [HMIC], 2014; Wong \& Hisashima, 2008). The first of these studies (HMIC, 2014) examined the use of the DASH tool (domestic abuse, stalking and harassment and honor based violence; Richards, 2009) in a number of police areas in England and Wales. One finding was that the mandatory form, which is a part of the DASH assessment, was not completely followed in a large number of cases in one of the police areas. The second study evaluated probation officers' use of the SARA guide. Information for the assessments was drawn from a database which contained little information regarding victims (Wong \& Hisashima, 2008). Consequently, the risk management plans for the victims were not as meaningful as they could have been if such information had been available. The authors also concluded that a SARA assessment was completed in less than half of the cases (38\%) that should have been assessed (according to specified criteria).

\footnotetext{
${ }^{1}$ Comparing the overlap of studies pairwise; Messing and Thaller (2013) and Nicholls et al. (2013) had 8 studies in common, Messing and Thaller (2013) and Helmus and Bourgon (2011) had 4 in common and Nicholls et al. (2013) and Helmus and Bourgon (2011) had 5 studies in common.
} 
Further, Cattaneo and Chapman (2011) interviewed 13 practitioners working with victims of IPV in different settings, e.g. shelters, courts and a hospital. A majority of the participants did not use any tools to assess and manage violence risk. Instead, they used their own professional experiences, their colleagues' professional experiences and their "gut feeling". These means of determining risk were often combined. Similar results were found in an inter-rater reliability study that compared police employees' violence risk assessments (Svalin, Mellgren, Torstensson Levander, \& Levander, 2017a). Two different tools were evaluated separately. However, the main results were similar for both tools. The global risk assessments were rather consistent across different raters whereas the assessments of the factors included in the tools differed. Thus it seemed as though the assessment of global risk was based on something other than the factors included in the tool. One suggestion was that the police employees based these assessments on tacit knowledge (gut feeling). Lack of education and training in risk assessment was discussed as a central explanation for the use of tacit knowledge in the police employees' risk assessments. Finally, Cattaneo and Chapman (2011) also studied different practitioners' use of assessments in management decision making and found that some of them allowed the assessment to fully guide their work, while others used it only as one part of this process.

\section{Method}

A systematic literature search was conducted in order to find material for the review. Five different databases were chosen based on the aim of the study, i.e. to study the IPV risk assessments of practitioners working in different settings. These were Sociological Abstracts, Psychinfo, Cinahl, Pubmed, and Medline. Thus, several different topics, such as psychology, sociology, social work, medicine, psychiatry and criminology were covered in the searches. In addition, searches were conducted at three different publisher sites, namely; Taylor \& Francis, SAGE Journals and Science Direct (Elsevier). ${ }^{2}$ The searches only included studies written in English.

\footnotetext{
${ }^{2}$ I also tried to conduct searches at the Springer and Wiley sites. However their search function only allowed searches among their journals and not among specific articles.
} 


\section{Procedure}

The database searches were conducted on October 24, 2017. No cut-off was specified for the earliest date on which studies were published. As has previously been noted, Nicholls and colleagues (2013) have recently conducted a comprehensive review on the predictive validity of IPV violence risk assessments. Their literature search was based on four clusters with related terms. The clusters were intimate partner violence, measurement, risk assessment and risk. Since the aim of this study is similar to one of the aims in Nicholls et al. (2013, see aim d, and predictive validity, p. 85), the choice of search clusters and related terms for the present study was inspired by their choices. However, some of their search terms were excluded and some were added, in order to narrow the search further and thus make it more appropriate to the more specific aim of the present study (see Table 1). For instance, our risk cluster only included search terms related to recidivism whereas their risk cluster was broader and included outcomes as "risk" and "dangerousness".

Table 1. (Inspired by Nicholls et al., 2013, p. 86)

\begin{tabular}{|l|l|}
\hline Cluster & Search terms \\
\hline Intimate partner violence & $\begin{array}{l}\text { partner violence, partner abuse, domestic violence, intimate partner } \\
\text { violence, wife abuse, wife assault, family violence, femicide, intimate } \\
\text { partner homicide, spouse abuse, spouse assault, spouse violence }\end{array}$ \\
\hline Measurement & $\begin{array}{l}\text { test validity, statistical validity, accuracy, predict*, sensitivity, } \\
\text { specificity }\end{array}$ \\
\hline Risk assessment & $\begin{array}{l}\text { actuarial, risk assessment, structured professional judgment, } \\
\text { dangerousness assessment, rating scale, assessment tool, instrument, } \\
\text { Domestic violence risk appraisal guide, Danger assessment, Kingston } \\
\text { screening instrument for domestic violence, Ontario domestic assault } \\
\text { risk assessment, Spousal assault risk assessment guide, Brief spousal } \\
\text { assault form for the evaluation of risk, domestic violence screening } \\
\text { instrument, Violence risk appraisal guide, Level of service inventory, } \\
\text { HCR-20 }\end{array}$ \\
\hline Risk & \begin{tabular}{l} 
Relapse, repeat, re-victimization, re-abuse, recidivism \\
\hline
\end{tabular} \\
\hline
\end{tabular}

The final search string (below) was the same in all database searches:

("partner violence" OR "partner abuse" OR "domestic violence" OR "intimate partner violence" OR “wife abuse" OR "wife assault" OR "family violence" OR femicide OR 
"intimate partner homicide" OR "spouse abuse" OR "spouse assault" OR "spouse violence") AND ("test validity" OR "statistical validity" OR accuracy OR predict* OR sensitivity OR specificity) AND (actuarial OR "risk assessment” OR "structured professional judgment” OR "dangerousness assessment" OR "rating scale" OR "assessment tool" OR instrument OR "Domestic violence risk appraisal guide" OR "Danger assessment" OR "Kingston screening instrument for domestic violence" OR "Ontario domestic assault risk assessment" OR "Spousal assault risk assessment guide" OR "Brief spousal assault form for the evaluation of risk" OR “domestic violence screening instrument" OR "Violence risk appraisal guide" OR "Level of service inventory" OR HCR-20) AND (relapse OR repeat OR re-victimization OR re-abuse OR recidivism)

The searches resulted in the identification of a total of 932 studies (Sociological Abstracts: 787 studies, Psychinfo: 70 studies, Cinahl: 13 studies, Pubmed: 34 studies and Medline: 28 studies). Once duplicates from the database searches had been excluded (manually), the total number of studies was reduced to 846 .

The publisher site searches were conducted on October 25, 2017 (Taylor \& Francis) and January 26, 2018 (Sage Journals and Science Direct (Elsevier)). Since the search string used in the database searches was too complex for use at the publishers sites, the following combination of terms was used: "violence risk assessment" AND "intimate partner violence". In total these searches identified 71 studies (Taylor \& Francis: 28 studies, SAGE Journals: 34 studies and Science Direct: 9 studies). Articles that had already been identified in the previous searches and duplicates from the different site searches were excluded, resulting in a total of 63 studies.

The next step was the sorting procedure, which was mainly carried out by reading all the abstracts. However, when the information in the abstract was not sufficient to determine whether or not a study would be included, parts of the full text were read.

\section{Inclusion- and exclusion criteria}

A number of inclusion and exclusion criteria were used to determine whether or not a study was eligible for inclusion. The first criterion relates to the type of study. Only original articles and dissertations were included, and thus reviews/research summaries, book chapters, conference contributions and editorials were excluded. The studies' abstracts were also of 
significance in the sorting process. The abstract had to state that the predictive validity of IPV risk assessments was going to be evaluated. Thus if there was no mention of this in the abstract, the article was not included. The type of risk assessment tool was not restricted to IPV risk assessment tools however. For example, evaluations of general risk assessment tools in samples consisting of IPV offenders were included, in line with Nicholls et al. (2013). I also, like Nicholls et al. (2013), included new tools, which means that there were no requirements regarding previous evaluations. Further, since the aim of the study was to examine practitioners' violence risk assessments, studies based on assessments conducted by other actors, e.g. researchers, were excluded. It was also important that the practitioners had conducted the assessments in the specific setting with which they were affiliated. For instance, in a new study by Gerth, Rossegger, Bauch and Endrass (2017), psychologists conducted risk assessments based on police data. This study was excluded, since the raters did not work in this setting normally, but only conducted assessments on behalf of the specific study. Studies of risk assessments based only on victims' self-reports/perceptions were also excluded. Finally, the dependent/outcome variable was restricted to IPV recidivism (any definition was acceptable, e.g. police-reported IPV, self-reported re-victimization etc.). However, while the victim did not have to be the same as in the index crime (i.e. the crime that had resulted in the risk assessment), it had to be a current or former intimate partner. Thus, studies of violence in other family relations (labelled IPV), were excluded (the same applies to the index crime).

\section{Results}

Eleven studies were included in the review (Belfrage \& Strand, 2012; Belfrage, Strand, Storey, Gibas, Kropp, \& Hart, 2012; Hendricks, Werner, Shipway, \& Turinetti, 2006; Hilton, Harris, Popham, \& Lang, 2010; Lauria, McEwan, Luebbers, Simmons, \& Ogloff, 2017; Rettenberger \& Eher, 2013; Shepard, Falk, \& Elliott, 2002; Storey, Kropp, Hart, Belfrage, \& Strand, 2014; Svalin, Mellgren, Torstensson Levander, \& Levander, 2017b; 2018; Williams \& Houghton, 2004). In total, nine different tools/versions of tools ${ }^{3}$ had been used in the studies (for a complete list of the tools see Table 2). In two of the studies, two tools had been employed (Rettenberger \& Eher, 2013; Williams \& Houghton, 2004) and in the rest of the

\footnotetext{
${ }^{3}$ In two studies, it was uncertain which version of the B-SAFER had been used (Storey et al., 2014; Svalin et al., 2018) and in one study it was unclear which version of the SARA had been used (Williams \& Houghton, 2004).
} 
studies one tool had been used. ${ }^{4}$ The SARA or the B-SAFER had been evaluated in six of the eleven studies, the ODARA had been evaluated twice and the rest of the tools were found only once. In Williams and Houghton's (2004) study, SARA assessments were used to evaluate the concurrent and discriminant validity of the DVSI tool. Thus the focus of the study was on the latter tool, and not the SARA. Further, Shepard et al. (2002) examined a batterer categorization rather than a risk assessment tool. However, the study was included nonetheless because the categorization included risk levels (ranging from (1) little risk - (4) serious risk). Some of the tools (3) were general tools (i.e. not specialized on a certain type of violence), but most of them (5) had been developed for the evaluation of IPV/domestic violence. One study had employed the psychopathy checklist revised (PCL-R $2^{\text {nd }}$ ed., Hare, 2003). In the majority of the settings, IPV risk assessments had been conducted to guide the implementation of interventions. These were either interventions primarily intended to protect the victim from repeat crimes or interventions intended to affect the offender and thereby prevent further offenses. The study samples ranged between 65 and 1,465 participants. In nine studies, the suspects/offenders were men, in one study the sample was a mix of both male and female suspects (Svalin et al., 2018) and one study lacked information regarding the sex of the offenders (Hendricks et al., 2006).

\section{Setting and raters}

All the studies had been conducted in criminal justice settings, with the exception of one that had been conducted in a treatment setting. ${ }^{5}$ In six studies, the assessments had been conducted by police employees. Five of these studies focused on Swedish police settings (Belfrage \& Strand, 2012; Belfrage et al., 2012; Storey et al., 2014; Svalin et al., 2017b; 2018) and one on an Australian police setting (Lauria et al., 2017). In three of the studies, the risk assessments had been conducted by probation officers or correction institutional staff (in Canada and the USA) (Hilton et al., 2010; Shepard et al., 2002; Williams \& Houghton, 2004), and in the treatment study, the IPV risk assessments had been carried out by master's level clinician/s (in the USA) (Hendricks et al., 2006). Finally, in one study the assessments had been conducted by forensic psychologists/psychiatrists at a federal evaluation center for violent and sexual offenders in Austria (Rettenberger \& Eher, 2013). The offender sample in this study differed

\footnotetext{
${ }^{4}$ In addition to the LSI-OR, Hilton et al. (2010) also evaluated the ODARA. However, since the ODARA assessments were conducted by researchers, the results of the ODARA analysis were not included in the present study.

${ }^{5}$ The offenders had been referred to the Children's Service Society of Wisconsin, which is associated with the Children's Hospital of Wisconsin.
} 
from the other offender samples, since the offenders in this case had been convicted of sexually motivated violent offenses towards (current or former) intimate partners. The suspects in the other studies had committed a wider range of IPV crimes.

Overall, the studies included a rather limited amount of information regarding the level of training/experience that the raters had in assessing violence risk or regarding their professional experience. Seven studies included a brief description and in three studies this issue was not mentioned at all. ${ }^{6}$ The descriptions included, for instance, who had been responsible for the training (e.g. one of the authors of a tool, see Storey et al., 2012), the overall content (e.g. theory and practice) and the length of the training (e.g. two days) (see Belfrage \& Strand, 2012). Overall, the amount of training appeared to be rather limited. For instance, the police officers in the study by Lauria et al. (2017) had not been given any training in the use of the ODARA. Further, the probation officers in the Shepard et al. (2002) study had recommended sentences based on their offender risk categorization, and in a survey presented in the study they expressed their satisfaction regarding the training they had received in sentencing recommendations. However, the interventions had nonetheless been implemented inconsistently.

Previous studies have highlighted the fact that violence risk assessment tools are not always used in accordance with the guidelines for a given tool (e.g. HMIC, 2014). Overall, the reviewed studies provided little information regarding the administration of the assessments. Five studies lacked information regarding whether or not the tools had been utilized as recommended (Hendricks et al., 2006; Hilton et al., 2010; Lauria et al., 2017; Shepard et al., $2002^{7}$; Svalin et al., $2017 b^{8}$ ). One study stated that the tools' guidelines had been followed (Williams \& Houghton, 2004). In yet another study, two tools had been used, one of them according to the recommendations (PCL-R) while the other (ODARA) had been used to assess cases retrospectively (Rettenberger \& Eher, 2013). In two studies, the global risk rating had been changed (Belfrage \& Strand, 2012; Svalin et al., 2018), and in addition, in the latter of these two studies, the information base had been less extensive than recommended (no information had been collected from victims). Finally, in two studies the police officers who

\footnotetext{
${ }^{6}$ One of those articles which lacked information regarding training/experiences of violence risk assessment was Svalin et al. (2018) study. Such information was therefore added for the purposes of this review.

${ }^{7}$ The reason to the lack of information regarding the administration of a tool, was probably because a batterer categorization rather than a tool was evaluated.

${ }^{8}$ Information regarding whether the PST-VC was used as recommended or not was missing in the study, and hence added for this study specifically (in Table 2).
} 
conducted the assessments had carried out their assessments together with their supervisor. Since this is not a mandatory procedure in the SARA or the B-SAFER, it might be viewed as an additional quality check (Belfrage et al., 2012; Storey et al., 2014).

\section{Predictive validity}

The predictive validity of the IPV risk assessments in relation to IPV recidivism was measured in a number of ways. However, the most common main analysis employed was the ROC analysis (conducted in eight studies). The AUC values for global risk assessments/numerical total scores, with the outcome IPV recidivism varied between .49 and.72 in the studies. The highest AUC was presented by Lauria et al. (2017) and related to the ODARA total scores with the outcome non-physical assault against the same victim as in the risk assessment. In total, 22 AUC values (using global risk assessments/numerical total score as test variables) were presented, with the results being evenly distributed between the highest and lowest values. Ten AUC values were lower than .60 and twelve were higher than .60. Overall, the predictive validity ranged from low (not predictive at all) to moderate.

Predictive validity was also measured in other ways than by means of ROC analysis. For instance, Belfrage and Strand (2012) and Shepard et al. (2002) compared the recidivism rates for different risk groups/categories. The first study compared the recidivism rates between the low-, medium- and high-risk groups for imminent/acute risk of IPV and severe/fatal IPV risk. No statistical differences were found for any of the categories (Belfrage \& Strand, 2012). The second study compared the rate of recidivism in four different battering categories ((1) no battering history, (2) low-level/not escalating, (3) clear pattern/likely to escalate, (4) high risk of serious harm) (Shepard et al., 2002). The pattern was almost the same on all follow-up occasions $(6,12$ and 18 months): the rate of recidivism increased by batterer category, with one exception. The rate of recidivism was higher in category 3 than in category 4 , at both the 12 and 18- month follow-up. However, category 4 included a total of only four offenders. The categories were significantly correlated with recidivism at the 6,12 and 18 month follow-ups, but the relationship was weak $(r=.20-.21, p \leq .05-.01)$. Further, Hendricks et al. (2006) evaluated the classification accuracy for LSI-R risk and need scales and LSI-R total scores on repeat IPV. The classification was correct in $64 \%$ and $66 \%$ of the cases respectively, and the sensitivity and specificity (best balance) of the total scores (cut-off 11.5 ) were $67 \%$ and $60 \%$ respectively. In sum, the predictive validity was rather low in all three studies. 
Svalin et al. (2018) conducted ROC analysis using test variables based on predictive values from stepwise/enter regression models with risk and victim vulnerability factors as independent variables and the global risk assessment as the outcome variable. The AUCs for predictions of repeat IPV varied between .51 and .57 for predictions of repeat IPV and repeat violence (identical range for both outcomes). Lauria et al. (2017) examined the predictive validity (AUC) of each risk factor in the ODARA, with physical and non-physical assault as the outcome variables. The results ranged between .46-.63 and .52-.66 respectively. The ODARA items were also examined in Rettenberger and Eher (2013), using correlations between each item and IPV recidivism. Five of the 13 ODARA items correlated significantly (range .25-.44, $p<.05-.001$ ).

\section{The significance of interventions on the predictive accuracy}

All but three of the reviewed studies (Lauria et al., 2017; Williams \& Houghton, 2004; Rettenberger \& Eher, $2013^{9}$ ) analyzed treatment or other interventions in one way or the other. In one of these, both risk assessment and treatment were related to the outcome ${ }^{10}$, but the relationship between the risk assessment and the treatment was not clear (Shepard et al., 2002). Further, in Hilton et al. (2010) the predictive accuracy of the LSI-OR scores on IPV recidivism was low $(\mathrm{AUC}=.50)$ and there was a negative significant relationship between the number of initiated offender treatment modules and IPV recidivism $(r=-.16, \mathrm{p}<.05)$. However, the number of completed treatment modules and IPV recidivism were not correlated, and there were no information regarding LSI-OR scores for those offenders who completed the treatment.

Hendricks et al. (2006) examined the accuracy of the LSI-R and the effect of two IPV offender treatment programs on IPV recidivism. However, there were some difficulties interpreting the results. For example, offenders who completed one of the treatment programs (SAFE) had a lower likelihood of IPV recidivism compared to those who did not complete the program. However, since the offenders who completed the specific program had significantly lower LSI-R scores than those who did not, it was not clear whether the effect was due to the treatment or their lower risk.

\footnotetext{
${ }^{9}$ In this study, treatment had been suggested in connection with the prison sentence. However, the authors had no information regarding who had then participated in treatment (Rettenberger \& Eher, 2013).

${ }^{10}$ The direction of the correlation differed depending on how the treatment variable was measured. For instance, completed treatment was associated with lower rates of IPV recidivism (Shepard et al., 2002). At the same time, court-mandated treatment was associated with higher rates of IPV recidivism in the same study.
} 
The five studies regarding IPV risk assessment in Swedish police settings evaluated whether the recommended and/or implemented interventions mediated the relationship between the risk assessment and IPV recidivism. In one of these studies, the implemented protective actions correlated significantly with the global risk assessment, but not with IPV recidivism (Belfrage and Strand, 2012). Focusing on IPV recidivism cases only in relation to implemented protective actions, the authors found a significant difference between the rates of recidivism in the low-, medium- and high-risk groups (severe/fatal violence). The higher the assessed risk, the lower the rate of recidivism. These results were suggested to be due to the effectiveness of protective actions implemented in the most severe cases. Belfrage et al. (2012) and Storey et al. (2014) found risk assessment to predict the number of recommended protective actions and IPV recidivism, and that risk assessment ${ }^{11}$ together with the number of recommended protective actions predicted IPV recidivism. Further, in Belfrage et al. (2012), the number of recommended protective actions also predicted IPV recidivism and mediated the relationship between risk assessment and IPV recidivism. In both studies, the rate of repeat IPV was lower in high-risk cases with a high level of interventions, compared to the recidivism rate in high-risk cases with a low level of interventions (Belfrage et al., 2012; Storey et al., 2014).

In line with both Belfrage et al. (2012) and Storey et al. (2014), the Svalin et al. (2017b) study also examined the effect of recommended protective actions on predictive accuracy. The results showed that the risk assessment (low/high risk) and the recommended protective actions (low/high level of protective actions) in interaction did not significantly predict repeat IPV, with one exception. In high-risk cases with a high level of recommended interventions, the risk of repeat IPV was significantly increased compared to the reference category (lowrisk cases with a low level of recommended protective actions). However, due to the small sample, the findings were considered preliminary. The question regarding the significance of protective interventions was also evaluated in a more recent study (Svalin et al., 2018), but this time with a larger sample and with a follow-up of the interventions ${ }^{12}$. The results showed that the risk of repeat IPV was significantly increased in high-risk cases (likelihood) with or without any implemented protective actions, compared to the reference category (i.e. cases

\footnotetext{
${ }^{11}$ Measured as the SARA total score in Belfrage et al. (2012) and the global risk assessment in Storey et al. (2014).

${ }^{12}$ The interventions were measures implemented by the police or with the knowledge of the police. Thus interventions implemented by other actors or victims themselves without the knowledge of the police were not included in the analysis.
} 
assessed as low risk in which no interventions were implemented). The low risk cases with at least one implemented protective action, did not significantly predict the outcome.

In sum, three studies included no information regarding treatment and other interventions (Lauria et al., 2017; Williams \& Houghton, 2004; Rettenberger \& Eher, 2013). In three other studies, different kinds of interventions were analyzed in one way or another, but it was difficult to draw conclusions regarding the role of the interventions in relation to the risk assessment and the outcome (Shepard et al., 2002; Hendricks et al., 2006; Hilton et al., 2010). In the remaining five studies, interventions were analyzed/discussed as possible mediating factors, with somewhat varying results. One article showed that the recommended protective actions mediated the relationship between the risk assessments and repeat IPV, and concluded that the risk assessment had prevented repeat victimization (Belfrage et al., 2012). Storey et al. (2014) did not find a similar effect, but an interaction between risk assessment and recommended interventions in relation to IPV recidivism. The implemented interventions in Belfrage and Strand (2012) did not correlate with repeat IPV recidivism. However, the rate of IPV recidivism was lower in the high risk group compare with the low- and medium risk groups (among recidivism cases only). On the other hand, the final two studies (Svalin et al., 2017b; 2018), did not find any support for the risk assessments with subsequent interventions to be violence preventive. Finally, none of these studies said anything about the importance of specific protective actions or about whether some actions are effective in some cases but not in others.

\section{Discussion}

The main aim of the present study has been to examine the predictive validity of IPV risk assessments conducted by practitioners in different settings. In a majority of the studies, the predictive validity for the global risk assessments/numerical total scores was measured using the AUC of ROC with IPV recidivism as the outcome. The AUC values ranged between .49 and .72; only three AUCs were .70 or higher. Thus overall, the predictive accuracy was rather weak. The results were similar in the three studies that measured predictive validity in other ways than by means of ROC: There were no differences between the rates of recidivism in the different risk groups (Belfrage \& Strand, 2012). The sensitivity and specificity measures that represented the best balance, were relatively low (Hendricks et al., 2006), and the correlation between the risk categories and IPV recidivism was non-significant (Shepard et al., 2002). 
A wide range of AUC values has also been noted in previous review studies. For instance, Nicholls et al. (2013) presented AUC values ranging between .48 and .92, and Helmus and Bourgon (2011) between .59 and .87. Messing and Thaller (2013) presented the average AUCs of different tools, which had a smaller range (.54-.67). As was mentioned previously, predictive validity is influenced by many factors, which makes it difficult to compare results from different studies. However, the overall accuracy was slightly higher in both Nicolls et al. (2013) and Helmus and Bourgon (2011) compared to the AUCs reported in the present study (.49-.72). The studies with the highest AUC values in those reviews included actuarial and SPJ tools assessed by risk evaluators (in some cases practitioners, while no information was presented in other studies) or based on self-reports by victims and offenders. Thus more research is needed to develop the knowledge on predictive validity and on what is required to produce accurate assessments in different settings. Some researchers have highlighted the need to shift the focus from those who are the subject of the risk assessment to those who examine the risk, since they argue we have reached a "predictive glass roof" (Sturup, Forsman, Haggård, Karlberg, \& Johansson, 2013).

Nine of the eleven studies analyzed interventions in one way or another. In four of these, it was difficult to interpret the role of the interventions in relation to the risk assessment and/or the outcome. In the study by Shepard et al. (2002), for example, both the risk assessment and treatment were related to IPV recidivism, although it was not clear how the risk assessment and treatment related to one another. The results of the five studies that examined the role of the interventions as possible mediators were inconclusive. In some of the studies the protective actions were shown to, or suggested to have an influence on IPV recidivism (Belfrage \& Strand, 2012; Belfrage et al., 2012; Storey et al., 2014), while in other studies, similar results were not found (Svalin et al., 2017b; 2018). More research is needed regarding the predictive validity of IPV assessments in different settings, and specifically regarding the effectiveness of crime preventive and victim protective actions, and whether different measures are suitable for different types of IPV offenders.

The low number of studies included in the review is itself an important result, since it indicates that there is a knowledge gap regarding the accuracy of practitioners' IPV risk assessments in different settings. There are a number of possible reasons for this finding. First, violence between intimate partners is not always separated from violence between other family members in studies of the predictive validity of IPV assessments (e.g. violence 
between parents and children, siblings etc., see for example Dayan, Fox, \& Morag, 2013). Thus, by choosing to study violence between intimate partners only, studies using the broader IPV definition were excluded from the review. Looking specifically at the definition of repeat IPV used in this review, it is actually rather inclusive, even though it only refers to intimate partners. All kinds of repeat IPV conducted towards former or current intimate partners (both the same victim as in the index crime and new victims) were included, as were studies based on information from any kind of sources (e.g. self-report, police registers etc.). As has previously been noted, however, different definitions of key terms are problematic when comparing the results from different studies and must be kept in mind when interpreting the review's findings.

Other possible reasons for the low number of studies are that practitioners conduct IPV risk assessments 1) without the use of assessment tools, 2) by means of general violence risk assessment tools together with other types of violence or 3) that tools are used, but that their predictive accuracy has not been evaluated. These possible reasons will be discussed one by one below.

1) The unstructured clinical approach is the most commonly used approach historically (Hart, 2008), i.e. assessments conducted without the use of a tool. There are indications that this is still a common way of assessing violence risk. For instance, Cattaneo and Chapman (2011) found that practitioners working with victims of IPV in different settings used their own or their colleagues' professional experiences and tacit knowledge to assess violence risk rather than a risk assessment tool. In another study, police employees were found to base their global risk assessments on information other than the factors included in the tools employed (Svalin et al., 2017a). A suggestion was that they were instead using their tacit knowledge.

2) General violence risk assessments, which include all kinds of violence, are conducted in some settings and thus not IPV assessments specifically. According to Hilton et al. (2010) at least one third of incarcerated male offenders have committed intimate partner violence and as a result of the low number of studies of IPV assessments conducted in correctional settings found in this review, one could speculate that other tools have been used in these cases. Further, Rettenberger and Eher (2013) note that different violence risk assessment tools are used in the Austrian prison system, although no IPV risk assessment tools had been used prior to the initiation of their own study, which evaluated the ODARA and DVRAG. 
3) The absence of evaluations of IPV assessments may be due to a number of different reasons. Perhaps it is simply a matter of prioritization or of difficulties related to the evaluation procedure, such as difficulties obtaining access to follow-up data, which are required for this kind of evaluation. A number of studies were excluded in the sorting procedure because the assessments had been conducted by researchers and not practitioners (e.g. Buchanan, 2009). It is reasonable to assume that some settings rely on the results from such evaluations. However, since conditions vary between different settings in general, and thus between different raters, for example with regard to the level of risk assessment training, access to information, the amount of time available to produce assessments etc. it is problematic to apply the results of evaluations conducted in other settings. Finally, this study confirms that IPV risk assessment tools are sometimes used in other ways than recommended. Since this may affect the accuracy of assessments, one cannot expect the results from different settings to be applicable under such circumstances.

The overall conclusion of this review is that the research regarding the accuracy of practitioners' IPV risk assessments is limited. Only 11 studies met the inclusion criteria and all but one were conducted in criminal justice settings. Possible reasons for the low number of studies have been discussed, for example that IPV risk assessments in practical settings are still being conducted without the use of risk tools. There was little information regarding the risk raters' training in assessing IPV risk, but based on the information that was available, this seemed to be limited for many of the raters. Information on whether or not the risk tools were used as recommended was also limited to a few studies; in three of the studies actual changes had been introduced into the tools or the assessments had been conducted retrospectively. The level of predictive validity was rather low overall, and the role played by protective actions in relation to the risk assessment and the outcome measure was not clear. IPV risk assessment has the potential to play an important role in preventing repeat violence and protecting victims. The studies included in this review indicate that there is more work to do be done in order to achieve this. However, in order to develop a more complete picture, the IPV risk assessments conducted in different settings and their related risk management strategies must be evaluated.

Finally, information regarding which inclusion criteria were not met in the studies that were excluded in the sorting procedure was not collected, and this constitutes a limitation of the 
current study. Although the exact numbers are unknown, many studies were excluded because the predictive validity of a risk tool was not evaluated or because the type of violence evaluated was not IPV. Nicholls et al. (2013) reviewed 39 studies which included all Englishlanguage studies regarding the predictive validity of IPV risk assessments conducted in western countries between 1990 and 2011. Thus not much has been written regarding the predictive validity of IPV risk assessments, and there is even less research available when the sample is limited to studies in which the risk assessments have been conducted by practitioners.

\section{References}

Almond, L. Michelle, M., Brian, D., \& Merrington, D. P. (2017). Exploration of the risk factors contained within the UK's existing domestic abuse risk assessment tool (DASH): do these risk factors have individual predictive validity regarding recidivism? Journal of Aggression, Conflict and Peace Research, 9(1), 58-68, doi: 10.1108/JACPR-01-2016-0211

Andrés-Pueyo, A., López, S., \& Álvarez, E. (2008). Assessment of the risk of intimate partner violence and the SARA. Papeles del Psicólogo, 29(1), 107-122.

Baldry, A. C. (2008). Intimate partner violence and risk assessment: The implementation of the SARA, screening version in Italy. In A. C. Baldry, \& F. W. Winkel (Eds.), Intimate partner violence prevention and intervention. The risk assessment and management approach (pp. 83105). New York: Nova Science Publishers.

Belfrage, H. (2005). PATRIARCH. Checklist for the assessment of risk for patriarchal violence with honour as motive. User manual. Sundsvall Forensic Psychiatric Hospital. Available: http://bit.ly/2moCZcv

Belfrage, H. (2008). Police-based structured spousal violence risk assessment: The process of developing a police version of the SARA. In A. C. Baldry, \& F. W. Winkel (Eds.), Intimate partner violence prevention and intervention. The risk assessment and management approach (pp. 33-44). New York: Nova Science Publishers. 
Belfrage, H., \& Strand, S. (2012). Measuring the outcome of structured spousal violence risk assessments using the B-SAFER: Risk in relation to recidivism and intervention. Behavioral Sciences \& the Law, 30(4), 420-430. doi: 10.1002/bs1.2019

Belfrage, H., Strand, S., Ekman, L., \& Hasselborg, A-K. (2012). Assessing risk of patriarchal violence with honour as a motive. Six years experience using the PATRIARCH checklist. International Journal of Police Science and Management 14(1), 20-29. doi: 10.1350/ijps.2012.14.1.250

Belfrage, H., Strand, S., Storey, J. E., Gibas, A. L., Kropp, P. R., \& Hart, S. D. (2012). Assessment and management of risk for intimate partner violence using the spousal assault risk assessment guide. Law and Human Behaviour, 36(1), 60-67. doi: 10.1007/s10979-0119278-0

Borum, R., Bartel, P., \& Forth, A. (2006). Manual for the structured assessment for violence risk in youth (SAVRY). Odessa, FL: Psychological Assessment Resources.

Cattaneo, L. B., \& Chapman, A. R. (2011). Risk assessment with victims of intimate partner violence investigating the gap between research and practice. Violence Against Women, 17(10), 1286-1298. doi: 10.1177/1077801211424477

Danis, F. S. (2003). Social work response to domestic violence: Encouraging news from a new look. Affilia, 18(2), 177-191. doi: 10.1177/0886109903251407

Dayan, K., Fox, S., \& Morag, M. (2013). Validation of spouse violence risk assessment inventory. Journal of Family Violence, 28(8), 811-821. doi: 10.1007/s10896-013-9547-4

Echeburúa, E., Fernández-Montalvo, J., de Corral, P., \& López-Goñi, J. J. (2009). Assessing risk markers in intimate partner femicide and severe violence. A new assessment instrument. Journal of Interpersonal Violence, 24(6), 925-939. doi: 10.1177/0886260508319370

Gerth, J., Rossegger, A., Bauch, E., \& Endrass, J. (2017). Assessing the discrimination and calibration of the Ontario Domestic Assault Risk Assessment in Switzerland. Partner Abuse, 7, 168-189. 
Gibas, A., Kropp, P. R., Hart, S. D., \& Stewart, L. (2008, July). Validity of the SARA in a Canadian sample of incarcerated males. Paper presented at the 8th Annual Conference of the International Association of Forensic Mental Health Services, Vienna, Austria.

Hare, R. D. (2003). Manual for the Psychopathy Checklist-Revised (2nd ed.). Toronto, ON, Canada: Multi Health Systems.

Helmus, L., \& Bourgon, G. (2011). Taking Stock of 15 Years of Research on the Spousal Assault Risk Assessment Guide (SARA): A Critical Review. International Journal of Forensic Mental Health, 10(1), 64-75, doi: 10.1080/14999013.2010.551709

Hendricks, B., Werner, T., Shipway, L., \& Turinetti, G. J. (2006). Recidivism among spousal abusers. Predictions and program evaluation. Journal of Interpersonal Violence, 21(6), 703716. doi: $10.1177 / 0886260506287310$

Her Majesty's Inspectorate of Constabulary [HMIC]. (2014). Everyone's business: Improving the police response to domestic abuse. Retrieved from www.hmic.gov.uk

Hilton, N. Z., Harris, G. T., Popham, S., \& Lang, C. (2010). Risk assessment among incarcerated male domestic violence offenders. Criminal Justice and Behavior, 37(8), 815832. doi: $10.1177 / 0093854810368937$

Hilton, N. Z., Harris, G. T., Rice, M. E., Lang, C., Cormier, C. A., \& Lines, K. J. (2004). A brief actuarial assessment for the prediction of wife assault recidivism: The Ontario Domestic Assault Risk Assessment. Psychological Assessment, 16(3), 267-275. doi:10.1037/10403590.16.3.267

Koziol-McLain, J., Garrett, N., Fanslow, J., Hassall, I., Dobbs, T., Henare-Toka, T. A., \& Lovell, V. (2010). A randomized controlled trial of a brief emergency department intimate partner violence screening intervention. Annals of Emergency Medicine, 56(4), 413-423. doi:10.1016/j.annemergmed.2010.05.001

Kropp, P. R. (2004). Some questions regarding spousal assault risk assessment. Violence Against Women, 10(6), 676-697. doi:10.1177/1077801204265019 
Kropp, P. R., \& Hart, S. D. (2004). The development of the brief spousal assault form for the evaluation of risk (B-SAFER): A tool for criminal justice professionals. Ottawa, Canada: Department of Justice.

Kropp, P. R., Hart, S. D., \& Belfrage, H. (2005). Brief spousal assault form for the evaluation of risk (B-SAFER): User manual. Vancouver, Canada: Proactive Resolutions Inc.

Kropp, P. R., Hart, S. D., \& Belfrage, H. (2010). Brief spousal assault form for the evaluation of risk (B-SAFER), version 2: User manual. Vancouver, Canada: Proactive Resolutions Inc.

Kropp, P. R., Hart, S. D., \& Lyon, D. R. (2008). Guidelines for stalking assessment and Management (SAM). Vancouver, Canada: ProActive ReSolutions.

Lauria, I., McEwan, T. E., Luebbers, S., Simmons, M., \& Ogloff, J. R. P. (2017). Evaluating the ontario domestic assault risk assessment in an Australian frontline police setting. Criminal Justice and Behavior, 44(12), 1545-1558. doi: 10.1177/0093854817738280

McEwan, T., Bateson, S., \& Strand, S. (2017). Improving police risk assessment and management of family violence through a collaboration between law enforcement, forensic mental health and academia. Journal of Criminological Research, Policy and Practice, 3(2), 119-131. doi: 10.1108/JCRPP-01-2017-0004

Mele, M. (2009). The time course of repeat intimate partner violence. Journal of Family Violence, 24(8), 619-624. doi: 10.1007/s10896-009-9260-5

Messing, J. T., \& Thaller, J. (2013). The average predictive validity of intimate partner violence risk assessment instruments. Journal of Interpersonal Violence, 28(7), 1537-1558. doi: $10.1177 / 0886260512468250$

Nesset, M. B., Bjørngaard, J. H., Nøttestad, J. A., Whittington, R. W., Lynum, C., \& Palmstierna, T. (2017). Factors associated with police decisions on immediate responses to intimate partner violence. Journal of Interpersonal Violence. Advance Online Publication. doi: $10.1177 / 0886260517706762$

Nicholls, T. L., Pritchard, M. M., Reeves, K. A., \& Hilterman, E. (2013). Risk assessment in intimate partner violence: A systematic review of contemporary approaches. Partner Abuse, 4(1), 76-168. doi: 10.1891/1946-6560.4.1.76 
Rettenberger, M., \& Eher, R. (2013). Actuarial risk assessment in sexually motivated intimate-partner violence. Law and Human Behavior, 37(2), 75-86. doi: 10.1037/b0000001

Richards, L. (2009). DASH: Domestic abuse, stalking and harassment and honour-based violence risk identification and assessment and management model, DASH risk checklist. Available: https://www.dashriskchecklist.co.uk

Shepard, M., Falk, D. R., \& Elliott, B. A. (2002). Enhancing Coordinated Community Responses to Reduce Recidivism in Cases of Domestic Violence. Journal of Interpersonal Violence, 17(5), 551-569.

Singh, J. P., Desmarais, S. L., Hurducase, C., Arbach-Lucioni, Condemarin, C., Dean, K., ... Otto, R. K. (2014). International Perspectives on the Practical Application of Violence Risk Assessment: A Global Survey of 44 Countries. International Journal of Forensic Mental Health, 13(3), 193-206. doi: 10.1080/14999013.2014.922141

Storey, J. E., Gibas, A. L., Reeves, K. A., \& Hart, S. D. (2011). Evaluation of a violence risk (threat) assessment training program for police and other criminal justice professionals. Criminal Justice and Behavior, 38(6), 554-564. doi: 10.1177/0093854811403123

Storey, J. E., Kropp, P. R., Hart, S. D., Belfrage, H., \& Strand, S. (2014). Assessment and management of risk for intimate partner violence by police officers using the brief spousal assault form for the evaluation of risk. Criminal Justice and Behavior, 41(2), 256-271. doi:10.1177/0093854813503960

Sturup, J., Forsman, M., Haggård, U., Karlberg, D., \& Johansson, P. (2013). Riskbedömning $i$ kriminalvård och rättspsykiatri. Sammanfattningsrapport. (Projektnummer 2013:269) [Violence risk assessment in prison service and forensic psychiatry. A summary report]. Norrköping: Kriminalvården.

Svalin, K., Mellgren, C., Torstensson Levander, M., \& Levander, S. (2017a). The inter-rater reliability of violence risk assessment tools used by police employees in Swedish police settings. Nordisk Politiforskning, 4(1), 9-28. doi: 10.18261/ISSN.1894-8693-2017-01-03

Svalin, K., Mellgren, C., Torstensson Levander, M., \& Levander, S. (2017b). Assessing and managing risk for intimate partner violence: Police employees' use of the police screening 
tool for violent crimes in Scania. Journal of Scandinavian Studies in Criminology and Crime Prevention, 18(1), 84-92. doi: 10.1080/14043858.2016.1260333

Svalin, K., Mellgren, C., Torstensson Levander, M., \& Levander, S. (2018). Police employees' violence risk assessments: The predictive validity of the B-SAFER and the significance of protective actions. International Journal of Law and Psychiatry, 56, 71-79. doi: 10.1016/j.ijlp.2017.09.001

van der Put, C. E., Geert, J., \& Stams, J. M. (2013). Youth offender care needs assessment tool (YO-CNAT): An actuarial risk assessment tool for predicting problematic child-rearing situations in juvenile offenders on the basis of police records. Psychological Assessment, 25(4), 1167-1178. doi: 10.1037/a0033453

Webster, C. D., Douglas, K. S., Eaves, D., \& Hart, S. D. (1997). HCR-20: Assessing risk for violence, version 2. Vancouver, Canada: Simon Fraser University and Forensic Psychiatric Services Commission of British Columbia.

Webster, C. D., Eaves, D., Douglas, K. S., \& Wintrup, A. (1995). The HCR-20 scheme: The assessment of dangerousness and risk. Vancouver, Canada: Simon Fraser University and Forensic Psychiatric Services Commission of British Columbia.

Williams, K. R, \& Houghton, A. B. (2004). Assessing the risk of domestic violence reoffending: A validation study. Law and Human Behavior, 28(4), 437-455.

Wong, T., \& Hisashima, M. A. (2008). Domestic violence exploratory study on the DVSI and SARA, State of Hawaii, 2003-2007. Hawaii: Interagency Council on Intermediate Sanctions. Available: http://icis.hawaii.gov/wp-content/uploads/2013/07/SARA-DVSI-ExploratoryStudy-Oct-2008.pdf 


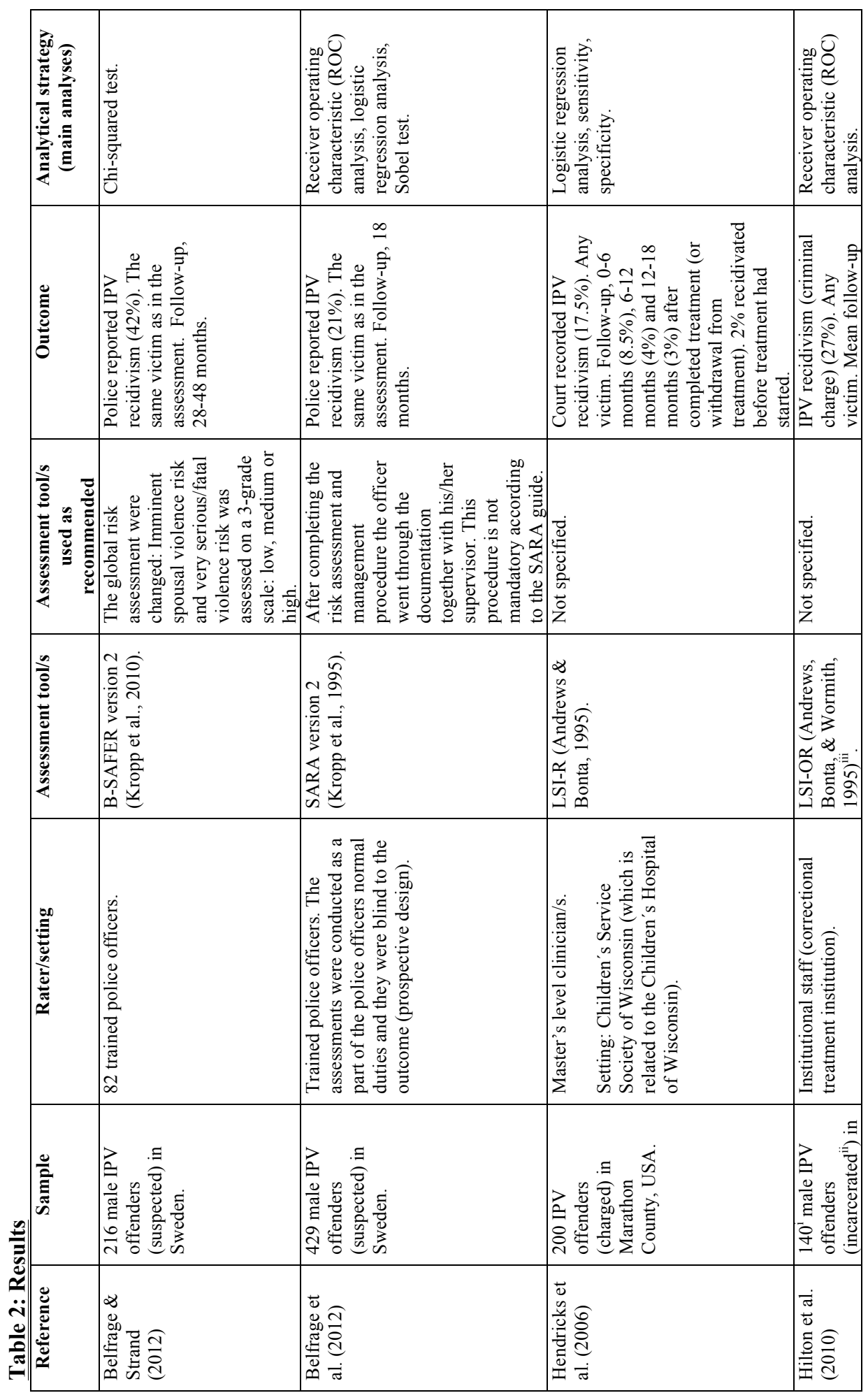




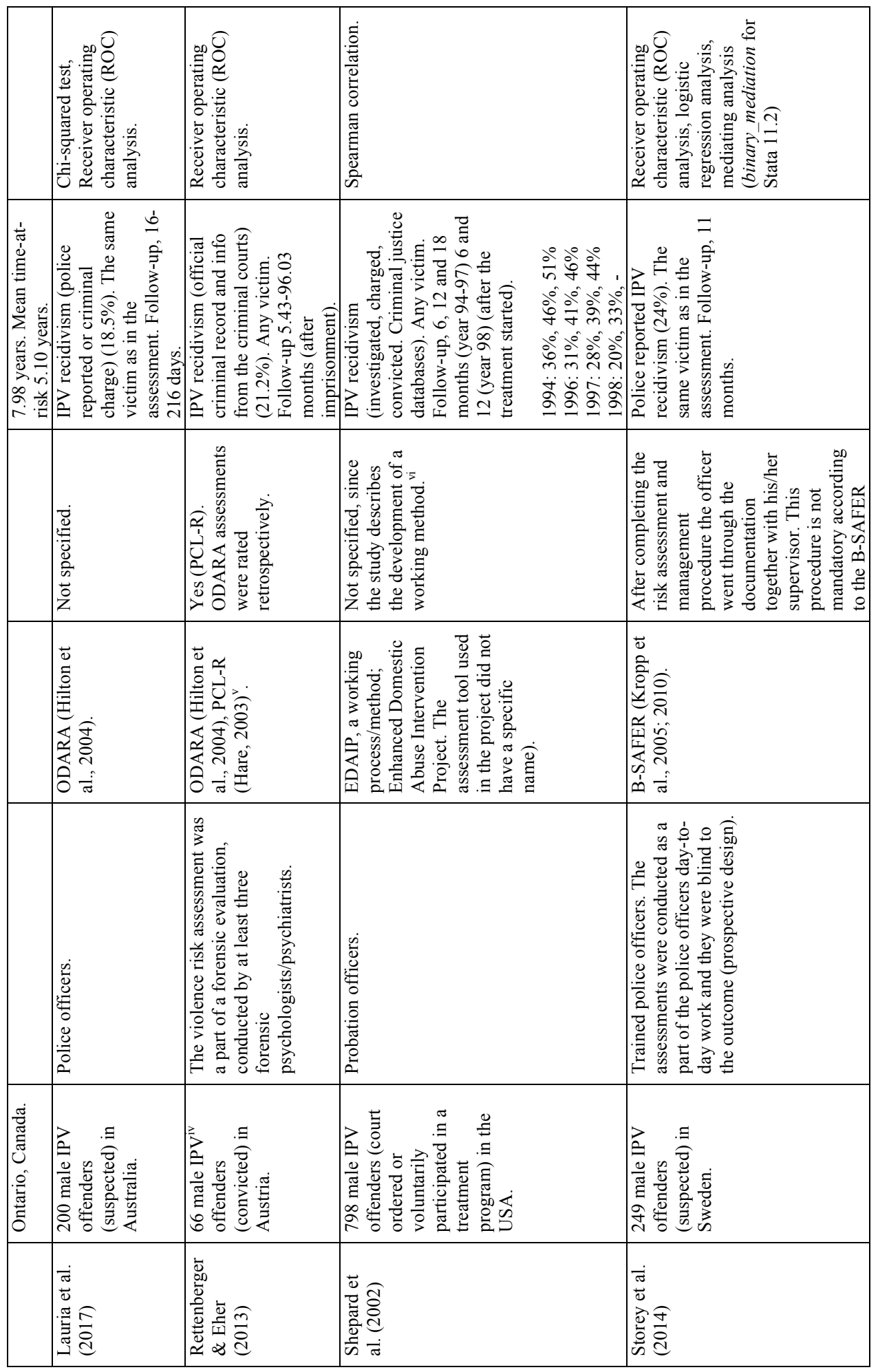




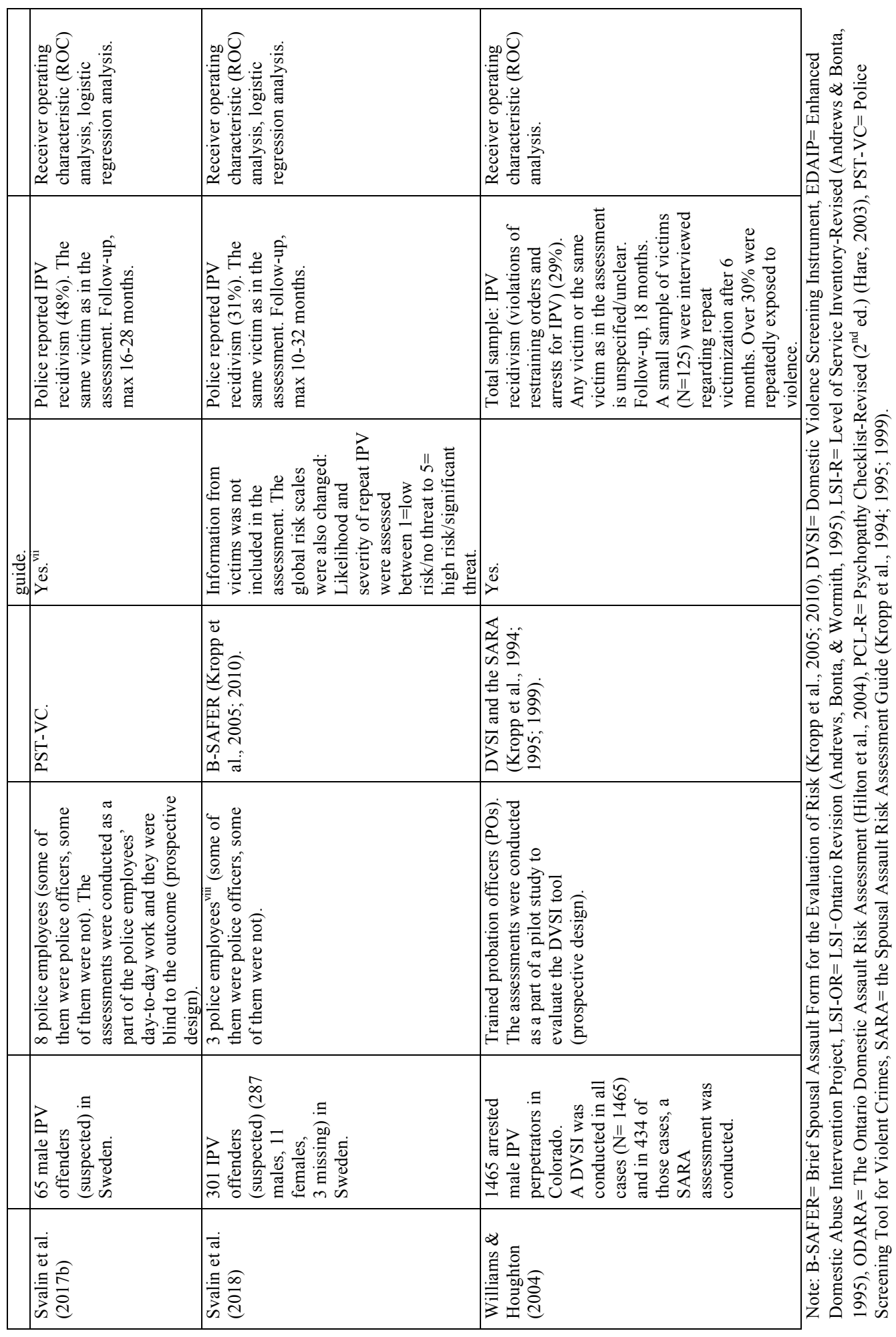




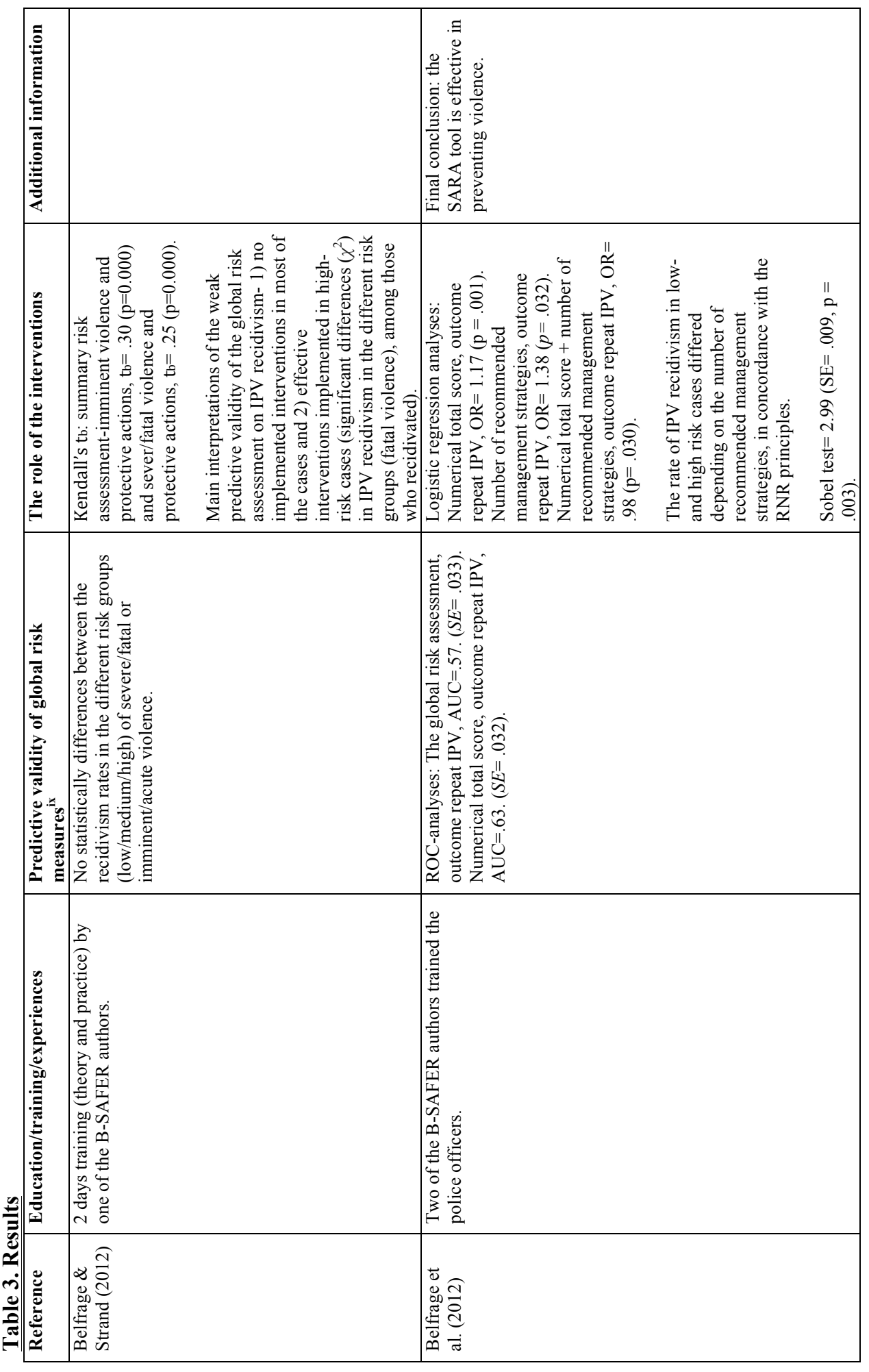




\begin{tabular}{|c|c|c|c|c|c|}
\hline & 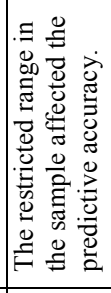 & & 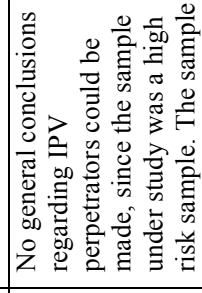 & 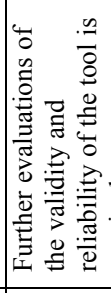 & 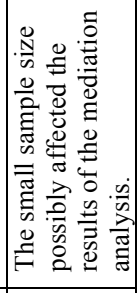 \\
\hline 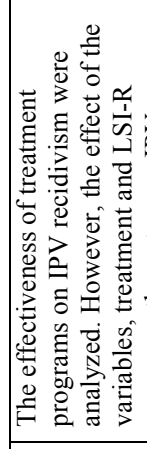 & 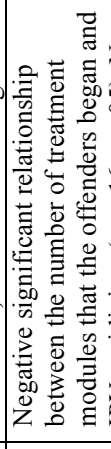 & $\stackrel{\Xi}{\tilde{D}}$ & 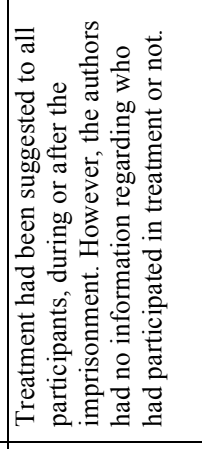 & 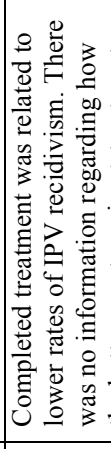 & 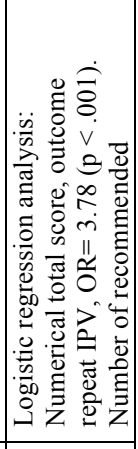 \\
\hline 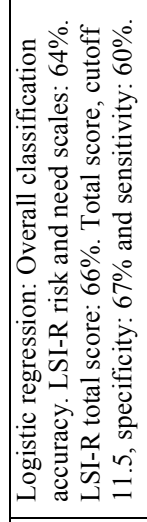 & 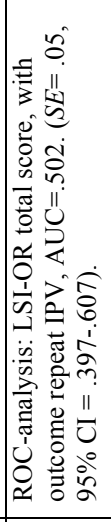 & 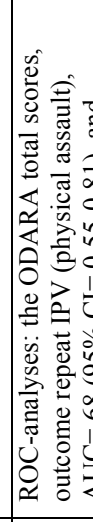 & 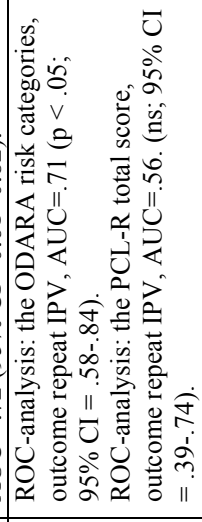 & 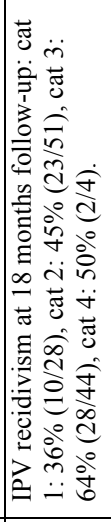 & 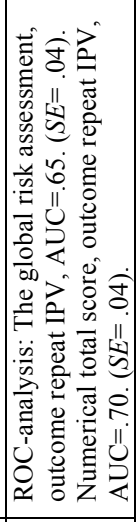 \\
\hline 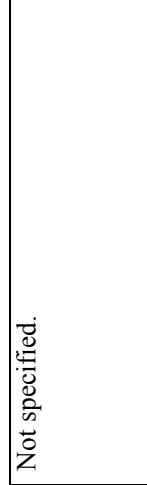 & 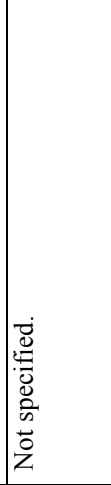 & 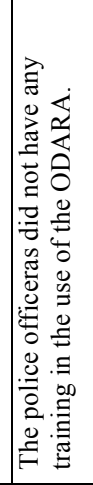 & 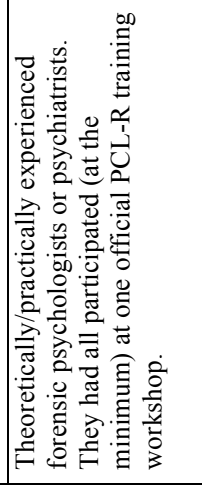 & 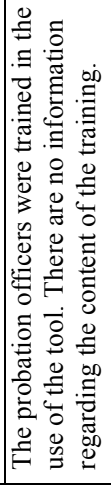 & 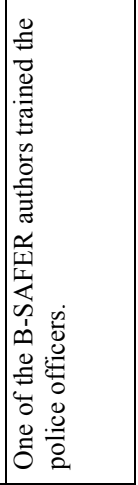 \\
\hline 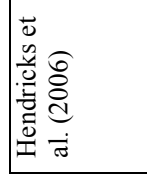 & 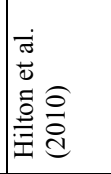 & 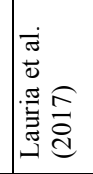 & 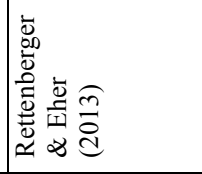 & 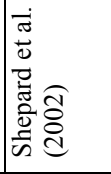 & 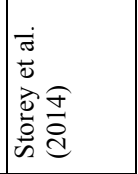 \\
\hline
\end{tabular}




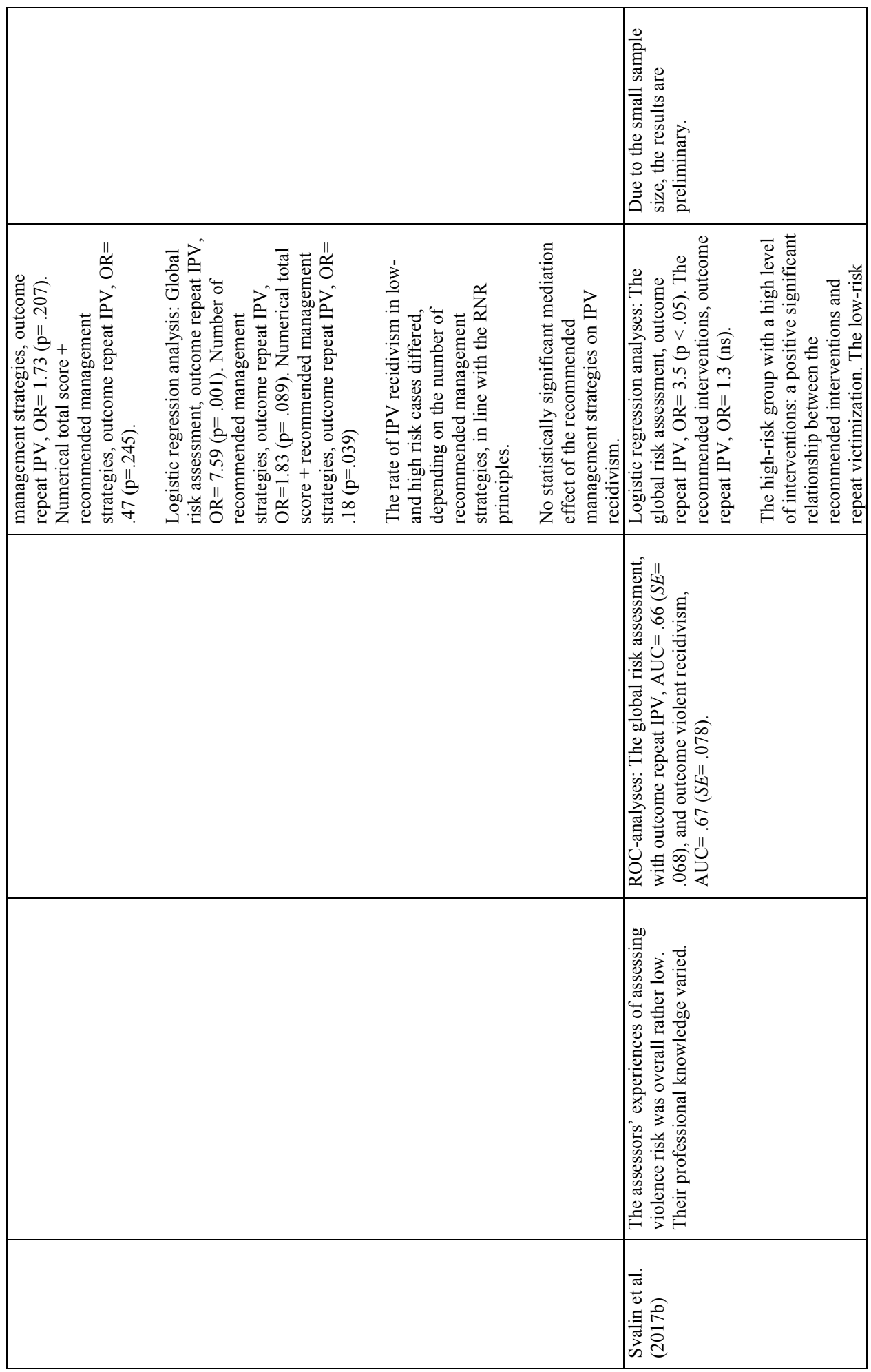




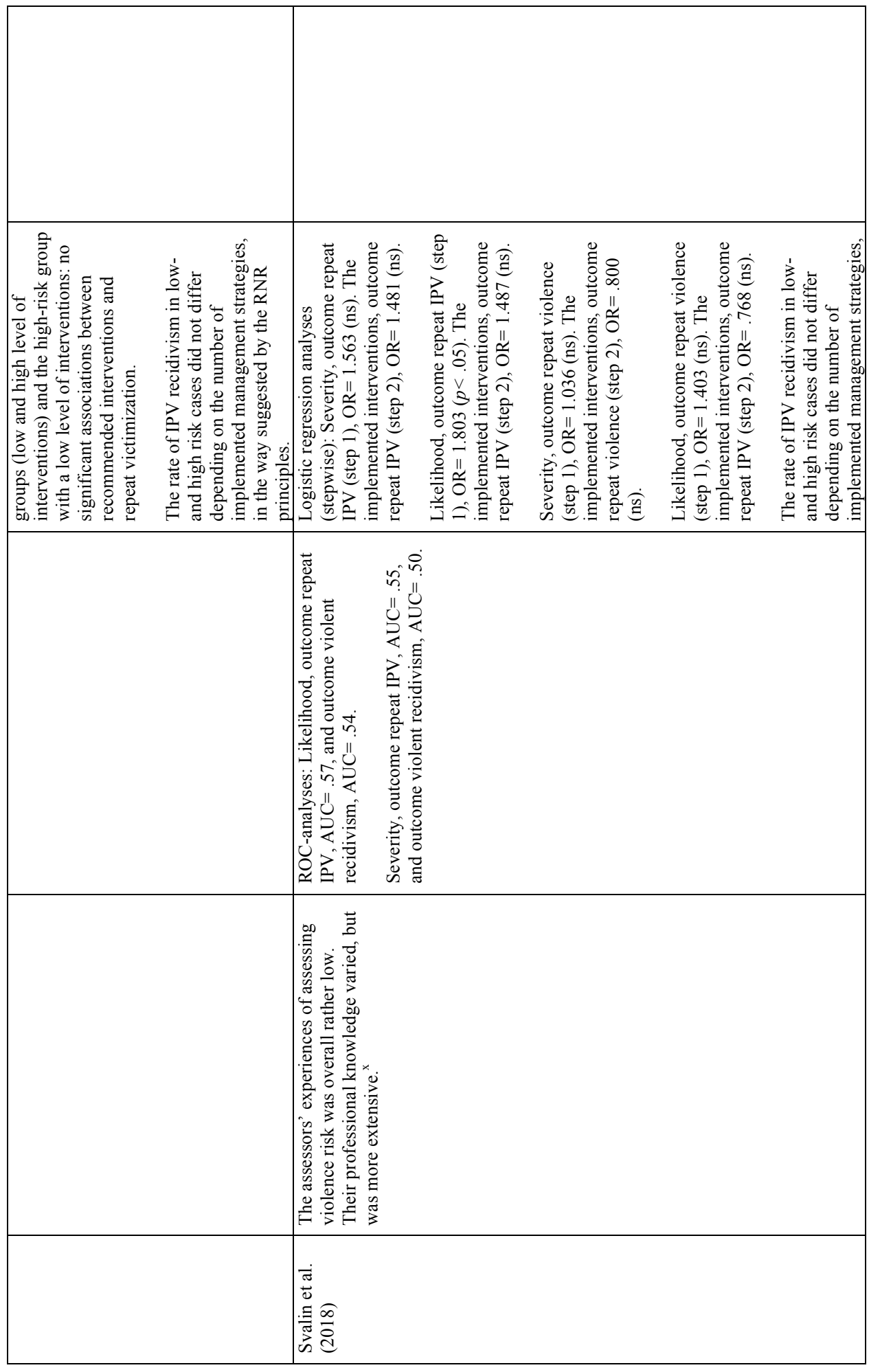



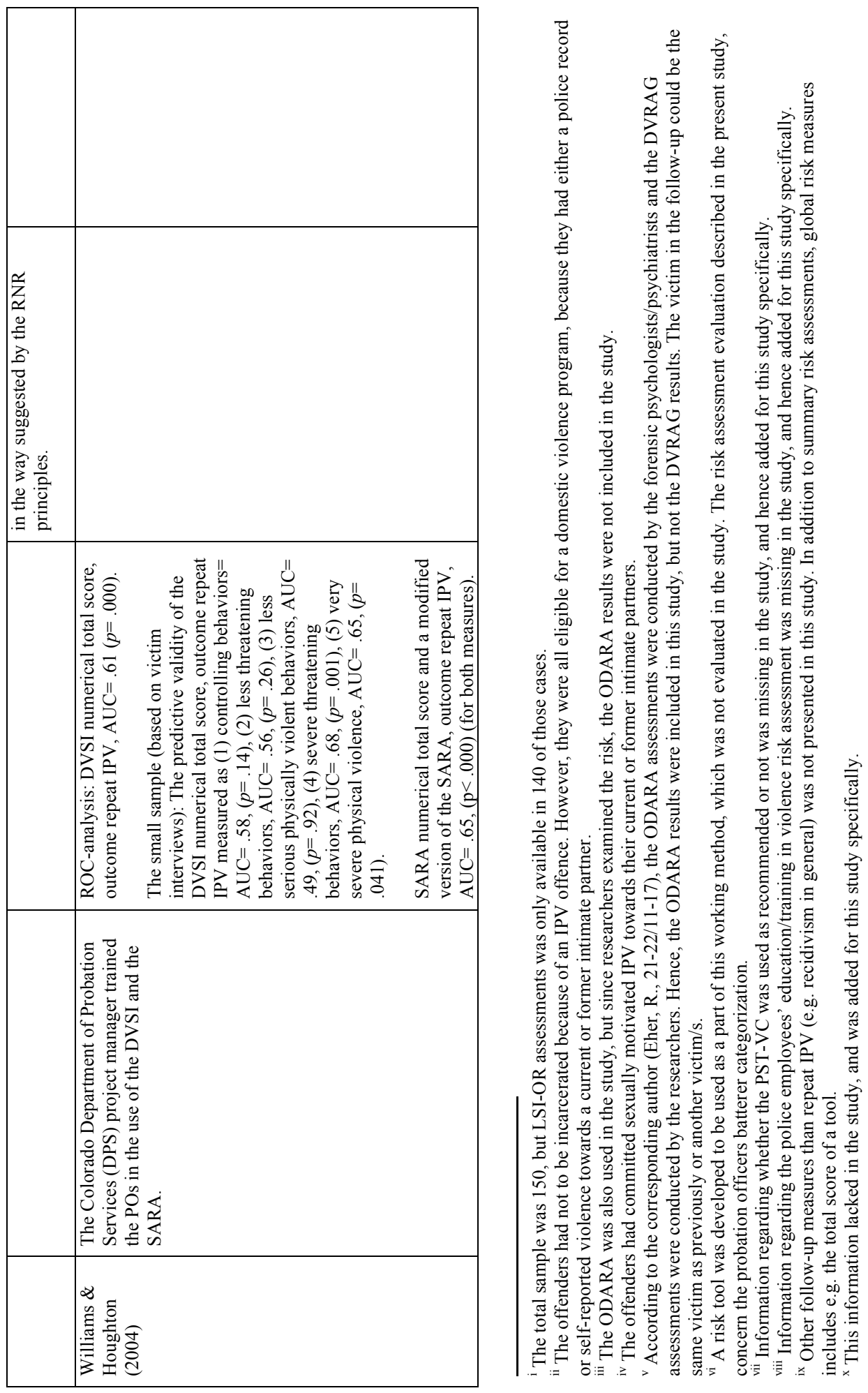



\section{Malmö University Health and Society Doctoral Dissertations}

Ross, M. W. Typing, doing and being. A study of men who have sex with men and sexuality on the Internet. 2006:1

Stoltz, P. Searching for meaning of support in nursing. A study on support in family care of frail aged persons with examples from palliative care at home. 2006:2

Gudmundsson, P. Detection of myocardial ischemia using real-time myocardial contrasts echocardiograpy. 2006:3

Holmberg, L. Communication in palliative home care, grief and bereavement. A mother's experiences. 2007:1

Ny, P. Swedish maternal health care in a multiethnic society - including the fathers. 2007:2

Schölin, T. Etnisk mångfald som organisationsidé. Chefs- och personalpraktiker i äldreomsorgen. 2008:1

Svensson, O. Interactions of mucins with biopolymers and drug delivery particles. 2008:2

Holst, M. Self-care behaviour and daily life experiences in patients with chronic heart failure. 2008:3

Bahtsevani, C. In search of evidence-based practices. Exploring factors influencing evidence based practice and implementation of clinical practice guidelines. 2008:4

Andersson, L. Endocytosis by human dendritic cells. 2009:1.

Svendsen, I. E. In vitro and in vivo studies of salivary films at solid/liquid interfaces. 2009:2.

Persson, K. Oral health in an outpatient psychiatric population. Oral status, life satisfaction and support. 2009:3.

Hellman, P. Human dendritic cells. A study of early events during pathogen recognition and antigen endocytosis. 2009:4.

Baghir-Zada, R. Illegal aliens and health (care) wants. The cases of Sweden and the Netherlands. 2009:5.

Stjernswärd, S. Designing online support for families living with depression. 2009:6.

Carlsson, A. Child injuries at home - prevention, precautions and intervention with focus on scalds. 2010:1.

Carlson, E. Sjuksköterskan som handledare. Innehåll i och förutsättningar för sjuksköterskors handledande funktion i verksamhetsförlagd utbildning - en etnografisk studie. 2010:2.

Sinkiewicz, G. Lactobacillus reuteri in health and disease. 2010:3.

Tuvesson, H. Psychiatric nursing staff and the workplace. Perceptions of the ward atmosphere, psychosocial work environment, and stress. 2011:1.

Ingvarsdotter, K. Mental ill health and diversity. Researching human suffering and resilience in a multicultural context. 2011:2.

Hamit-Eminovski, J. Interactions of biopolymers and metal complexes at biological interfaces. 2011:3. 
Mellgren, C. What's neighbourhood got to do with it? The influence of neighbourhood context on crime and reactions to crime. 2011:4.

Annersten Gershater, M. Prevention of foot ulcers in patients with diabetes mellitus. Nursing in outpatient settings. 2011:5.

Pooremamali P. Culture, occupation and occupational therapy in a mental care context- the challenge of meeting the needs of Middle Eastern immigrants. 2012:1

Gustafsson A. Aspects on sepsis: treatment and markers. 2012:2

Lavant, E. Multiplex HLA-DR-DQ genotyping. For genetic epidemiology and clinical risk assessment. 2012:3

Wangel, A-M. Mental ill-health in childbearing women. Markers and risk factors. 2012:4

Scaramuzzino, R. Equal opportunities? - A cross-national comparison of immigrant organisations in Sweden and Italy. 2012:5

Ivert, A-K. Adolescent mental health and utilisation of psychiatric care - The role of parental country of birth and neighbourhood of residence 2013:1

Znamenskaya, Y. Effect of hydration on thermodynamic, rheological and structural properties of mucin. 2013:2

Andersson, F. The female offender. Patterning of antisocial and criminal activity over the life-course. 2013:3

Lindroth, M. Utsatthet och sexuell hälsa - en studie om unga på statliga ungdomshem. 2013:4

Hulusjö, A. The multiplicities of prostitution experience - narratives about power and resistance. 2013:5

Falk, M. Direct electron transfer based biofuel cells. Operation in vitro and in vivo. 2014:1

Finnbogadóttir, H. Exposure to domestic violence during pregnancy. Impact on outcome, midwives' awareness, women's experience and prevalence in the south of Sweden. $2014: 2$

Fagerström, A. Effects of surfactant adjuvants on barrier properties of plant leaf cuticle. 2014:3

Lamberg, P. Design and characterization of direct electron transfer based biofuel cells including tests in cell cultures. 2014:4

Richert, T. Överdoser, försörjningsstrategier och riskhantering - livsvillkor för personer som injicerar narkotika. 2014:5

Örmon, K. Experiences of abuse during the life course. - Disclosure and the care provided among women in a general psychiatric context. 2014:6

Sjöblom, I. Planerade hemförlossningar i Norden - kvinnors och barnmorskors perspektiv. 2014:7

Albèr, C. Humectants and Skin - Effects of hydration from molecule to man. 2015:1

Kisch M., A. Allogeneic stem cell transplantation. - Patients' and sibling donors' perspectives. 2015:2

Weiber, I. Children in families where the mother has an intellectual or developmental disability - incidence, support and first person perspectives. 2015:3 
Schlyter, M. Myocardial infarction, Personality factors, Coping strategies, Depression and Secondary prevention 2016:1

Carlström, C. BDSM - Paradoxernas praktiker. 2016:2

El-Schich, Z. Novel imaging technology and tools for biomarker detection in cancer. 2016:3

Boonsatean, W. Living with type 2 diabetes in Thai population: Experiences and socioeconomic characteristics. 2016:4

Vejzovic, V. Going through a colonoscopy and living with inflammatory bowel disease: Children's and parents' experiences and evaluation of the bowel cleansing quality prior to colonoscopy. 2016:5

Isma, G.E. Overweight and obesity in young children: Preventive work in child health care with focus on nurses' perceptions and parental risk factors. 2016:6

Brännvall, M. Frigörelse med förhinder - Om polisanmälan när kvinnor tar sig ur mäns våld i nära relationer. 2016:7

Pankratov, D. Self-charging biosupercapacitors. 2016:8

Guidi, P. Social work assessment of families with children at risk: Similarities and differences in Italian and Swedish public social services. 2016:9

Jakobsson, J. The process of recovery after colorectal cancer surgery: Patients' experiences and factors of influence. 2017:1

Gerell, M. Neighborhoods without community. Collective efficacy and crime in Malmö, Sweden. 2017:2

Wierzbicka, C. New fractionation tools targeting elusive post-translational modifications. 2017:3

Afzelius, M. Families with parental mental illness: Supporting children in psychiatric and social services. 2017:4

Nordgren, J. Making drugs ethnic - Khat and minority drug use in Sweden. 2017:5

Nilsson, E-L. Parental socialization and adolescent offending. 2017:6

Sixtensson, J. Härifrån till framtiden. Om gränslinjer, aktörskap och motstånd i tjejers vardagsliv. 2018:1

Vasiljevic, Z. Ambulatory risk assessment and intervention in the prison services. Using Interactive Voice Response to assess and intervene on acute dynamic risk among prisoners on parole. $2018: 2$

González Arribas, E. Flexible and transparent biological electric power sources based on nanostructured electrodes. 2018:3

Svalin, K. Risk assessment of intimate partner violence in a police setting. Reliability and predictive accuracy. 2018:4

The publications are available online.

See www.mah.se/muep 



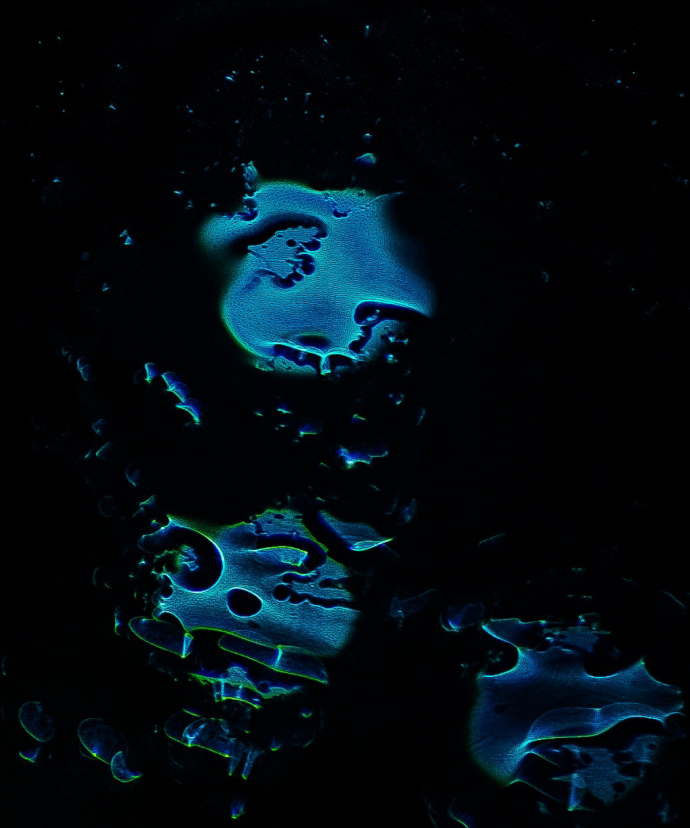

ISBN 978-9I-7 IO4-898-I (print)

ISBN 978-9I-7IO4-899-8 (pdf)

ISSN I $653-5383$

MALMÖ UNIVERSITET

20506 MALMÖ, SWEDEN

WWW.MAU.SE 